\title{
Comparison of mesospheric winds from a high-altitude meteorological analysis system and meteor radar observations during the boreal winters of 2009-2010 and 2012-2013
}

\author{
J. McCormack ${ }^{1, *}$, K. Hoppel ${ }^{2}$, D. Kuhl ${ }^{2}$, R. de Wit ${ }^{3}$, G. Stober ${ }^{4}$, P. Espy ${ }^{5}$, \\ N. Baker ${ }^{6}$, P. Brown ${ }^{7}$, D. Fritts ${ }^{8}$, C. Jacobi ${ }^{9}$, D. Janches ${ }^{3}$, N. Mitchell ${ }^{10}$, B. \\ Ruston $^{6}$, S. Swadley ${ }^{6}$, K. Viner ${ }^{6}$, T. Whitcomb ${ }^{6}$, R. Hibbins ${ }^{5}$
}

\begin{abstract}
We present a study of horizontal winds in the mesosphere and lower thermosphere (MLT) during the boreal winters of 2009-2010 and 2012-2013 produced with a new high-altitude numerical weather prediction (NWP) system. This system is based on a modified version of the Navy Global Environmental Model (NAVGEM) with an extended vertical domain up to $\sim 116 \mathrm{~km}$ altitude coupled with a hybrid four-dimensional variational (4DVAR) data assimilation system that assimilates both standard operational meteorological observations in the troposphere and satellite-based observations of temperature, ozone and water vapor in the stratosphere and mesosphere. NAVGEM-

\footnotetext{
${ }^{*}$ Corresponding author

${ }^{1}$ Space Science Division, Naval Research Laboratory, Washington DC, USA

${ }^{2}$ Remote Sensing Division, Naval Research Laboratory, Washington DC, USA

${ }^{3}$ Space Weather Laboratory, NASA Goddard Space Flight Center, Greenbelt, Maryland, USA

${ }^{4}$ Leibniz- Institute for Atmospheric Physics, Rostock University, Kühlungsborn, Germany

${ }^{5}$ Norwegian University of Science and Technology (NTNU), Trondheim, Norway

${ }^{6}$ Marine Meteorology Division, Naval Research Laboratory, Monterey CA, USA

${ }^{7}$ Department of Physics \& Astronomy, University of Western Ontario, London, Ontario, Canada

${ }^{8}$ GATS Inc., Boulder, Colorado, USA

${ }^{9}$ University of Leipzig, Leipzig, Germany

${ }^{10}$ Centre for Space, Atmospheric and Oceanic Science, University of Bath, Bath, UK
}

For submission to JASTP

December 14, 2016

(C) 2016. This manuscript version is made available under the Elsevier user license

http://www.elsevier.com/open-access/userlicense/1.0/ 
based MLT analyzed winds are validated using independent meteor radar wind observations from nine different sites ranging from $69^{\circ} \mathrm{N}-67^{\circ} \mathrm{S}$ latitude. Time-averaged NAVGEM zonal and meridional wind profiles between 75-95 km altitude show good qualitative and quantitative agreement with corresponding meteor radar wind profiles. Wavelet analysis finds that the 3-hourly NAVGEM and 1-hourly radar winds both exhibit semi-diurnal, diurnal, and quasi-diurnal variations whose vertical profiles of amplitude and phase are also in good agreement. Wavelet analysis also reveals common time-frequency behavior in both NAVGEM and radar winds throughout the Northern extratropics around the times of major stratospheric sudden warmings (SSWs) in January 2010 and January 2013, with a reduction in semidiurnal amplitudes beginning around the time of a mesospheric wind reversal at $60^{\circ} \mathrm{N}$ that precedes the SSW, followed by an amplification of semi-diurnal amplitudes that peaks 10-14 days following the onset of the mesospheric wind reversal. The initial results presented in this study demonstrate that the wind analyses produced by the high-altitude NAVGEM system accurately capture key features in the observed MLT winds during these two boreal winter periods.

Keywords:

MLT Winds, Tides, Radar Observations

\section{Introduction}

It has become increasingly clear in recent years that day-to-day variability in the composition and structure of the thermosphere and ionosphere is influenced by meteorological variability in the lower atmosphere, i.e., the region of the atmosphere between $0-100 \mathrm{~km}$ altitude. This coupling arises from upward propagating planetary waves and tides (both migrating and non-migrating) that are forced in the lower atmosphere and become the dominant drivers of the atmospheric circulation in the equatorial dynamo region between 100-150 km (see, e.g. Akmaev, 2011, and references therein). The vertical propagation of these waves and tides, and their projection onto global resonant modes in the atmospheric circulation, depends strongly on variations in horizontal winds throughout the stratosphere and mesosphere. Consequently, efforts to identify and, ultimately, predict the physical origins of this vertical atmospheric coupling require accurate and detailed wind information extending globally from the surface to the lower thermosphere. 
Currently, there are relatively few sources of wind observations in the mesosphere and lower thermosphere (MLT). Ground-based wind observations from, e.g., medium frequency radar and meteor radar instruments (Hocking et al., 2001; Riggin et al., 2003) generally offer excellent temporal sampling but are limited in their geographical coverage. Direct satellite observations of winds from space-based platforms (Limpasuvan et al., 2005; Niciejewski et al., 2006; Baron et al., 2013) are valuable sources of information, but global coverage can be limited due to a combination of factors involving orbital geometry, observational method, and mission lifetime. Satellite observations of temperature and geopotential height have been used to infer horizontal winds in the stratosphere and mesosphere based on gradient wind balance (Manney et al., 2008; McLandress et al., 2013; Lieberman et al., 2013). This method may be useful in some cases for diagnosing general features of the background flow in the extratropical MLT that affect the vertical propagation of waves and tides. However, balanced winds cannot be used reliably in the mesosphere due to forcing by gravity waves or by local variations in solar heating because these forcing mechanisms violate the assumptions of gradient wind balance.

Due to these limitations, most information on coupling between the thermosphere/ionosphere system and meteorological variability in the lower atmosphere involving vertical propagation of waves and tides currently does not come from direct observations, but instead comes from "whole atmosphere" models that encompass the neutral atmosphere and ionosphere (e.g. FullerRowell et al., 2010; Jin et al., 2012; Akmaev, 2011; Pedatella and Liu, 2013; Sassi et al., 2013). An advantage of these models is that they provide a fully self-consistent set of wind, temperature, and constituent fields throughout the MLT region where global observations are relatively scarce. However, an intercomparison among four different whole atmosphere models published in Pedatella et al. (2014) shows considerable disagreement in the modeled MLT winds due to the differing physical parameterizations employed in each model. This disagreement among models highlights the need for accurate, observations-based global wind information in the MLT region.

Earlier studies by Xu et al. (2011a,b) have shown that a global circulation model extending up to the MLT region that is constrained by tropospheric and stratospheric observations can capture much of the observed variability in both mean and tidal components of mesospheric horizontal winds. This paper seeks to extend these types of studies by including data assimilation throughout the MLT region using a new high-altitude NWP system based 
on the Navy Global Environmental Model (NAVGEM) described in Hogan et al. (2014) coupled with a hybrid ensemble 4DVAR assimilation system described in Kuhl et al. (2013). The present study builds upon earlier work by Eckermann et al. (2009) and Hoppel et al. (2013) to develop an NWP system for middle atmosphere research that combines standard meteorological observations, space-based temperature and constituent observations in the stratosphere and mesosphere, and a general circulation model to generate global synoptic analyses of wind and temperature extending from 0 to $\sim 100 \mathrm{~km}$ altitude. The present validation study compares NAVGEM MLT wind analyses with independent ground-based meteor radar wind observations from nine different stations that are listed in Table 1 . These comparisons focus on the Northern Hemisphere (NH) winters of 2009-2010 and 2012-2013 when numerous observational studies report large changes in both MLT dynamics (Stober et al., 2012; Matthias et al., 2013; de Wit et al., 2015) and ionospheric structure (Chau et al., 2009; Anderson and Araujo-Pradere, 2010; Pedatella and Forbes, 2010; Jin et al., 2012; Goncharenko et al., 2010; Lin et al., 2012; Goncharenko et al., 2013a) following the onset of major sudden stratospheric warmings (SSWs).

Several recent studies using whole atmosphere models link changes in ionospheric features such as vertical plasma drift and total electron content to changes in the global circulation of the stratosphere and mesosphere during an SSW that modify the upward propagation of both migrating and nonmigrating tides into the equatorial dynamo region (Fuller-Rowell et al., 2010; Jin et al., 2012; Pedatella and Liu, 2013; Sassi et al., 2013). A SSW is caused by the rapid amplification of planetary wave (PW) activity in the extratropical winter stratosphere, which produces increased westward drag on the eastward polar night jet and a resulting increase in descent over the winter pole that leads to anomalously warm polar stratosphere temperatures through adiabatic heating. The effects of the increased PW drag on the polar jet first appear in the mesosphere and can descend into the stratosphere over the course of several days. In the case of a major SSW, the increased PW drag is strong enough to produce a reversal in the direction of the polar jet (from eastward to westward) down to $\sim 30 \mathrm{~km}$ altitude. This reversal limits the upward propagation of planetary waves into the stratosphere, and also acts to favor vertical propagation of eastward propagating gravity waves (GWs) into the mesosphere, resulting in a diminished polar descent and a net cooling in the mesospheric region overlying the SSW. As the eastward polar jet begins to recover, increased downwelling appears over the pole in 
the mesosphere to form an "elevated stratopause" (e.g. Siskind et al., 2010).

As Figure 1 shows, these characteristic dynamical signatures of a major SSW in zonal mean zonal wind and zonal mean temperature are captured in the NAVGEM analyses for the 2009-2010 and 2012-2013 NH winters. While it is common practice to describe the timing of an SSW in terms of the zonal wind reversal at, e.g., $60^{\circ} \mathrm{N}$ and $10 \mathrm{hPa}(\sim 30 \mathrm{~km}$ altitude), in the present study we will focus instead on the date when a sustained ( $>5$ days) reversal of mesospheric winds from westerly to easterly at $60^{\circ} \mathrm{N}$ begins. This is done in order to better relate variability in periodic MLT wind variations (e.g., tides) to the dramatic reversals in background MLT winds that precede the SSW; similar methods have also been employed in recent studies examining the mesospheric response during SSWs (Stober et al., 2012; Matthias et al., 2012; Stray et al., 2015; Limpasuvan et al., 2016). During the 2010 SSW event, which was characterized by a rapid amplification of planetary wave 1 at $10 \mathrm{hPa}$ in late January (Goncharenko et al., 2013a), the NAVGEM analyses in Fig. 1 indicate this mesospheric reversal began on 27 January, approximately 2 weeks prior to the sustained stratospheric zonal wind reversal at $60^{\circ} \mathrm{N}$ and $10 \mathrm{hPa}$ that began on 9 February (Kuttippurath and Nikulin, 2012). During the $2013 \mathrm{SSW}$, which was characterized by a rapid amplification of planetary wave 2 at $10 \mathrm{hPa}$ in early January, the mesospheric wind reversal at $60^{\circ} \mathrm{N}$ begins on 7 January, nearly the same time that the stratospheric jet reversal first appears at $10 \mathrm{hPa}$.

There is both modeling and observational evidence that these changes in PW drag, GW drag, and the meridional circulation associated with a major SSW can exert an impact on the dynamics of the MLT that extends to the equatorial regions and possibly the Southern Hemisphere as well (see, e.g. Limpasuvan et al., 2016, and references therein). One common feature that has been identified in several studies is the amplification of the semi-diurnal westward migrating zonal wave number 2 (SW2) tide after the onset of the SSW (Wang et al., 2011; Jin et al., 2012; Goncharenko et al., 2013b; Pedatella and Liu, 2013; Limpasuvan et al., 2016). A possible mechanism to explain this behavior is that changes in the spatial distribution of stratospheric ozone heating caused by meridional circulation anomalies related to the SSW alter the forcing of the migrating semi-diurnal tide (Goncharenko et al., 2012). Another possible mechanism is that changes in vorticity throughout the tropical stratosphere and mesosphere affect the vertical propagation of migrating tides into the thermosphere (Sassi and Liu, 2014). The search for a definitive mechanism (or mechanisms) to explain how the onset of an SSW impacts the 
behavior of SW2 is complicated by the fact that there is broad disagreement in the amplitude of the SW2 response to an SSW among whole atmosphere models (Pedatella et al., 2014, their Figure 10).

The goal of the present study is to evaluate the behavior of MLT winds during two NH winter periods when major SSWs occurred through detailed comparisons of NAVGEM analyzed winds with independent meteor radar winds for the 2009-2010 and 2012-2013 winters. The results of this validation study show that high-altitude NAVGEM analyses provide an accurate description of global MLT winds that can be used to inform future studies on coupling between the lower atmosphere and ionosphere through modulation of tides.

Section 2 provides a description of the high-altitude NAVGEM system as well as the nine ground-based meteor radar wind records used for validating the NAVGEM results. Section 3 presents detailed comparisons of the dayto-day variations in zonal and meridional winds from both NAVGEM and meteor radar observations. Section 4 examines vertical profiles of tidal amplitude and phase from NAVGEM and radar winds. Section 5 compares the temporal variations in the dominant planetary wave and tidal components derived from the NAVGEM and meteor radar winds. Section 6 summarizes the major findings and discusses their significance for improving our understanding of how meteorological variability in the lower atmosphere influences ionospheric conditions during recent SSWs.

\section{Data Description}

This section presents descriptions of both the high-altitude NAVGEM analyses and the meteor radar observations that are used to provide information on tidal variations in MLT winds around the times of SSWs in January 2010 and 2013.

\subsection{High-altitude NAVGEM with NAVDAS-AR}

The high-altitude NWP system used in the present study provides atmospheric specifications of wind, temperature, and composition from the surface to $\sim 100 \mathrm{~km}$ altitude that can be used to constrain lower atmospheric variability in whole atmosphere models. It is based on the operational system described in Hogan et al. (2014), which combines the semiLagrangian/semi-implicit (SL/SI)NAVGEM global spectral forecast model with a four-dimensional variational (4DVAR) data assimilation algorithm. 
This 4DVAR algorithm is based on the NRL Atmospheric Variational Data Assimilation System with Accelerated Representer (NAVDAS-AR) and routinely processes over 3 million observations every 6-hour assimilation cycle from a variety of in-situ sources (e.g., surface reports, radiosondes, ship and aircraft data) and satellite-based remote sensing data (e.g., radiance measurements from infrared and microwave sensors, global positioning system radio occultations, cloud track winds) that are available operationally. The high-altitude version of the combined NAVGEM/NAVDAS-AR system used in the present study (which we will refer to simply as high-altitude NAVGEM) includes several additional features that are key to producing accurate meteorological analyses in the MLT region.

First, the vertical domain of the forecast model was extended from its current operational 60-level (L60) configuration with a top pressure of $0.04 \mathrm{hPa}$ to a 74-level (L74) configuration with top pressure of $6 \times 10^{-5} \mathrm{hPa}(\sim 116 \mathrm{~km}$ altitude) and a vertical spacing of $\sim 2 \mathrm{~km}$ in the stratosphere and mesosphere. The model employs a hybrid vertical coordinate that is terrain-following near the surface and smoothly transitions to pure pressure levels in the lower stratosphere (Eckermann et al., 2009). Enhanced diffusion is applied in the top three model levels to limit wave reflection, producing an effective "sponge layer" above $100 \mathrm{~km}$ altitude. To avoid the possibility of the analyses being affected by this sponge layer, we only report NAVGEM results below the $100 \mathrm{~km}$ level.

Next, virtual potential temperature $\theta_{v}$ was replaced with a perturbation virtual potential temperature $\theta_{v}^{\prime}$ as the prognostic thermodynamic variable in the L74 NAVGEM forecast model. This change addresses stability issues that arose in earlier versions of NAVGEM related to the use of the SL/SI method with a conservative thermodynamic variable (see, e.g. Staniforth et al., 2006; Juang, 2011). These issues were traced to the vertical advection of $\theta_{v}$ related to gravity wave activity; in certain cases excessive variability of the local flow led to violations of the Lipschitz condition (Smolarkiewicz and Pudykiewicz, 1992). For NWP purposes, stability at larger time steps $(>5 \mathrm{~min}$ ) had to be maintained through either strong implicit biasing (also called decentering or off-centering) of the SI scheme or imposed numerical diffusion, measures that smooth the local flow and reduce the accuracy of the method.

To improve both the stability and accuracy of the SL/SI scheme, the L74 NAVGEM forecast model uses the perturbation virtual potential temperature $\theta_{v}^{\prime}=\theta_{v}-\theta_{0}$ as the prognostic thermodynamic variable, where $\theta_{0}$ is a climatological basic state potential temperature. This method allows the 
SL/SI scheme to sufficiently damp the gravity waves by extracting the vertical advection of $\theta_{0}$ from the trajectory calculation. In the L74 NAVGEM forecast model, the vertical profile of $\theta_{0}$ is defined as a diagnostic function of Exner pressure calculated using a nonlinear regression fit to a combination of the 1976 US Standard atmosphere below the $10 \mathrm{hPa}$ level $(\sim 30 \mathrm{~km}$ altitude) and a global mean temperature profile based on ten years of observations from the Sounding of the Atmosphere using Broadband Emission of Radiation (SABER) instrument on the NASA TIMED satellite (Rezac et al., 2015) above the $10 \mathrm{hPa}$ level. Dynamical core tests have shown that use of the perturbation virtual potential temperature based on this $\theta_{0}$ profile provides stable model performance throughout the vertical domain of the L74 model over a wide range of horizontal resolutions and model time steps.

To augment the operational meteorological observations in the troposphere and lower stratosphere, three data sources for the stratosphere, mesosphere, and lower thermosphere were added to the input stream for the highaltitude L74 NAVGEM system following procedures described in Eckermann et al. (2009) and Hoppel et al. (2013). The include: (1) profiles of temperature, ozone mixing ratio, and water vapor mixing ratio from the Version 2.2 retrievals of the Microwave Limb Sounder (MLS) on board the NASA Aura satellite (Schwartz et al., 2008); (2) temperature profiles from version 2.0 SABER retrievals; and (3) microwave radiances from the upper atmosphere sounding (UAS) channels of the Special Sensor Microwave Imager/Sounder (SSMIS) on the F16, F17, and F18 series of Defense Meteorological Satellite Program (DMSP) platforms (Swadley et al., 2008). The MLS constituent profiles are assimilated into the system's prognostic ozone and water vapor fields, which are used in the forecast model's radiative heating calculations.

Finally, a new hybrid data assimilation method that linearly combines static 4DVAR background error covariance estimates with covariances derived from an 80-member flow-dependent ensemble of instantaneous 6-hour forecasts (Kuhl et al., 2013) was coupled with the high altitude NAVGEM forecast model. Ensembles for this system are generated with the ensemble transform method describe in McLay et al. (2010). This hybrid approach has been shown to improve tropospheric analyses and forecasts by providing more realistic estimates of background (i.e., forecast model) uncertainty in atmospheric state variables, which in turn produces an analysis closer to the maximal likelihood state of the atmosphere compared to the conventional approach that uses static error covariances (Kuhl et al., 2013). The relative lack of observations in the stratosphere and mesosphere compared to the 
troposphere emphasizes the need for the improved background covariance estimates that this hybrid approach provides. Based on the result of sensitivity studies, a tuned background covariance ratio of 0.5 that equally weights the flow dependent and static background covariances yielded the smallest analysis errors in the high-altitude NAVGEM analyses discussed here.

Figure 2 plots an example of the geographic coverage provided by the MLS, SABER, and UAS observations over a 6-hour interval that are used as input for the high altitude NAVGEM system. MLS profiles of temperature, ozone, and water vapor are assimilated at pressure levels between 100 $-0.002 \mathrm{hPa}\left(\sim 16-90 \mathrm{~km}\right.$ altitude) over the latitude range from $82^{\circ} \mathrm{S}$ to $82^{\circ} \mathrm{N}$. SABER temperature profiles are assimilated over the $100-0.0002$ hPa range $(\sim 16-105 \mathrm{~km})$. The latitude coverage of the SABER instrument continuously switches between a "north-viewing" mode $\left(52^{\circ} \mathrm{S}-83^{\circ} \mathrm{N}\right)$ and a "south-viewing" mode $\left(83^{\circ} \mathrm{S}-52^{\circ} \mathrm{N}\right)$ every 60 days. During the $2009-2010$ winter, SABER switched from south-viewing mode to north-viewing mode on 11 January 2010 and remained there until 15 March. During the 20122013 winter, SABER switched from south-viewing to north-viewing mode on 7 January 2013, and returned to south-viewing mode on 11 March. SSMIS UAS microwave radiances from channels 19, 20, and 21 on the polar orbiting F16, F17, and F18 platforms are assimilated throughout the two NH winter periods. The weighting functions of these three channels lie between approximately $50-80 \mathrm{~km}$ altitude and are vertically deep, spanning up to 20 $\mathrm{km}$ altitude at full width of half maximum (see, e.g., Figure 1 of Hoppel et al., 2013). The altitude of peak sensitivity varies by as much as $10 \mathrm{~km}$ with geomagnetic activity due to Zeeman splitting, which is accounted for by preprocessing UAS radiances prior to assimilation in NAVGEM using a fast radiative transfer model (Bell et al., 2008; Han et al., 2010).

For the 2009-2010 and 2012-2013 winter cases, the high-altitude NAVGEM system was initialized on 5 November 2009 and 15 November 2013, respectively, to allow a 2-3 week "spin-up" period for the satellite radiance variational bias correction scheme (Hogan et al., 2014). These initialization dates were determined by the availability of archived operational NAVGEM atmospheric analyses. Lower boundary conditions were specified using archived analyses of sea surface temperatures and sea ice concentrations provided by the Navy Fleet Numerical Meteorology and Oceanography Center (FNMOC). For the current study, the L74 NAVGEM forecast model employed a triangular spectral truncation at wave number 119 (T119), giving an effective horizontal grid spacing of $1^{\circ}$ in latitude and longitude. The model time step 
is 15 minutes. The ensemble of forecasts used within the hybrid 4DVAR system were carried out at the data assimilation system's T47 resolution $\left(2.5^{\circ}\right.$ horizontal grid spacing). The standard NAVGEM assimilation cycle is every 6 hours, producing global synoptic analyses of winds, temperature, geopotential height, ozone, water vapor, and derived state variables such as horizontal divergence and vorticity four times daily at 00UTC, 06UTC, 12UTC, and 18UTC on a $1^{\circ}$ latitude/longitude grid. Here we augment this output using 3-hour T119 NAVGEM forecasts initialized from each of these 6-hourly analyses that are generated each assimilation cycle as part of the 4DVAR system. In doing so, we obtain corresponding output fields at 03UTC, 09UTC, 15UTC, and 21UTC that, when combined with the 6-hourly analyses, gives a net sampling frequency of 3 hours capable of resolving waves up to the Nyquist frequency of $4 \mathrm{cpd}$.

For comparison with the meteor radar winds, vertical profiles of highaltitude NAVGEM analyzed winds are converted from the model vertical grid to a geometric altitude grid using analyzed geopotential heights as in Eckermann et al. (2009). Figure 3 compares 14-day time series of NAVGEM 3-hourly analysis/forecast meridional winds at $87-88 \mathrm{~km}$ with corresponding hourly meteor radar winds from 4 different sites: Trondheim, Juliusruh, Ascension Island and Tierra del Fuego. To evaluate the correlation between the NAVGEM and radar wind time series at each location in Fig. 3, we subsampled the hourly meteor radar wind time series every three hours corresponding to the NAVGEM forecast/analysis times. Figure 3 lists the resulting values of the Pearson correlation coefficient $r$ at each station, which range from 0.69 at Ascension Island to 0.44 at Tierra del Fuego. Cross correlation with lags of \pm 18 hours finds the largest correlations at zero lag in all four cases. The comparisons in Fig. 3 demonstrate that the combined 3-hourly NAVGEM analysis/forecast winds successfully captures key periodic structures in the observed meridional winds over a wide range of latitude. A more detailed analysis of the temporal variability in the NAVGEM and meteor radar winds is presented in Section 4.

\subsection{Meteor radar observations}

Meteor radars detect plasma trails that are created when meteoroids encounter the earth's upper atmosphere. Information on horizontal winds in the MLT is obtained from the observed drift of these trails. The present study analyzes zonal and meridional MLT wind components obtained from 
nine separate radar sites. The location of these sites, technical details, and references for each radar system are listed in Table 1.

The meteor radar data can be divided into two groups based on the data processing used to derive the winds. The first group consists of data from the Trondheim, Bear Lake, Ascension Island, Tierra del Fuego and Rothera sites. For these stations, winds have been determined using the method described in Fritts et al. (2010a, and references therein), to produce vertical profiles of hourly zonal and meridional winds between $75-80 \mathrm{~km}, 80-84 \mathrm{~km}, 84-86 \mathrm{~km}$, $86-88 \mathrm{~km}, 88-90 \mathrm{~km}, 90-92 \mathrm{~km}, 94-96 \mathrm{~km}$, and 96-100 km. This method uses a least squares fit to the measured radial velocities of meteor trails when a minimum of 7 meteors are present in each time-altitude interval. In addition, the double loop system described in Hocking et al. (2001) was implemented to discard large outliers in the radial velocities that are not representative of the mean winds. The resulting wind estimates are assigned to the middle of each time-altitude interval, i.e., observations from 0400-0500 UTC and 90$92 \mathrm{~km}$ altitude are assigned to $0430 \mathrm{UTC}$ and $91 \mathrm{~km}$ altitude. The variable altitude spacing corrects for the change of meteor counts as a function of altitude.

The wind retrievals from Andenes, Juliusruh, Collm and the Canadian Meteor Orbit Radar (CMOR) are based on an updated version of the wind fitting algorithm first described in Hocking et al. (2001), and later used in Stober et al. (2012), which accounts for error propagation of each individual radial velocity uncertainty and the angular error of the interferometer. In the present study, the fitting algorithm obtains the instantaneous threedimensional wind vector $\mathbf{V}=(u, v, w)$ using a constrained least squares solution where the vertical and time derivatives of each wind vector component $(u, v, w)$ are assumed to be constant between adjacent time and altitude bins. Furthermore, it is assumed that the vertical wind is small $(w \approx 0)$, which is justified considering the large observation volume (400-600 $\mathrm{km}$ in diameter) of the meteor radars. This analysis is applied to a minimum of 5 meteors within each time-altitude interval. Wind estimates from all four sites are processed using $2 \mathrm{~km}$ altitude gates with oversampling of $3 \mathrm{~km}$ and 2 hours in time to produce hourly time series of zonal and meridional winds at $2 \mathrm{~km}$ intervals between $70-110 \mathrm{~km}$ altitude. Each meteor is weighted by a Gaussian kernel depending on its vertical distance from the altitude reference grid as well as by its time difference from the reference time of each bin.

The numerical methods used in this study to characterize tidal variability in MLT winds (described in the following section) require continuous time 
series. Table 1 lists the time periods over which the meteor radar winds from each station are analyzed with these methods. These periods were selected to avoid extended gaps (one day or longer) in an individual site's data record. Within these selected periods, smaller data gaps (typically 2-3 hours) occur sporadically due to, e.g., low meteor rate counts or instrumental issues. To obtain a continuous data record, we perform a linear interpolation across these smaller gaps to fill in the missing data.

\section{Analysis of temporal variability in MLT winds}

To characterize the dominant modes of temporal variability in the NAVGEM and meteor radar time series used in this study, we use the $S$-transform method described in Stockwell et al. (1996), which is an extension of a continuous wavelet transform analysis that utilizes an adjustable Gaussian window. For a continuous time series $u(t)$ with a corresponding Fourier transform $\hat{u}(\alpha)$, the complex $S$-transform can be expressed as

$$
S(\tau, f)=\int_{-\infty}^{+\infty} \hat{u}(\alpha+f) e^{-2\left(\frac{\pi k \alpha}{f}\right)^{2}} e^{i 2 \pi \alpha \tau} d \alpha
$$

where $\tau$ and $f$ represent the time and frequency dependence of the $S$-transform, respectively, and $\alpha$ is the frequency associated with the Fourier transform of $u(t)$. The width of the Gaussian window, expressed as $\frac{\pi k \alpha}{f}$, is a function of frequency $f$ that can be adjusted by the choice of scaling factor $k>0$ (Ventosa et al., 2008, their equation 2). Values of $0<k<1$ increase the temporal resolution of $S$ at the expense of spectral resolution, whereas values of $k>1$ increase the spectral resolution at the expense of the temporal resolution.

One advantage of the $S$-transform is that it can provide information on the temporal variability of both the magnitude and phase of each frequency component in the time series $u(t)$ without a priori assumptions about the nature of the variability in the time series. This is in contrast to conventional fitting methods often used to extract tidal signals from MLT wind records, which assume the presence of a dominant mode (or modes) of variability throughout the entire data record.

Another advantage of the $S$-transform is that, unlike other wavelet techniques, the time-integrated complex $S$-transform yields exactly the Fourier spectrum, i.e.,

$$
\langle S\rangle=\int_{-\infty}^{+\infty} S(\tau, f) d \tau=\hat{u}(f) .
$$


This property is helpful for comparison of $S$-transform results with one- and two-dimensional Fourier analyses commonly used to identify tidal and planetary wave signals in MLT winds (e.g., McCormack et al., 2010, 2014).

In the present study, the $S$-transform is applied to time series of zonal and meridional winds from both 3-hourly NAVGEM output and 1-hourly meteor radar observations. To isolate the temporal variability of specific periodic features such as tides, instantaneous values of wave amplitude $|S|$ and phase $\phi$ are calculated as a function of time and frequency as

$$
|S(\tau, f)|=\sqrt{\operatorname{Re}(S)^{2}+\operatorname{Im}(S)^{2}} \quad \phi(\tau, f)=\arctan \left[\frac{\operatorname{Im}(S)}{\operatorname{Re}(S}\right] .
$$

Although the time-integrated complex $S$-transform is equivalent to the Fourier transform over the time window being analyzed for any value of the scaling factor $k$, instantaneous values of the amplitude $|S|$ are sensitive to the choice of $k$. To illustrate this sensitivity, Figure 4 plots values of $|S|$ as a function of time and frequency obtained from hourly Ascension Island meridional wind time series at $87 \mathrm{~km}$ for February 2010 using three different values of $k$. As Figure 4a shows, this time series exhibits a strong 2-day oscillation in early February that transitions to a combination of diurnal and semi-diurnal variability later in the month. This transition can be clearly seen in Fig. 4b, $4 \mathrm{c}$, and $4 \mathrm{~d}$, which plot values of $|S|$ using factors of $k=0.5, k=1$, and $k=1.5$, respectively. Wave amplitudes using $k=0.5$ (Fig. 4b) have higher time resolution at the expense of frequency resolution, while amplitudes using $k=1.5$ (see Fig. 4d) have higher frequency resolution at the expense of temporal resolution. A comparison of the wave spectra derived using a fast Fourier transform or FFT (Fig. 4e-f, black curves) with values of $\langle S\rangle$ (Fig. 4e-f, orange dashed curves) shows that the time-averaged complex $S$ transform matches the FFT spectra regardless of the value of scaling factor $k$. However, the choice of $k$ does affect the spectral shape of instantaneous values of $|S|$, which can be seen in the monthly mean values of $|S|$ plotted in Fig. 4e-f (gray curves).

The results plotted in Figure 4 illustrate the trade-off between time and frequency resolution of $|S|$ associated with the choice of scaling factor $k$. Based on these results, and on examination of $S$-transform spectra (not shown) derived from the other stations listed in Table 1, we adopt a scaling factor of $k=1.0$ in order to capture the temporal variability in $|S|$ (see Fig. $4 c$ ) while also preserving the main spectral characteristics in time-averaged 
values of $|S|$ that are present in the FFT and $\langle S\rangle$ results (Fig. 4f), i.e., the peak amplitudes at $0.5 \mathrm{cpd}, 1 \mathrm{cpd}$, and $2 \mathrm{cpd}$.

\section{Results}

This section presents a detailed comparison of high-altitude NAVGEM analyzed winds and meteor radar wind observations in the MLT. First, we examine the time variations in vertical profiles of zonal and meridional winds for each station location and time period listed in Table 1. Next, we compare the monthly mean amplitudes and phases of the main periodic features (i.e., diurnal and semi-diurnal tide and 2-day wave) in the NAVGEM and meteor radar winds at each location using the $S$-transform. We then analyze the time variations in these periodic features during the SSWs in January 2010 and January 2013 to determine how well the NAVGEM analyses capture the observed variations in the MLT winds.

\subsection{Vertical profiles of $U$ and $V$}

Figures 5-18 plot the time variations in the vertical profiles of meridional wind $(V)$ and zonal wind $(U)$ from the hourly meteor radar observations (left column) and the corresponding 3-hourly NAVGEM analyzed winds (center column). The right column in Figs. 5-18 plots the vertical profiles of the time-averaged winds for each station and month. Where a complete month's worth of meteor radar observations are available, the time average is simply the monthly mean. Where there are extended data gaps of 1 day or longer, the time averaging is carried out over the longest continuous time interval within a given month. For example, Figure 5 plots the zonal and meridional wind profiles at Andenes (AND) for the December 2009 - February 2010 period. Due to missing meteor radar data over December 18-19 (Fig. 5, upper left), the wind profiles plotted in the upper right panel of Fig. 5 represent the time mean from 1-17 December 2009 (see also Table 1). Similarly, due to missing data over the January 26-28 and February 9-10 periods, the time averaged wind profiles for these months are limited to 1-25 January and 12-28 February, respectively.

Overall, there is good agreement between the meteor radar winds and NAVGEM analyzed winds at Andenes during the winters of 2009-2010 and 2012-2013 plotted in Figures 5 and 6, respectively. The dominant periodic feature throughout the winter is the semi-diurnal tide in both meridional and zonal winds. The semi-diurnal tide also dominates the wind profiles at 
the nearby Trondheim (THM) station during the 2012-2013 winter shown in Figure 7. In addition to the semi-diurnal tide, there is also sporadic lowfrequency variability with apparent periods of $\sim 5-10$ days in both NAVGEM and meteor radar winds at Andenes and Trondheim. The time mean profiles of $U$ and $V$ in Figs. 5, 6, and 7 are in good agreement overall, although we note that the NAVGEM zonal winds often exhibit a westerly (i.e., positive) bias of $5-10 \mathrm{~m} \mathrm{~s}^{-1}$ relative to the meteor radar winds. For reference, typical values of the corresponding standard deviations in the time means of $U$ and $V$ over these periods range from $\sim 20 \mathrm{~m} \mathrm{~s}^{-1}$ at $75 \mathrm{~km}$ to $\sim 40 \mathrm{~m} \mathrm{~s}^{-1}$ at $90 \mathrm{~km}$, regardless of whether the time period considered is a full month or only 23 weeks. Although the differences between the time mean NAVGEM and meteor radar wind profiles are small compared to these standard deviations, these differences can be useful for identifying possible systematic biases in NAVGEM winds that will need to be studied (and rectified) in the future.

Figures 8 and 9 compare $U$ and $V$ profiles from NAVGEM and from the Juliusruh (JUL) meteor radar for the 2009-2010 and 2012-2013 winters, respectively. The wind profiles are characterized by a combination of semidiurnal and low-frequency variations, similar to the Andenes and Trondheim wind profiles. These same characteristics are also seen in wind profiles from the nearby Collm (COL) site for the two winters, which are plotted in Figures 10 and 11. The mean NAVGEM $U$ and $V$ profiles in Figs. 8-11 are in good overall agreement with the mean meteor radar winds; some exceptions are seen in the December 2009 mean profiles of $V$ (Figs. 8 and 10, top right) and the February 2010 mean profiles of $U$ (Figs. 8 and 10, bottom right), where the NAVGEM winds above $85 \mathrm{~km}$ are $15-20 \mathrm{~ms}^{-1}$ stronger than the meteor radar winds. The NAVGEM winds capture the observed interannual variations in the mean wind profiles at Juliusruh and Collm between the two winter cases. Specifically, both data sets show stronger westerly flow between 78-85 km in January and February 2013 (Figs. 9 and 11) compared to January and February 2010 (Figs. 8 and 10).

Figures 12 and 13 plot the $U$ and $V$ profiles from NAVGEM analyses and CMOR (CMO) observations for the 2009-2010 and 2012-2013 winters, respectively. Again, a combination of semi-diurnal and longer-period oscillations are evident. The NAVGEM and CMOR meridional wind profiles during both winters are in good agreement. The zonal wind profiles exhibit considerable differences, particularly between $78-85 \mathrm{~km}$ where the NAVGEM westerly winds are $20-25 \mathrm{~m} \mathrm{~s}^{-1}$ stronger than the CMOR winds during the month of December 2009 (Fig. 12), and throughout the December 2010 to 
February 2013 period (Fig. 13).

Figures 14 and 15 plot the $U$ and $V$ profiles from NAVGEM analyses and meteor radar observations at Bear Lake (BLK) for the 2009-2010 and 2012-2013 winters, respectively. The Bear Lake records contain numerous gaps, particularly below $82 \mathrm{~km}$ and above $91 \mathrm{~km}$ throughout the 2012-2013 winter (Fig. 15). At altitudes between $82-91 \mathrm{~km}$ where both NAVGEM and Bear Lake meridional wind profiles are available, the monthly mean $V$ values during both winters (Figs. 14 and 15) are in good agreement. The monthly mean $U$ profiles during the 2009-2010 winter exhibit considerable differences below $85 \mathrm{~km}$ during December 2009 and January 2010, where the NAVGEM westerly winds are 10-20 $\mathrm{m} \mathrm{s}^{-1}$ stronger than the Bear Lake radar winds. (Fig. 14). The monthly mean $U$ profiles for the 2012-2013 winter (Fig. 15) are in good agreement during December and January. In February, the NAVGEM mean zonal winds are up to $20 \mathrm{~m} \mathrm{~s}^{-1}$ weaker than the radar winds between $80-90 \mathrm{~km}$.

In addition to the six $\mathrm{NH}$ stations discussed above, this study also compares NAVGEM analyzed winds with meridional and zonal wind profiles from three Southern Hemisphere (SH) stations during the 2009-2010 and 20122013 winters (see Table 1). Examining the winds in both hemispheres during these two winters provides an excellent opportunity to validate the global behavior of NAVGEM winds around the time of SSWs in January 2010 and January 2013.

Figure 16 plots $U$ and $V$ profiles over Ascension Island (AI) for the period from 1 January - 31 March 2010. In contrast to the NH stations where the semi-diurnal oscillation dominates, the NAVGEM and meteor radar meridional winds at this tropical location $\left(8.0^{\circ} \mathrm{S}, 14.4^{\circ} \mathrm{W}\right)$ exhibit a combination of 2-day, diurnal, and semi-diurnal variability (see also Fig. 4). The monthly mean profiles of $V$ from NAVGEM analyses and meteor radar observations are in overall good agreement at this location. A comparison of the monthly mean $U$ profiles in Fig. 16 shows that the NAVGEM zonal winds have a strong westerly bias of $20-40 \mathrm{~m} \mathrm{~s}^{-1}$ in February and March 2010.

Figures 17 and 18 offer comparisons of NAVGEM and meteor radar winds at the higher-latitude SH (summer) locations of Tierra del Fuego (TDF) and Rothera (RTH) during 2012-2013 winter period, respectively. Due to missing data in January 2013, $U$ and $V$ profiles from Tierra del Fuego are compared with NAVGEM winds for December 2012, February 2013, and March 2013 (Fig. 17). At this location, $S$-transform analysis finds that the main periodic variations in both $U$ and $V$ are at $1 \mathrm{cpd}$, consistent with the diurnal tide. 
There is also lower frequency variability in $V$ with a mean period of 2.5 days. We note that the amplitude of the diurnal variation in $V\left(\sim 15 \mathrm{~m} \mathrm{~s}^{-1}\right)$ is roughly one-half the amplitude of the variation at the other extratropical NH and tropical SH stations. The monthly mean $U$ and $V$ profiles at Tierra del Fuego from NAVGEM and meteor radar wind observations are in good qualitative and quantitative agreement for these three months. In particular, the NAVGEM zonal winds capture the sharp vertical gradient in $U$ observed between 82-95 km in December 2012 and February 2013.

Figure 18 plots $U$ and $V$ over Rothera during the period from December 2012 to February 2013. At this high southern latitude, the wind variations consist mainly of a relatively weak $\left(\sim 10 \mathrm{~m} \mathrm{~s}^{-1}\right)$ diurnal variation. Due to large data gaps in the meteor radar record at this location during December 2012 and early January 2013, only mean profiles of $U$ and $V$ from the meteor radar observations for 15-31 January and 1-28 February of 2013 are plotted in Fig. 18. Overall, the NAVGEM mean $U$ and $V$ profiles for January and February 2013 are in good agreement with the meteor radar observations between $85-95 \mathrm{~km}$.

In summary, these initial comparisons of the $U$ and $V$ profiles from NAVGEM and meteor radar wind observations over the 2009-2010 and 2012$2013 \mathrm{NH}$ winter periods demonstrate that the NAVGEM analyses accurately capture the main characteristics in the MLT winds at these nine locations, both in terms of the periodic variations and of the time-averaged flow. The main deficiency in the NAVGEM winds appears to be a westerly bias of approximately $10-20 \mathrm{~m} \mathrm{~s}^{-1}$ in mean zonal wind profiles below $\sim 85 \mathrm{~km}$ at NH midlatitudes (e.g., Figs. 12, 13, and 14), and a stronger westerly bias of 20-40 $\mathrm{m} \mathrm{s}^{-1}$ during February and March of 2013 at the SH tropical station of Ascension Island (Fig. 16). As discussed in Section 5, these types of biases in the NAVGEM zonal wind analyses could arise from systematic errors in the physical parameterizations used in the forecast model component of NAVGEM (e.g., gravity wave drag). A more systematic validation of global zonal wind fields from NAVGEM high-altitude analyses to clearly identify possible sources of any systematic errors is currently ongoing and will be the subject of a follow-on study.

\subsection{Amplitude and phase of semi-diurnal, diurnal, and quasi-2 day features}

The results in Figures 4-18 together show that the vertical profiles of $U$ and $V$ between $75-95 \mathrm{~km}$ during the two $\mathrm{NH}$ winter periods exhibit periodic variations mainly at semi-diurnal, diurnal, and $\sim 2$-day periods. In 
this section, we examine the vertical profiles of $S$-transform amplitude and phase associated with these features to determine how well the high-altitude NAVGEM wind variations agree with the observed meteor radar wind variations over the broad geographic range offered by the meteor radar sites. To do so, the $S$-transform was applied to time series of $U$ and $V$ between 75-95 $\mathrm{km}$ altitude from each of the meteor radar sites over the time periods listed in Table 1 and to the corresponding NAVGEM $U$ and $V$ time series. Time averaged values of the amplitude $|S|$ and phase $\phi$ were computed from both NAVGEM and meteor radar winds at $2 \mathrm{cpd}, 1 \mathrm{cpd}$, and $0.5 \mathrm{cpd}$ using the scaling factor $k=1$. Standard deviations of the amplitude and phase about the time mean for each period were also computed at each of these frequencies in order to quantify the geophysical variability in the periodic features. The following sections present results from the first 8 sites listed in Table 1. Results for the ninth site, Rothera, are not presented since the $S$-transform analysis found very weak $\left(<10 \mathrm{~m} \mathrm{~s}^{-1}\right)$ variations at these frequencies in both NAVGEM and radar winds.

\subsubsection{Semi-diurnal variations}

Our analysis finds that the semi-diurnal (2 cpd) variations of $U$ and $V$ during both 2009-2010 and 2012-2013 winters are strongest at the NH extratropical stations of Andenes, Trondheim, Juliusruh, Collm, CMOR, and Bear Lake. Figures 19-24 plot the vertical profiles of the time averaged amplitude and phase of the semi-diurnal component in $U$ and $V$ from these six stations. The error bars in these plots represent the standard deviation of the amplitude and phase about the time mean. The phase is expressed as local time of maximum wind.

The semi-diurnal amplitude and phase profiles in $U$ and $V$ at the high northern latitude locations of Andenes and Trondheim (Figs. 19 and 20) show very good qualitative and quantitative agreement overall between the NAVGEM and meteor radar results. Exceptions to this agreement are found at Andenes (Fig. 19) where semi-diurnal amplitudes in NAVGEM $V$ are consistently $\sim 10 \mathrm{~m} \mathrm{~s}^{-1}$ smaller than the meteor radar $V$ amplitudes throughout the 75-95 km altitude range during December 2012 and February 2013, and also during January 2013 when the NAVGEM semi-diurnal $U$ amplitudes are $10-20 \mathrm{~m} \mathrm{~s}^{-1}$ larger than the meteor radar $U$ amplitudes. There is also disagreement between the NAVGEM and radar wind semi-diurnal $U$ and $V$ amplitudes at Trondheim (Fig. 20) during February 2013, when the NAVGEM amplitudes are 10-15 $\mathrm{m} \mathrm{s}^{-1}$ less than the meteor radar amplitudes between 
85-95 km.

Figures 21 and 22 compare the semi-diurnal amplitude and phase in $U$ and $V$ from NAVGEM and meteor radar observations at the Northern European stations of Juliusruh and Collm, respectively, for the two NH winter periods. The peak amplitudes in both $U$ and $V$ at these two midlatitude stations are larger than at the two Scandinavian station locations (Fig. 19 and 20). Again, we find good overall agreement between the vertical profiles of semidiurnal amplitude and phase from the NAVGEM and meteor radar winds at these two locations, although we note that the NAVGEM amplitudes during most months are $\sim 5-10 \mathrm{~m} \mathrm{~s}^{-1}$ larger than the meteor radar amplitudes. The largest discrepancies are found during January 2013 when NAVGEM $V$ amplitudes at both Juliusruh and Collm exceed the meteor radar amplitudes by $20 \mathrm{~m} \mathrm{~s}^{-1}$ between $90-95 \mathrm{~km}$.

Figures 23 and 24 compare the vertical profiles of the semi-diurnal amplitude and phase in NAVGEM and meteor radar $U$ and $V$ at the North American CMOR and Bear Lake sites, respectively. We find that the NAVGEM semi-diurnal amplitudes at CMOR (Fig. 23) are consistently $10-20 \mathrm{~m} \mathrm{~s}^{-1}$ larger than the meteor radar amplitudes during all months. There is better agreement between the NAVGEM and meteor radar semi-diurnal amplitudes in $U$ and $V$ at Bear Lake (Fig. 24). At both of these locations, the phase profiles are in agreement. However, the standard deviations of the time averaged phase values are large compared to the northern European stations. These larger standard deviations suggest a non-stationary semi-diurnal signal in local time at these locations, particularly in the meridional wind profiles.

Figure 25 plots time averaged vertical profiles of semi-diurnal amplitude and phase at Ascension Island for the January-March 2010 period. There is good overall agreement between the NAVGEM and meteor radar amplitudes in $U$ and $V$, with the exception of March 2010 when NAVGEM $V$ amplitudes above $90 \mathrm{~km}$ are significantly larger than the meteor radar observations indicate. At altitudes where the time averaged semi-diurnal amplitudes are relatively large $\left(\sim 10-20 \mathrm{~m} \mathrm{~s}^{-1}\right)$, there is good agreement between the semidiurnal phases derived from the NAVGEM and meteor radar winds.

\subsubsection{Diurnal variations}

Our analysis finds robust diurnal variations in horizontal winds at Ascension Island during the January-March 2010 period and at Tierra del Fuego during the months of December 2012, February 2013, and March 2013. Figure 26 plots time averaged profiles of diurnal (1 cpd) amplitude $|S|$ and phase 
$\phi$ in $U$ and $V$ at both of these locations. At Ascension Island (left three columns in Fig. 26), the meteor radar observations show the largest diurnal variations in $V\left(\sim 40-45 \mathrm{~m} \mathrm{~s}^{-1}\right)$ during February and March 2010. Diurnal variations in NAVGEM $V$ are exhibit good agreement with the radar estimates in January 2010 when diurnal amplitudes are smaller; during February and March 2010 the NAVGEM estimates are $10-20 \mathrm{~m} \mathrm{~s}^{-1}$ larger than the radar-based values between $75-88 \mathrm{~km}$, and are $\sim 10 \mathrm{~m} \mathrm{~s}^{-1}$ smaller than radar estimates above $90 \mathrm{~km}$. Both NAVGEM analyses and radar observations at Ascension Island show somewhat weaker diurnal variations in $U$ during the January-March 2010 period, with peak values of $20-30 \mathrm{~m} \mathrm{~s}^{-1}$. Profiles of diurnal phase in $U$ and $V$ at this location exhibit good agreement.

Profiles of diurnal amplitude and phase in $U$ and $V$ at Tierra del Feugo from the radar winds and NAVGEM analyses are plotted in the right three columns of Figure 26. At this higher southern latitude $\left(53^{\circ} \mathrm{S}\right)$, peak diurnal amplitudes are smaller $\left(\sim 10-15 \mathrm{~m} \mathrm{~s}^{-1}\right)$ than at Ascension Island $\left(8^{\circ} \mathrm{S}\right)$. Certain months show relatively poor agreement between the diurnal phase in the radar and NAVGEM winds, e.g., March 2013 for $V$ and February 2013 for $U$. For these months, the amplitude of the diurnal variation in $U$ and $V$ are very small $\left(\sim 5 \mathrm{~m} \mathrm{~s}^{-1}\right)$, making it difficult to isolate the phase as evidenced by the relatively large standard deviations in both radar and NAVGEM phase estimates.

\subsubsection{Quasi-2 day variations}

The $S$-transform analysis finds variations in $V$ at frequencies near $0.5 \mathrm{cpd}$ over Ascension Island during the January-March 2010 period. The quasi-2 day wave is a dominant feature of SH summer MLT winds that typically exhibits peak amplitudes over a range of frequencies between $0.45-0.6 \mathrm{cpd}$ shortly after solstice (see, e.g. Pancheva, 2006). Our analysis finds that peak amplitudes in $V$ of $30 \mathrm{~m} \mathrm{~s}^{-1}$ occur at $0.52 \mathrm{cpd}$, and are comparable to the amplitude of the diurnal variations in $V$ seen at Ascension Island (Fig. 26). To illustrate this feature, Figure 27 plots vertical profiles of the time-averaged amplitude and phase at $0.52 \mathrm{cpd}$ in both $U$ and $V$ from the Ascension Island observations and NAVGEM analyses. There is good qualitative agreement in the amplitude and phase of the quasi-2 day signal in $U$ and $V$ from the radar and NAVGEM winds, although the NAVGEM results consistently underestimate the peak amplitudes in $V$ during February 2010 by $\sim 10 \mathrm{~m} \mathrm{~s}^{-1}$ relative to the radar winds. 


\subsection{Time dependence of periodic features during 2010 and 2013 SSWs}

In this section, we apply the $S$-transform to time series of $U$ and $V$ from both meteor radar observations and NAVGEM analyses to characterize the temporal variability of the semi-diurnal, diurnal, and quasi-2 day features discussed in the previous section. We focus in particular on time periods centered on the occurrence of SSWs in January 2010 and 2013 to determine how these features evolve during such large-scale changes in middle atmospheric circulation. We analyze NAVGEM and radar winds at the Juliusruh, Collm, Bear Lake, and CMOR locations during the periods from 15 January to 15 February 2010 and 25 December 2012 to 25 January 2013. In addition, we also examine winds at Ascension Island from 15 January to 15 February 2010, and winds at Trondheim from December 252012 to January 252013. For this discussion, we limit our comparisons to the $87-88 \mathrm{~km}$ altitude range. This altitude range is chosen for several reasons: first, there are ample meteor radar observations during these two time periods at this level; second, NAVGEM analyses in this region assimilate both MLS and SABER temperature profiles; third, NAVGEM results at this level should avoid possible influences of the imposed diffusion at the model upper boundary.

Figures 28, 29, 30, and 31 plot values of $|S|$ as a function of time and frequency from NAVGEM and radar $U$ and $V$ at Juliusruh (88 $\mathrm{km}$ altitude), Collm $(88 \mathrm{~km})$, CMOR $(88 \mathrm{~km})$, and Bear Lake $(87 \mathrm{~km})$, respectively. In each of these figures, the vertical red lines denote the beginning of the NAVGEM mesospheric wind reversals on 27 January 2010 and 7 January 2013 associated with the onset of each SSW period, as discussed in Section 2 and illustrated in Fig. 1. The frequency range of these plots extends to $4 \mathrm{cpd}$, which is the Nyquist frequency for the 3-hourly NAVGEM output.

Figure 28a and 28b plot the time variations in $|S|$ derived from NAVGEM $V$ and $U$, respectively, at Juliusruh during the January 2010 SSW period. The main feature in both fields is a semi-diurnal variation whose amplitude decreases starting around the time of the mesospheric wind reversal on 27 January for a period of 3-4 days, then begins to increase until reaching peak amplitude 7-10 days following the initial wind mesospheric wind reversal. Similar behavior is also seen in the Juliusruh meteor radar winds (Fig. 28c and 28d). Both NAVGEM and meteor radar winds show peak semi-diurnal amplitudes in $U$ and $V$ of $\sim 50 \mathrm{~m} \mathrm{~s}^{-1}$. Figure 28e and $28 \mathrm{f}$ show that semidiurnal amplitudes in NAVGEM $V$ and $U$, respectively, for the January 2013 SSW period also decrease around the time of the mesospheric wind reversal beginning on 7 January 2013. In this case, however, semi-diurnal amplitudes 
take longer to increase compared to the January 2010 case. Peak amplitudes in $U$ and $V$ are seen 12-14 days after the onset of the mesospheric wind reversal. The meteor radar winds (Fig. 28g and 28h) also show this behavior.

Figure 29 plots similar results for the nearby Collm site, showing decreases in the semi-diurnal amplitudes around the time of the mesospheric wind reversal in both winters, followed by a relatively rapid increase in early February 2010 and a more gradual increase in mid-January 2013. We note that for both Juliusruh and Collm the peak NAVGEM amplitudes in midJanuary 2013 are $\sim 10-20 \mathrm{~m} \mathrm{~s}^{-1}$ larger than the corresponding peak radar wind amplitudes. This is consistent with the larger time averaged semidiurnal amplitudes in NAVGEM $U$ and $V$ compared to the meteor radar results seen in January 2013 in both Figs. 21 and 22.

Figures 30 and 31 plot the temporal evolution of the periodic features in NAVGEM and meteor radar $U$ and $V$ fields during the January 2010 and January 2013 SSW periods at the CMOR and Bear Lake sites, respectively. At these locations $\left(42^{\circ}-43^{\circ} \mathrm{N}\right.$ latitude), semi-diurnal variations are again the dominant feature, although the amplitudes of these variations are generally smaller than at Juliusruh and Collm $\left(51^{\circ}-54^{\circ} \mathrm{N}\right)$. During the January 2010 event, the $U$ and $V$ fields from both NAVGEM analyses and radar observations at CMOR and Bear Lake show semi-diurnal peaks on 23-24 January and 5-7 February. However, there is no clear decrease in semi-diurnal amplitudes around the time of the mesospheric wind reversal on 27 January as was seen at Juliusruh and Collm. During the January 2013 event, the NAVGEM and radar winds at both CMOR and Bear Lake exhibit peaks between 15-22 January, which is consistent with the behavior observed at Juliusruh and Collm (Figs. 28 and 29, panels e-h). In contrast to the Juliusruh and Collm results, the semi-diurnal variability at CMOR and Bear Lake does not show a decrease in amplitude around the time of the mesospheric wind reversal on 7 January; instead the NAVGEM and meteor radar winds show consistently weak semi-diurnal amplitudes in both $U$ and $V$ throughout late December 2012 and the first half of January 2013.

Figure 32 plots the $S$-transform results for NAVGEM and radar winds at $87 \mathrm{~km}$ over Trondheim during the January $2013 \mathrm{SSW}$ event. The semidiurnal variations at this high-latitude location $\left(63^{\circ} \mathrm{N}\right)$ are similar to those seen at the lower-latitude locations, particularly the peak amplitudes in both $U$ and $V$ occurring over the 15-22 January time frame. Overall there is good agreement between the semi-diurnal amplitudes from the NAVGEM and meteor radar winds during January 2013. 
Figure 33 plots the $S$-transform results for Ascension Island $\left(8^{\circ} \mathrm{N}\right)$ during the January 2010 SSW period from the NAVGEM analyses and radar winds at $88 \mathrm{~km}$. To better highlight the lower-frequency variability, the frequency range in these plots is limited to $3 \mathrm{cpd}$. Prior to the stratospheric wind reversal, both NAVGEM and meteor radar $V$ fields exhibit peaks at $1 \mathrm{cpd}$ and $0.5 \mathrm{cpd}$. Beginning on 31 January, there is a rapid increase in amplitude near $0.5 \mathrm{cpd}$ that is accompanied by a reduction in diurnal amplitudes. This amplification of the quasi-2 day wave in the Southern Hemisphere summer MLT around the time of a major SSW in NH winter is consistent with earlier studies of the quasi-2 day wave during January 2006 and January 2010 (McCormack et al., 2009, 2010). In contrast to the $V$ results, the NAVGEM and meteor radar $U$ results at Ascension Island show comparatively modest variations in diurnal amplitudes throughout January 2013 and no strong quasi-2 day variations.

\section{Discussion}

The results presented in the previous section demonstrate that the 3hourly output from the high-altitude NAVGEM forecast-analysis system accurately captures many of the key features in the meteor radar wind observations over the 2009-2010 and 2012-2013 NH winter periods. These features include the altitude dependence of the time averaged amplitude and phase of the semi-diurnal tide in zonal and meridional winds, and the time evolution of the main periodic features at semi-diurnal, diurnal, and quasi-2 day frequencies around the time of the SSWs in the two winters.

As discussed in the Introduction, several recent whole atmosphere modeling studies indicate that the migrating semi-diurnal tide is amplified in the NH extratropical MLT region following a major SSW event. Because these studies typically focus on one particular SSW event, it is difficult to generalize their results to all SSWs. As Figure 1 illustrates, the timing and structure of the major SSWs in January 2010 and January 2013 are quite different, particularly with respect to the evolution and descent of easterly flow at high Northern latitudes from the mesosphere to the mid-stratosphere. These differences extend to the behavior of the semi-diurnal variation in $U$ and $V$ following the 2010 and 2013 SSWs seen in Figs. 29-31.

With the understanding that no two SSWs will produce exactly the same MLT response, it is still useful to establish a generalized picture of how these events may influence tidal motions that can in turn impact the ther- 
mosphere/ionosphere system. To this end, a recent study by Limpasuvan et al. (2016) used a chemistry-climate model constrained by meteorological reanalyses below the $50 \mathrm{~km}$ level to examine the composite response of MLT dynamics to 13 SSW events between 1994 and 2012. A key finding of this study was that among the several different migrating and non-migrating tidal components examined, only the migrating semi-diurnal (SW2) amplitudes in the $\mathrm{NH}$ extratropics exhibited a robust response to the onset of a major SSW. Specifically, this study found an average amplification of $\sim 3 \mathrm{~m}$ $\mathrm{s}^{-1}$ in SW2 amplitudes over the latitude range $20^{\circ} \mathrm{N}-60^{\circ} \mathrm{N}$ near $80 \mathrm{~km}$ altitude that increased to $\sim 8-10 \mathrm{~m} \mathrm{~s}^{-1}$ at $100 \mathrm{~km}$. The largest SW2 responses were found to occur 10-20 days following the onset of what was defined in Limpasuvan et al. (2016) to be an elevated-stratopause stratospheric sudden warming event (ES-SSW), which requires a zonal wind reversal at $1 \mathrm{hPa}$, a polar cap temperature below $190 \mathrm{~K}$ between $80-100 \mathrm{~km}$, and an $10 \mathrm{~km}$ altitude discontinuity in stratopause height at high Northern latitudes.

To determine whether a similar type of response is evident in the highaltitude NAVGEM analyses of the January 2010 and January 2013 events, we computed mean semi-diurnal amplitude time series obtained from $S$ transform analysis of both NAVGEM and radar winds at altitudes between 80-90 km using all NH radar locations with a continuous 30-day period of observations around the times of the 27 January 2010 and 7 January 2013 mesospheric wind reversals. For the 2010 case, these locations are Juliusruh, Collm, CMOR, and Bear Lake. For the 2012-2013 case, these locations include Juliusruh, Collm, CMOR, Bear Lake, and Trondheim. Figure 34 plots mean amplitudes of the semi-diurnal variation in $V$ derived from NAVGEM analyses and radar observations from 15 January - 15 February 2010 (left column) and from 25 December 2012 - 25 January 2013 (right column). Vertical red lines in Fig. 34 indicate the dates of the mesospheric wind reversals in each year (see also Fig. 1).

In the 2010 case (Fig. 34, left column) both NAVGEM and radar wind observations indicate a mean increase in semi-diurnal $V$ amplitudes that begins $\sim 4-5$ days after the wind reversal and peaks 10 days later. The NAVGEM results averaged among the four station locations show a peak semi-diurnal amplitude of $51 \mathrm{~m} \mathrm{~s}^{-1}$ between at $90 \mathrm{~km}$, while the corresponding peak semidiurnal amplitude from the radar wind data is $54 \mathrm{~m} \mathrm{~s}^{-1}$. In the $2012 / 2013$ case (Fig. 34, right column), the mean NAVGEM and radar semi-diurnal $V$ amplitudes both exhibit a double peak structure between $85-90 \mathrm{~km}$ with two maxima on 17 January and 21 January, which occurs 10-14 days follow- 
ing the mesospheric wind reversal. For the January 2013 event, the mean NAVGEM results have a peak semi-diurnal amplitude of $70 \mathrm{~m} \mathrm{~s}^{-1}$ at $90 \mathrm{~km}$ on January 17, while the corresponding peak mean radar amplitude is only $50 \mathrm{~m} \mathrm{~s}^{-1}$.

Overall, the results in Fig. 34 indicate that the NAVGEM analyses capture the qualitative nature of the mean response of the semi-diurnal variation in meridional winds between $80-90 \mathrm{~km}$ altitude obtained from the available NH meteor radar observations for the January 2010 and 2013 SSW events. In particular, both data sets show very similar behavior consisting of a peak in semi-diurnal $V$ amplitudes 2-3 days prior to the mesospheric wind reversal, then a decrease in amplitude shortly after the reversal, followed by a steady increase in amplitude that peaks 10-14 days following the reversal. There are large discrepancies in the 2012/2013 case, where NAVGEM overestimates the peak semi-diurnal amplitudes from the radar observations by $20 \mathrm{~m} \mathrm{~s}^{-1}$ at $90 \mathrm{~km}$. Overestimation of the NAVGEM semi-diurnal amplitudes in both $V$ and $U$ were also noted in the time averaged profiles at the Juliusruh, Collm, and CMOR sites during January 2013 (see Figs. 21, 22, and 23). The exact cause (or causes) of these quantitative discrepancies is not known at this time and is the subject of ongoing investigations. Here we discuss several possible factors that could affect the representation of the semi-diurnal tides and other dominant periodic motions in the current high-altitude NAVGEM analyzed winds.

First, we note that in the 25 December 2012 - 25 January 2013 case (Fig. 34, right column), no SABER temperature profiles were available poleward of $52^{\circ} \mathrm{N}$ until after 7 January 2013, the date when the NAVGEM analyses indicate the onset of the mesospheric zonal wind reversal. Although changes in SABER coverage would be expected to mostly affect the NAVGEM analyses at high latitude locations such as Trondheim $\left(63^{\circ} \mathrm{N}\right)$, and possibly midlatitude locations near Collm and Juliusruh $\left(51^{\circ} \mathrm{N}-54^{\circ} \mathrm{N}\right.$ latitude), it is not clear at this time exactly how the changes in coverage would impact assimilation of the tides. Observation sensitivity experiments are needed to determine the exact latitude and time ranges over which the semi-diurnal feature (and other periodic variations) are affected by the introduction of SABER temperature profiles into the assimilation due to the satellite yaw cycle.

Second, differences in the semi-diurnal amplitudes extracted using the $S$-transform may arise due to the different temporal sampling, i.e., 3-hourly NAVGEM analysis/forecast winds versus hourly meteor radar wind observations. The coarser NAVGEM time resolution might be expected to system- 
atically underestimate the semi-diurnal wind variations seen in the hourly radar winds. This does not seem to be the case in general, as there is good quantitative agreement between NAVGEM and radar wind estimates of the semi-diurnal amplitudes in most months throughout the $75-95 \mathrm{~km}$ region; there is no indication in Figs. 19-24 that the 3-hourly NAVGEM analyses systematically underestimate the semi-diurnal amplitudes relative to the radar wind results throughout the December - February period. However, several recent modeling studies have found that disturbed conditions in the MLT around the time of an SSW promote interactions between migrating tides, non-migrating tides, and planetary waves that can amplify a variety of tidal modes with frequencies at or near multiples of $0.5 \mathrm{cpd}$ (e.g, FullerRowell et al., 2010; Pedatella and Liu, 2013; Pedatella et al., 2014). It is possible that the 3-hourly NAVGEM output is not sufficient to isolate the semi-diurnal component among these other components around the time of an SSW, leading to discrepancies between estimates of the semi-diurnal amplitude in winds from the high-altitude NAVGEM analysis and the meteor radar winds. To investigate this issue further, we plan to compare meteor radar observations with NAVGEM analyzed winds supplemented with 1hourly NAVGEM forecast model output in a future study. In addition, we also plan to perform spatial filtering of the global NAVGEM analyzed winds to better isolate the migrating tides, e.g. the zonal wavenumber 1 diurnal tide, zonal wavenumber 2 semi-diurnal tide, etc., which can then be evaluated through comparison with whole atmosphere model estimates of tidal behavior during SSW events.

Third, the representation of the tides in the high-altitude NAVGEM analyses could be affected by general biases in the forecast model. Global MLT observations consist mainly of satellite-based temperature measurements, which are assimilated in the high-altitude NAVGEM system. Accordingly, the primary method to evaluate model bias is to examine spatial and temporal mean characteristics of the difference between the observed and forecast MLT temperatures, referred to as the innovation or $O-F$. Improving the treatment of key physical processes in the NAVGEM forecast model to reduce $O-F$ in MLT analyses is an ongoing area of research. However, there are limitations on the ability of MLT temperature observations alone to constrain the MLT wind fields, especially given their sparse sampling relative to available observations in the troposphere and lower stratosphere. Further comparisons with MLT wind observations, as we have done here, will also be invaluable in diagnosing and reducing model bias. The main 
areas where the current high-altitude NAVGEM forecast model can be improved to eliminate potential sources of bias are the treatment of gravity wave drag (GWD), the parameterization of odd-oxygen photochemistry, and the description of exothermic chemical heating, and non-local thermodynamic equilibrium (non-LTE) effects that affect the energy budget of the atmospheric region above $90 \mathrm{~km}$. Here we discuss each of these areas in more detail.

The GWD parameterization of Eckermann (2011) specifies tropospheric sources of momentum flux using empirically-derived analytic functions that may not, in certain cases, accurately capture GW sources related to the "flow of the day". To address this issue, alternative approaches in which GW sources are more closely tied to the model's tropospheric flow are under investigation. The ultimate goal of this work is to produce a physically-based description of GW momentum flux sources that produces the most realistic flow in the MLT region, thereby minimizing forecast model bias that could degrade the quality of the analyzed winds. Minimizing this bias is important for accurate representation of tides in the analyses, since a mean model wind bias could influence the vertical propagation of tides from their source regions in the lower atmosphere, ultimately leading to errors in the MLT region.

Currently, NAVGEM only assimilates ozone profiles up to the $0.6 \mathrm{hPa}$ level ( $\sim 55 \mathrm{~km}$ altitude), and relaxes the prognostic ozone fields back to a monthly zonal mean climatology above this level (Eckermann et al., 2009). This is necessary due to the fact that the model's ozone photochemistry parameterization (McCormack et al., 2008) was originally designed for the stratosphere and does not account for diurnal ozone variations that become relatively large in the mesosphere. Given the established role that ozone heating plays in determining the temperature structure throughout the middle atmosphere, and in light of recent results suggesting that modifications in stratospheric ozone heating can contribute to SW2 variations around the time of major SSWs (e.g. Goncharenko et al., 2012; Limpasuvan et al., 2016), efforts are underway to implement a comprehensive parameterization of oddoxygen photochemistry valid from $10-100 \mathrm{~km}$ altitude.

Finally, the effects of exothermic chemical heating via, e.g., collisional deactivation and chemical recombination of atomic oxygen and non-LTE cooling to space by $\mathrm{CO}_{2}$ have not yet been incorporated into the high-altitude NAVGEM forecast model. Future investigations will examine the impact of these processes on both short-term (0-6 hour) and longer term (0-5 day) forecasts in the MLT in an effort to reduce model bias and improve the upper 
level temperature and wind analyses.

While the above discussion identifies several areas for improvement in the high-altitude NAVGEM forecast model, it should be emphasized here that the initial comparisons between NAVGEM MLT winds and meteor radar observations show very good overall agreement. This indicates that current forecast model performance is sufficient to generate accurate analysis/forecast fields within the 6-hour assimilation window, and that additional research devoted to improving overall system performance in the MLT is warranted.

\section{Summary}

This study of MLT winds produced with a new high-altitude NWP system shows, for the first time, that global meteorological analyses extending from the surface to $\sim 100 \mathrm{~km}$ based on assimilation of middle atmospheric temperature and constituent observations can accurately reproduce observed diurnal, semi-diurnal, and quasi-2 day variations in horizontal winds. Through detailed comparisons with meteor radar wind observations from nine different sites ranging in latitude from $69^{\circ} \mathrm{N}$ to $67^{\circ} \mathrm{S}$ over two $\mathrm{NH}$ winter periods (20092010 and 2012-2013), we find that, overall, high-altitude NAVGEM analyzed winds capture the observed time-averaged vertical structure in both zonal and meridional winds in the MLT between 75-90 km altitude. Furthermore, the NAVGEM analyses also accurately reproduce the observed time-averaged vertical profiles of both amplitude and phase associated with these periodic features in zonal and meridional wind.

The occurrence of major SSWs in January 2010 and January 2013 provide an opportunity evaluate how well the NAVGEM MLT winds capture observed changes in semi-diurnal amplitude during periods when the dynamics of the middle atmosphere are highly disturbed. We find that both NAVGEM analyses and meteor wind observations indicate a decrease in semi-diurnal amplitudes over the NH extratropics for several days beginning around the time of the mesospheric wind reversals at $60^{\circ} \mathrm{N}$ that precede the major SSW event. This is followed by an increase in semi-diurnal wind amplitudes which peaks 10-14 days following the onset of mesospheric wind reversals.

The results of this initial validation study are encouraging, and support additional efforts to improve high-altitude data assimilation products that can be used to constrain whole atmosphere models. These results also highlight the fact that continued high-quality MLT wind observations provided from a global network of meteor radars are critical for validation of future 
high-altitude specification and modeling efforts. Continued validation studies that employ direct MLT wind observations, high-altitude data assimilation products, and whole atmosphere modeling are needed to further improve our understanding of how variability in the lower atmosphere impacts the thermosphere/ionosphere system.

\section{Acknowledgments}

The authors thank two anonymous reviewers for their constructive comments. NAVGEM development was supported by the Chief of Naval Research. All NAVGEM experiments were performed under a grant of computer time from the Department of Defense High Performance Computing Modernization Program. Additional support for J. McCormack was provided by the NASA Heliophysics Division Living with a Star Program award NNH13AV95I. Support for R. de Wit was provided by the NASA Postdoctoral Program, administered by the Universities Space Research Association. Support for D. Fritts was provided the National Science Foundation grant AGS-1112830. Support for P. Espy and R. Hibbins was provided by the ARISE2 project, funded by the European Community's Horizon 2020 programme under grant agreement number 653980 . 
Table 1: Location, time coverage, and technical details of the meteor radar observations used for comparison with NAVGEM winds. $F$ represents radar frequency in $\mathrm{MHz}, P R F$ represents the pulse repetition frequency in $\mathrm{Hz}$, and $P$ is power in $\mathrm{kW}$.

\begin{tabular}{|c|c|c|c|c|c|c|}
\hline Station & Location & $F(\mathrm{MHz})$ & $\begin{array}{l}P R F \\
(\mathrm{~Hz})\end{array}$ & $\begin{array}{l}P \\
(\mathrm{~kW})\end{array}$ & Period & Reference \\
\hline Andenes & $69.3^{\circ} \mathrm{N} 16.0^{\circ} \mathrm{E}$ & 32.55 & 2094 & 30 & $\begin{array}{l}\text { 1-18 Dec 2009,1-26 Jan,12-28 Feb } 2010 \\
\text { 1-20 Dec 2012,1-28 Jan,1-24 Feb } 2013\end{array}$ & Stober et al. (2012) \\
\hline Trondheim & $63.4^{\circ} \mathrm{N} 10.5^{\circ} \mathrm{E}$ & 34.21 & 925 & 30 & 1 Dec $2012-28$ Feb 2013 & de Wit et al. (2015) \\
\hline Juliusruh (dual) & $54.6^{\circ} \mathrm{N} 13.4^{\circ} \mathrm{E}$ & $32.5 / 53.5$ & 2144 & $15 / 15$ & $\begin{array}{l}1 \text { Dec } 2009-28 \text { Feb } 2010 \\
1 \text { Dec } 2012-28 \text { Feb } 2013\end{array}$ & Stober et al. (2012) \\
\hline Collm & $51.3^{\circ} \mathrm{N} 13.0^{\circ} \mathrm{E}$ & 36.20 & 2144 & 6 & $\begin{array}{l}1 \text { Dec } 2009-28 \text { Feb } 2010 \\
1 \text { Dec } 2012-28 \text { Feb } 2013\end{array}$ & Jacobi (2012) \\
\hline CMOR (dual) & $43.3^{\circ} \mathrm{N} 80.0^{\circ} \mathrm{W}$ & $29.85 / 38.15$ & 5532 & $6 / 6$ & $\begin{array}{l}1 \text { Dec } 2009-28 \text { Feb } 2010 \\
1 \text { Dec } 2012-26 \text { Feb } 2013\end{array}$ & Brown et al. (2008) \\
\hline Bear Lake & $41.9^{\circ} \mathrm{N} 111.4^{\circ} \mathrm{W}$ & 35.20 & 2144 & 12 & $\begin{array}{l}1 \text { Dec } 2009-28 \text { Feb } 2010 \\
1 \text { Dec } 2012-28 \text { Feb } 2013\end{array}$ & Day et al. (2012) \\
\hline Ascension Is. & $8.0^{\circ} \mathrm{S} 14.4^{\circ} \mathrm{W}$ & 43.5 & 2144 & 6 & 1 Jan $2010-31$ Mar 2010 & de Wit et al. (2013) \\
\hline Tierra del Feugo & $53.7^{\circ} \mathrm{S} 67.7^{\circ} \mathrm{W}$ & 32.55 & 1765 & 60 & 1-31 Dec 2012,1 Feb-31 Mar 2013 & Fritts et al. (2010b) \\
\hline Rothera & $67.5^{\circ} \mathrm{S} 68.0^{\circ} \mathrm{W}$ & 32.50 & 2144 & 6 & 15 Jan $2013-28$ Feb 2013 & Sandford et al. (2010) \\
\hline
\end{tabular}




\section{References}

Akmaev, R.A., 2011. Whole atmosphere modeling: Connecting terrestrial and space weather. Rev. Geophys. 49. doi:10.1029/2011RG000364.

Anderson, D., Araujo-Pradere, E.A., 2010. Sudden stratospheric warming event signatures in daytime $\mathrm{E} \times \mathrm{B}$ drift velocities in the Peruvian and Philippine longitude sectors for January 2003 and 2004. J. Geophys. Res. 115. doi:10.1029/2010JA015337.

Baron, P., Murtaugh, D., Urban, J., Sagawa, H., Ochiai, S., Kasai, Y., Kikuchi, K., Khosrawi, F., Körnich, H., Mizobuchi, S., Sagi, K., Yasui, M., 2013. Observation of horizontal winds in the middle-atmosphere between $30^{\circ} \mathrm{S}$ and $55^{\circ} \mathrm{N}$ during the northern winter 2009-2010. Atmos. Chem. Phys. 13, 60496064. doi:10.5194/acp-13-6049-2013.

Bell, W., English, S.J., Candy, B., Atkinson, N., Hilton, F., Baker, N., Swadley, S.D., Campbell, W.F., Bormann, N., Kelly, G., Kazumori, M., 2008. The assimilation of SSMIS radiances in numerical weather prediction models. IEEE Trans. Geosci. Remote Sens. 46. doi:10.1109/TGRS.2008.917335.

Brown, P.G., P.G., Weryk, R.J., Wong, D., Jones, J., 2008. A meteoroid stream survey using the Canadian Meteor Orbit Radar I. Methodology and radiant catalogue. Icarus 195, 317-319. doi:10.1016/j.icarus.2007.12.002.

Chau, J.L., Fejer, B.G., Goncharenko, L.P., 2009. Quiet variability of equatorial E x B drifts during a sudden stratospheric warming event. Geophys. Res. Lett. 36. doi:10.1029/2008GL036785.

Day, K.A., Taylor, M.J., Mitchell, N.J., 2012. Mean winds, temperatures and the 16- and 5-day planetary waves in the mesosphere and lower thermosphere over Bear Lake Observatory $\left(42^{\circ} \mathrm{N}, 111^{\circ} \mathrm{W}\right)$. Atmos. Chem. Phys. 12, 1571-1585. doi:10.5194/acp-12-1571-2012.

Eckermann, S.D., 2011. Explicitly stochastic parameterization of nonorographic gravity-wave drag. J. Atmos. Sci 68, 1749-1765. doi:10.1175/2011JAS3684.1.

Eckermann, S.D., Hoppel, K.W., Coy, L., McCormack, J.P., Siskind, D.E., Nielsen, K., Kochenash, A., Stevens, M.H., Englert, C.R., Singer, W., 
Hervig, M., 2009. High-altitude data assimilation system experiments for the northern summer mesosphere season of 2007. J. Atmos. Sol.-Terr. Phys. 71, 531-551. doi:10.1016/j.jastp.2008.09.036.

Fritts, D.C., Janches, D., Hocking, W.K., 2010a. Southern Argentina Agile Meteor Radar: Initial assessment of gravity wave momentum fluxes. J. Geophys. Res. 115. doi:10.1029/2010JD013891.

Fritts, D.C., Janches, D., Iimura, H., Hocking, W.K., Mitchell, N.J., Stockwell, R.G., Fuller, B., Vandepeer, B., Hormaechea, J., Brunini, C., Levato, H., 2010b. Southern Argentina Agile Meteor Radar: System design and initial measurements of largescale winds and tides. J. Geophys. Res. 115. doi:10.1029/2010JD013850.

Fuller-Rowell, T., Wu, F., Akmaev, R., Fang, T., AraujoPradere, E., 2010. A whole atmosphere model simulation of the impact of a sudden stratospheric warming on thermosphere dynamics and electrodynamics. J. Geophys. Res. 115. doi:10.1029/2010JA015524.

Goncharenko, L.P., Chau, J.L., Condor, P., Coster, A., Benkevitch, L., 2013a. Ionospheric effects of sudden stratospheric warming during moderate-tohigh solar activity: Case study of January 2013. Geophys. Res. Lett. 40, 4982-4986. doi:10.1029/grl.50980.

Goncharenko, L.P., Chau, J.L., Liu, H.L., Coster, A.J., 2010. Unexpected connections between the stratosphere and ionosphere. Geophys. Res. Lett. 37. doi:10.1029/2010GL043125.

Goncharenko, L.P., Coster, A.J., Plumb, R.A., Domeisen, D.I.V., 2012. The potential role of stratospheric ozone in the stratosphere-ionosphere coupling during stratospheric warmings. Geophys. Res. Lett. 39. doi:10.1029/2012GL051261.

Goncharenko, L.P., Hsu, V.W., Garnett, C., Brum, M., Zhang, S.R., Fentzke, J.T., 2013b. Wave signatures in the midlatitude ionosphere during a sudden stratospheric warming of January 2010. J. Geophys. Res. 118, 472-487. doi:10.1029/2012JA018251.

Han, Y., van Delst, P., Weng, F., 2010. An improved fast radiative transfer model for special sensor microwave imager/sounder upper atmosphere sounding channels. J. Geophys. Res. 115. doi:10.1029/2010JD013878. 
Hocking, W., Fuller, B., Vandepeer, B., 2001. Real-time determination of meteor-related parameters utilizing modern digital technology. J. Atm. Sol-Terr. Phys. 63, 155 - 169.

Hogan, T., Liu, M., Ridout, J., Peng, M., Whitcomb, T., Ruston, B., Reynolds, C., Eckermann, S., Moskaitis, J., Baker, N., McCormack, J., Viner, K., McLay, J., Flatau, M., Xu, L., Chen, C., Chang, S., 2014. The Navy Global Environmental Model. Oceanography 27, 116-125. doi:10.5670/oceanog.2014.73.

Hoppel, K.W., Eckermann, S.D., Coy, L., Nedoluha, G.E., Allen, D.R., Swadley, S.D., Baker, N.L., 2013. Evaluation of SSMIS upper atmosphere sounding channels for high-altitude data assimilation. Mon. Wea. Rev. 141, 3314 - 3330. doi:10.1175/MWR-D-13-00003.1.

Jacobi, C., 2012. 6 year mean prevailing winds and tides measured by VHF meteor radar over Collm $\left(51.3^{\circ} \mathrm{N}, 13.0^{\circ} \mathrm{E}\right)$. J. Atmos. Sol.-Terr. Phys. 78 $79,8-18$.

Jin, H., Miyoshi, Y., Pancheva, D., Mukhtarov, P., Fujiwara, H., Shinagawa, H., 2012. Response of migrating tides to the stratospheric sudden warming in 2009 and their effects on the ionosphere studied by a whole atmosphereionosphere model GAIA with COSMIC and TIMED/SABER observations. J. Geophys. Res. 117. doi:10.1029/2012JA017650.

Juang, H., 2011. A Multiconserving Discretization with Enthalpy as a Thermodynamic Prognostic Variable in Generalized Hybrid Vertical Coordinates for the NCEP Global Forecast System. Mon. Wea. Rev. 139, 15831607.

Kuhl, D., Rosmond, T., Bishop, C., McLay, J., Baker, N., 2013. Comparison of hybrid ensemble/4DVar and 4DVar within the NAVDAS-AR data assimilation framework. Mon. Wea. Rev. 141, 2740-2758. doi:10.1175/MWRD-12-00182.1.

Kuttippurath, J., Nikulin, G., 2012. A comparative study of the major sudden stratospheric warmings in the Arctic winters 2003/20042009/2010. Atmos. Chem. Phys. 12, 81158129. doi:10.5194/acp-12-8115-2012.

Lieberman, R.S., Riggin, D.M., Siskind, D.E., 2013. Stationary waves in the wintertime mesosphere: Evidence for gravity wave filtering 
by stratospheric planetary waves. J. Geophys. Res. 118, 3129-3149. doi:10.1002/jgrd.50319.

Limpasuvan, V., Orsolini, Y.J., Chandran, A., Garcia, R.R., Smith, A.K., 2016. On the composite response of the MLT to major sudden stratospheric warming events with elevated stratopause. J. Geophys. Res. 121, 451845376. doi:10.1002/2015JD024401.

Limpasuvan, V., Wu, D.L., Schwartz, M.J., Waters, J.W., Wu, Q., Killeen, T.L., 2005. The two-day wave in EOS MLS temperature and wind measurements during 2004-2005 winter. Geophys. Res. Lett. 32. doi:10.1029/2005GL023396.

Lin, J.T., Lin, C.H., Chang, L.C., Huang, H.H., Liu, J.Y., Chen, A.B., Chen, C.H., Liu, C.H., 2012. Observational evidence of ionospheric migrating tide modification during the 2009 stratospheric sudden warming. Geophys. Res. Lett. 39. doi:10.1029/2011GL050248.

Manney, G.L., Kruger, K., Pawson, S., Minschwaner, K., Schwartz, M.J., Daffer, W.H., Livesey, N.J., Remsberg, M.G.M.E.E., III, J.M.R., Waters, J.W., 2008. The evolution of the stratopause during the 2006 major warming: Satellite data and assimilated meteorological analyses. J. Geophys. Res. 113. doi:10.1029/2007JD009097.

Matthias, V., Hoffmann, P., Manson, A., Meek, C., Stober, G., Brown, P., Rapp, M., 2013. The impact of planetary waves on the latitudinal displacement of sudden stratospheric warmings. Annales Geophysicae 31, 1397-1415. URL: http://www . ann-geophys . net/31/1397/2013/, doi:10.5194/angeo-31-1397-2013.

Matthias, V., Hoffmann, P., Rapp, M., Baumgarten, G., 2012. Composite analysis of the temporal development of waves in the polar mlt region during stratospheric warmings. Journal of Atmospheric and Solar-Terrestrial Physics 90 - 91, 86 - 96. doi:http://dx.doi.org/10.1016/j.jastp.2012.04.004. recent Progress in the Vertical Coupling in the Atmosphere-Ionosphere System.

McCormack, J.P., Coy, L., Hoppel, K.W., 2009. Evolution of the quasi-2 day wave during January 2006. J. Geophys. Res. 114. doi:10.1029/2009JD012239. 
McCormack, J.P., Coy, L., Singer, W., 2014. Intraseasonal and interannual variability of the quasi-2 day wave in the Northern Hemisphere summer mesosphere. J. Geophys. Res. 119, 2928-2946. doi:10.1002/2013JD020199.

McCormack, J.P., Eckermann, S.D., Hoppel, K.W., Vincent, R.A., 2010. Amplification of the quasi-two day wave through nonlinear interaction with the migrating diurnal tide. Geophys. Res. Lett. 37. doi:10.1029/2010GL043906.

McCormack, J.P., Hoppel, K.W., Siskind, D.E., 2008. Parameterization of middle atmospheric water vapor photochemistry for high-altitude NWP and data assimilation. Atmos. Chem. Phys. 8, 7519-7532.

McLandress, C.M., Scinocca, J.F., Shepherd, T.G., Reader, M.C., Manney, G.L., 2013. Dynamical control of the mesosphere by orographic and nonorographic gravity wave drag during the extended northern winters of 2006 and 2009. J. Atmos. Sci. 70, 2152-2169. doi:10.1175/JAS-D-120297.1.

McLay, J., Bishop, H., Reynolds, C., 2010. A local formulation of the Ensemble Transform (ET) analysis perturbation scheme. Wea. Forecasting 25, 985-993.

Niciejewski, R., Wu, Q., Skinner, W., Gell, D., Cooper, M., Marshall, A., Killeen, T., Solomon, S., Ortland, D., 2006. TIMED Doppler Interferometer on the Thermosphere Ionosphere Mesosphere Energetics and Dynamics satellite: Data product overview. J. Geophys. Res. 111. doi:10.1029/2005JA011513.

Pancheva, D.V., 2006. Quasi-2-day wave and tidal variability observed over Ascension Island during January/February 2003. J. Atmos. Sol.-Terr. Phys. 68, 390-407. doi:10.1016/j.jastp.2005.02.028.

Pedatella, N.M., Forbes, J.M., 2010. Evidence for stratospheric sudden warming-ionosphere coupling due to vertically propagating tides. Geophys. Res. Lett. 37. doi:10.1029/2010GL043560.

Pedatella, N.M., Fuller-Rowell, T., Wang, H., Jin, H., Miyoshi, Y., Fujiwara, H., Shinagawa, H., , Liu, H.L., Sassi, F., Schmidt, H., Matthias, V., Goncharenko, L., 2014. The neutral dynamics during the 2009 sudden 
stratosphere warming simulated by different whole atmosphere models. J. Geophys. Res. 119, 13061324. doi:10.1002/2013JA019421.

Pedatella, N.M., Liu, H.L., 2013. The influence of atmospheric tide and planetary wave variability during sudden stratosphere warmings on the low latitude ionosphere. J. Geophys. Res. 118, 5333-5347. doi:10.1002/jgra.50492.

Rezac, L., Jian, Y., Yue, J., III, J.M.R., Kutepov, A., Garcia, R., Walker, K., Bernath, P., 2015. Validation of the global distribution of CO2 volume mixing ratio in the mesosphere and lower thermosphere from SABER. J. Geophys. Res. 120, 12,067-120,081. doi:10.1002/2015JD023955.

Riggin, D., Meyer, C., Fritts, D., Jarvis, M., Murayama, Y., Singer, W., Vincent, R., Murphy, D., 2003. MF radar observations of seasonal variability of semidiurnal motions in the mesosphere at high northern and southern latitudes. J. Atm. Sol.-Terr. Phys 65, 483-493. doi:10.1016/S13646826(02)00340-1.

Sandford, D.J., Beldon1, C.L., Hibbins, R.E., Mitchell, N.J., 2010. Dynamics of the Antarctic and Arctic mesosphere and lower thermosphere Part 1: Mean winds. Atmos. Chem. Phys. 10, 10273-10289. doi:10.5194/acp-1010273-2010.

Sassi, F., Liu, H.L., 2014. Westward traveling planetary wave events in the lower thermosphere during solar minimum conditions simulated by SD-WACCM-X. J. Atm. Sol-Terr.,Phys. 119, 11-26. doi:10.1016/j.jastp.2014.06.009.

Sassi, F., Liu, H.L., Ma, J., Garcia, R.R., 2013. The lower thermosphere during the northern hemisphere winter of 2009: A modeling study using high-altitude data assimilation products in WACCM-X. J. Geophys. Res. 118, 8954-8969. doi:10.1002/jgrd.50632.

Schwartz, M.J., Lambert, A., Manney, G., Read, W., Livesey, N., Froidevaux, L., Ao, C., Bernath, P., Boone, C., Cofield, R., Daffer, W., Drouin, B., Fetzer, E., Fuller, R., Jarnot, R., Jiang, J., Jiang, Y., Knosp, B., Kruger, K., Li, J.L., Mlynczak, M., Pawson, S., III, J.R., Santee, M., Snyder, W., Stek, P., Thurstans, R., Tompkins, A., Wagner, P., Walker, K., Waters, J., Wu, D., 2008. Validation of the Aura Microwave Limb Sounder temperature and geopotential height measurements. J. Geophys. Res. 113. doi:10.1029/2007JD008783. 
Siskind, D.E., Eckermann, S.D., McCormack, J.P., Coy, L., Hoppel, K.W., Baker, N.L., 2010. Case studies of the mesospheric response to recent minor, major, and extended stratospheric warmings. J. Geophys. Res. 115. doi:10.1029/2010JD014114.

Smolarkiewicz, P.K., Pudykiewicz, J., 1992. A class of semi-Lagrangian approximations for fluids. J. Atmos. Sci. 49, 2082-2096.

Staniforth, A., White, A., Wood, N., Thuburn, J., Zerroukat, M., Cordero, E., Davies, T., 2006. The Joy of U.M. 6.3- Model Formulation. Technical Report 15. United Kingdom Meteorological Office. Met Office, FitzRoy Road, Exeter, UK.

Stober, G., Jacobi, C., Matthias, V., Hoffmann, P., Gerding, M., 2012. Neutral air density variations during strong planetary wave activity in the mesopause region derived from meteor radar observations. J. of Atmos. and Sol.-Terr. Phys. 74, $55-63$. doi:http://dx.doi.org/10.1016/j.jastp.2011.10.007.

Stockwell, R.G., Mansinha, L., Lowe, R.P., 1996. Localization of the complex spectrum: The S transform. IEEE Trans. Sig. Process. 44, 998-1001.

Stray, N., Orsolini, Y.J., Espy, P.J., Limpasuvan, V., Hibbins, R.E., 2015. Observations of planetary waves in the mesosphere-lower thermosphere during stratospheric warming events. Atmos. Chem. Phys. 15, 4997-5005. doi:10.5194/acp-15-4997-2015.

Swadley, S., Poe, G., Bell, W., Hong, Y., Kunkee, D.B., McDermid, I.S., Leblanc, T., 2008. Analysis and characterization of the SSMIS Upper Atmosphere Sounding Channel Measurements. IEEE Trans. Geosci. Remote Sens. 46, 962-983. doi:10.1109/TGRS.2008.916980.

Ventosa, S., Simon, C., Schimmel, M., Danobeitia, J.J., Manuel, A., 2008. The S-Transform from a wavelet point of view. IEEE Trans. Signal Process. 56, 2771-2780. doi:10.1109/TSP.2008.917029.

Wang, H., Fuller-Rowell, T.J., Akmaev, R.A., Hu, M., Kleist, D.T., Iredell, M.D., 2011. First simulations with a whole atmosphere data assimilation and forecast system: The January 2009 major sudden stratospheric warming. J. Geophys. Res. 116. doi:10.1029/2011JA017081. 
de Wit, R., Hibbins, R., Espy, P., 2015. The seasonal cycle of gravity wave momentum flux and forcing in the high latitude northern hemisphere mesopause region. J. Atmos. Sol.-Terr. Phys. 127, 21-29.

de Wit, R.J., Hibbins, R.E., Espy, P.J., Mitchell, N.J., 2013. Interannual variability of mesopause zonal winds over AscensionIsland: Coupling to the stratospheric QBO. J. Geophys. Res. 118, 12052-12060.

Xu, X., Manson, A., Meek, C., Jacobi, C., Hall, C., Drummond, J., 2011a. Verification of the mesospheric winds within the Canadian Middle Atmosphere Model Data Assimilation System using radar measurements. J. Geophys. Res. 116. doi:10.1029/2011JD015589.

Xu, X., Manson, A.H., Meek, C., Jacobi, C., Hall, C., Drummond, J., 2011b. Mesospheric wind semidiurnal tides within the Canadian Middle Atmosphere Model Data Assimilation System. J. Geophys. Res. 116. doi:10.1029/2011JD015966. 
(a) T $90^{\circ} \mathrm{N} 1$ JAN - 28 FEB 2010

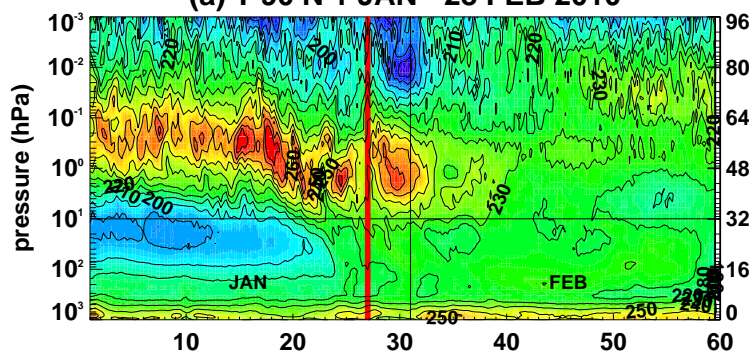

(c) U $60^{\circ} \mathrm{N} 1$ JAN - 28 FEB 2010

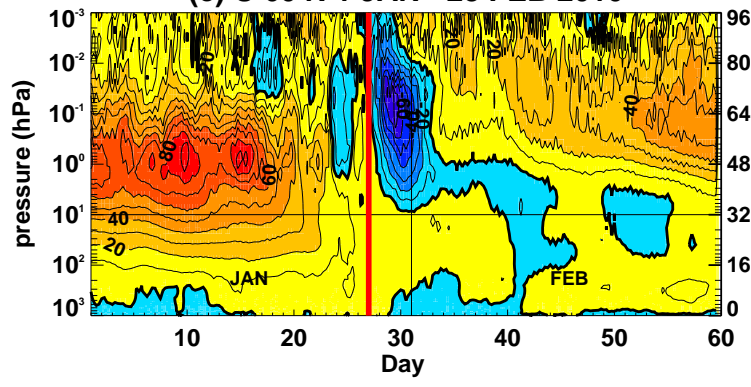

(b) T 90N 15 DEC 2012 - 15 FEB 2013

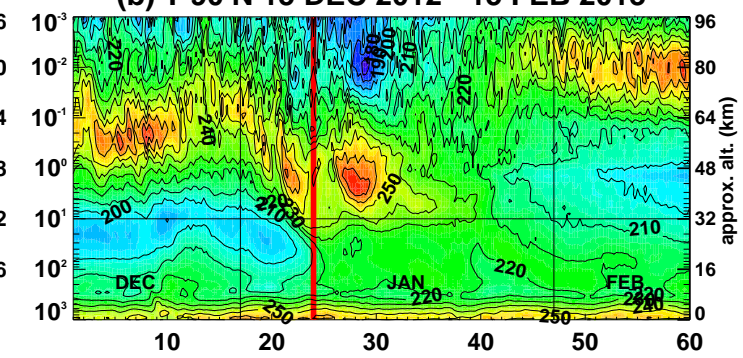

(d) U 60N 15 DEC 2012 - 15 FEB 2013

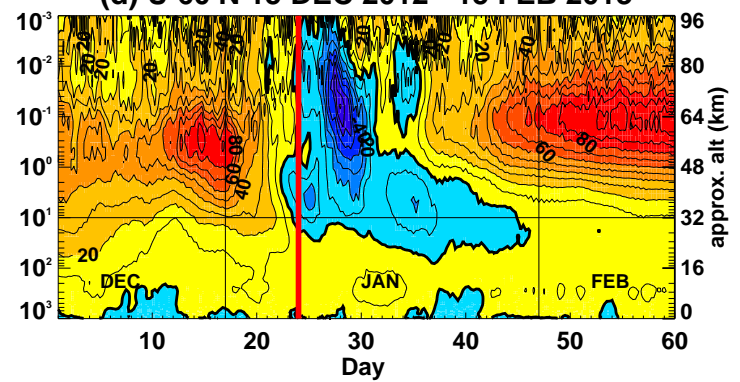

Figure 1: Altitude-time sections of zonal mean temperatures (a \& b) and zonal mean zonal winds (c \& d) from 6-hourly NAVGEM analyses for (a \& c) 1 January - 28 February 2010 and (b \& d) for 15 December 2012 - 15 February 2013. Values along the abscissa denote days from the beginning of each period. Black vertical lines denote separate months. Red vertical lines denote onset of sustained mesospheric wind reversals at $60^{\circ} \mathrm{N}$ in each winter, i.e., 27 January 2010 and 7 January 2013, as described in the text. Contours are drawn every $10 \mathrm{~K}$ and $10 \mathrm{~m} \mathrm{~s}^{-1}$. Bold contour in (c) and (d) denotes zero wind line. 


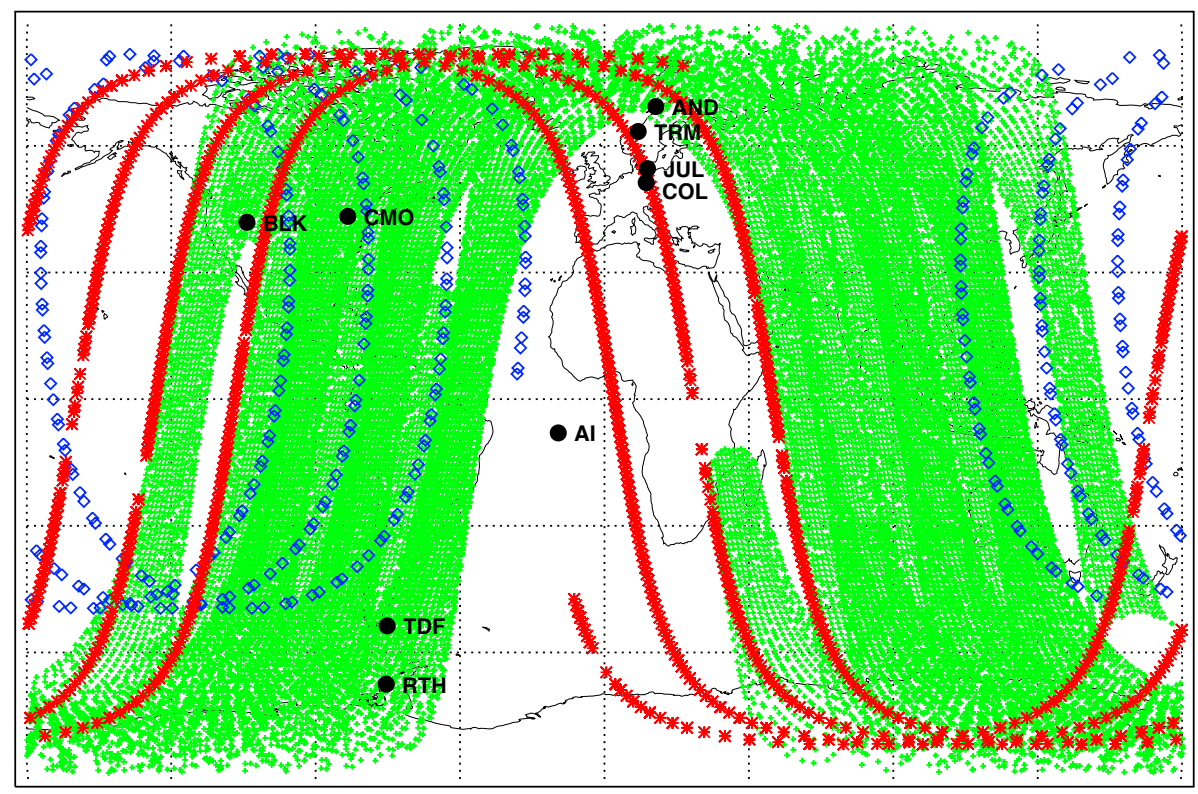

Figure 2: An example of the geographic coverage of SABER (blue), MLS (red), and UAS (green) observations for a single 6-hour NAVGEM analysis window centered on 12 UTC 30 January 2010. Black dots indicate locations of the nine meteor radar stations listed in Table 1.) 

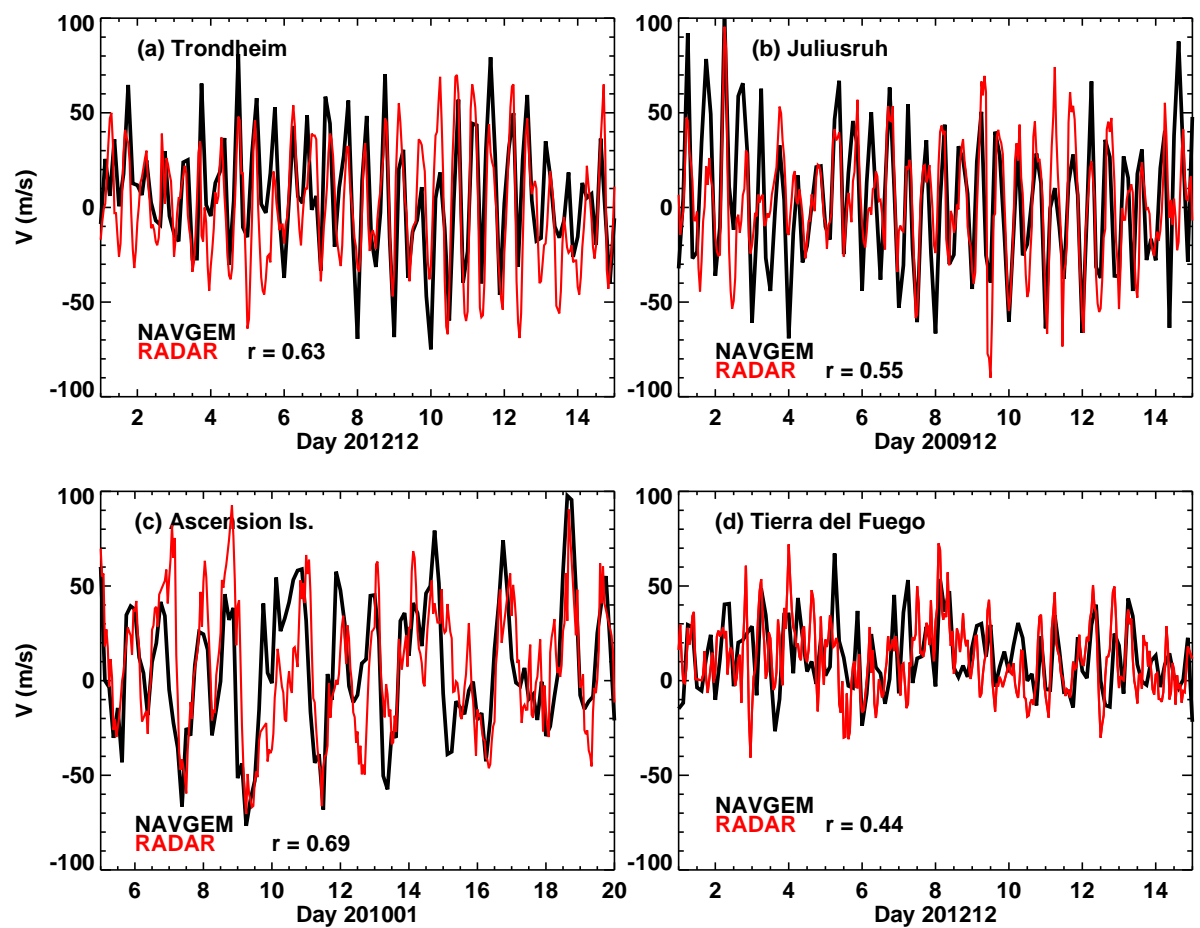

Figure 3: Time series of meridional wind from 3-hourly high-altitude NAVGEM analyses/forecasts (black) and from hourly meteor radar observations (red) for (a) 1-15 December 2012 over Trondheim at $87 \mathrm{~km}$, (b) 1-15 December 2009 over Juliusruh at $88 \mathrm{~km}$ altitude, (c) 5-20 January 2010 over Ascension Island at $87 \mathrm{~km}$; (d) 1-15 December 2012 over Tierra del Fuego at $87 \mathrm{~km}$. Each panel lists the Pearson's correlation coefficient $r$ between the NAVGEM time series and corresponding subsampled 3-hourly meteor radar wind time series. 
(a) Ascension Island
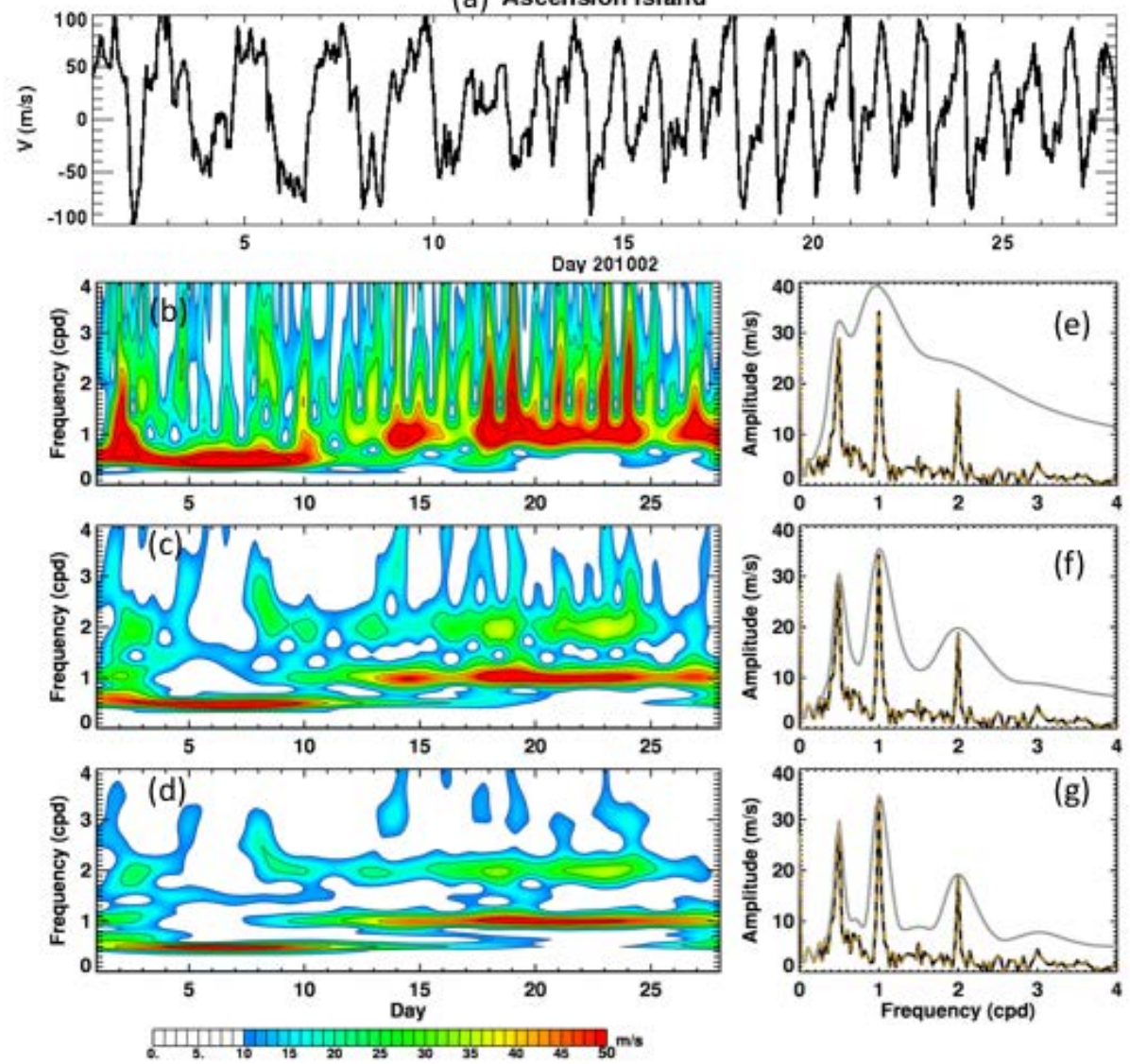

Figure 4: (a) Time series of hourly meridional winds at $87 \mathrm{~km}$ from the Ascension Island meteor radar over 1-28 February 2010. (b)-(d) Time-varying wave spectra of the $87 \mathrm{~km}$ winds obtained with the $S$-transform. (e)-(g) Wave spectra obtained using a fast Fourier transform (black curves), time-integrated complex wave spectra $\langle S\rangle$ (orange dashed curves), and monthly averages of the instantaneous amplitudes $|S|$ (gray curves). $S$-transform results in (b) and (e) use a scaling factor of $k=0.5$; (c) and (f) use $k=1.0$; (d) and (g) use $k=1.5$. 

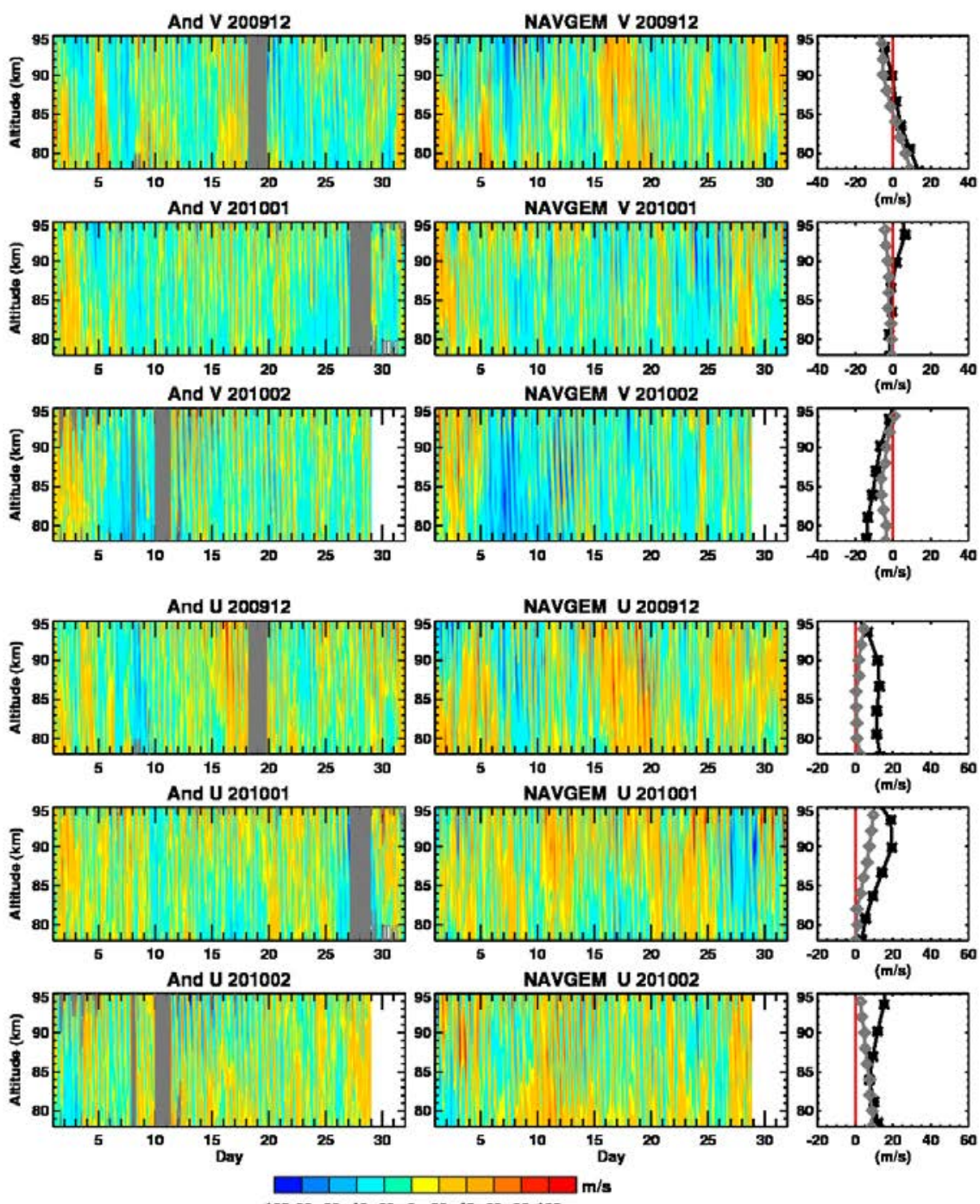

$-100-80-60-40-200204060 \quad 80100$

Figure 5: Meridional and zonal winds from meteor radar observations (left column) and NAVGEM analyses (center column) at Andenes for the 2009-2010 winter. The upper, middle, and lower panels correspond to December, January and February, respectively. Gray areas denote missing data. Corresponding monthly mean wind profiles (right column) from NAVGEM (black stars) and meteor radar observations (gray diamonds). 

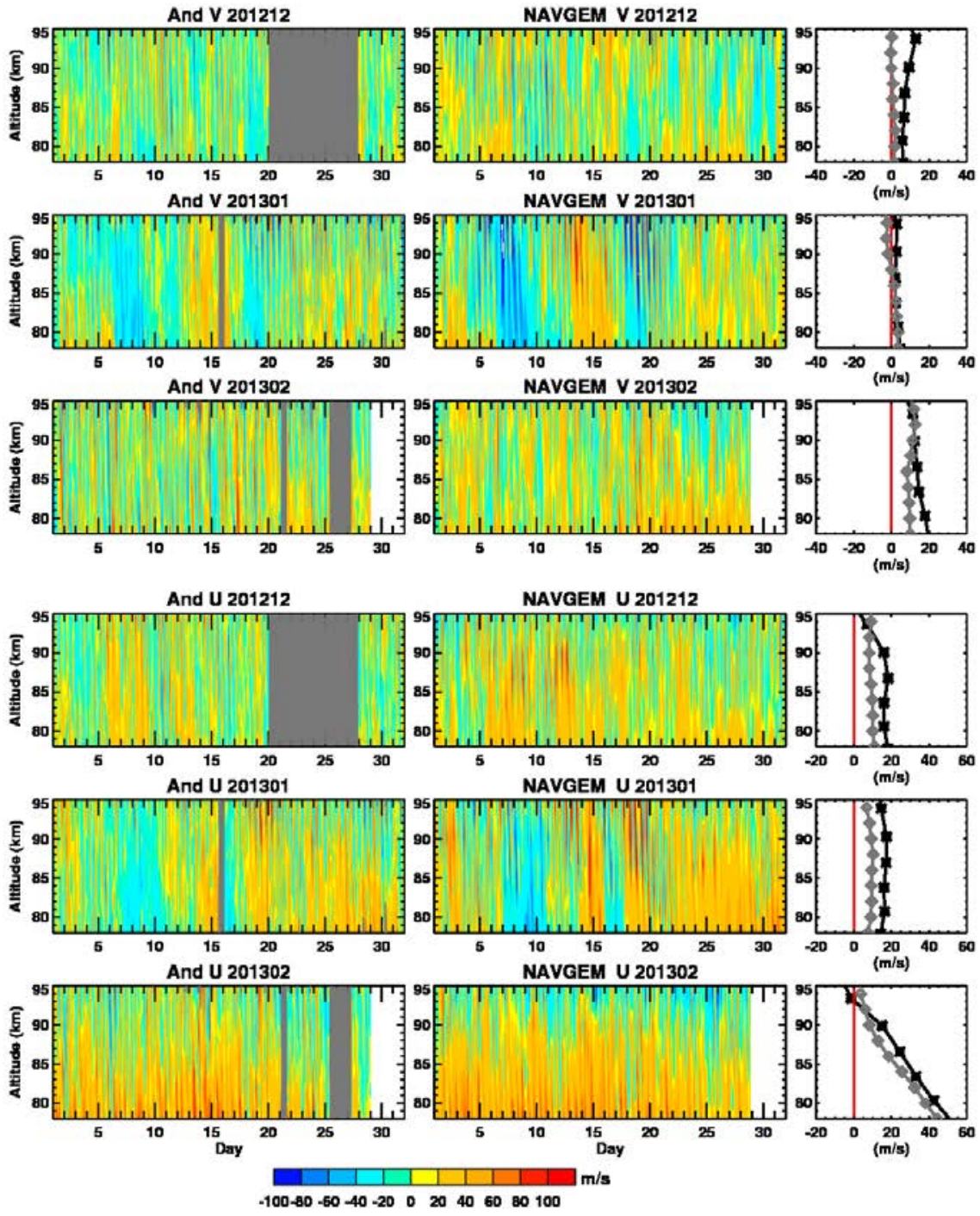

Figure 6: As in Figure 5 but for the 2012-2013 winter. 

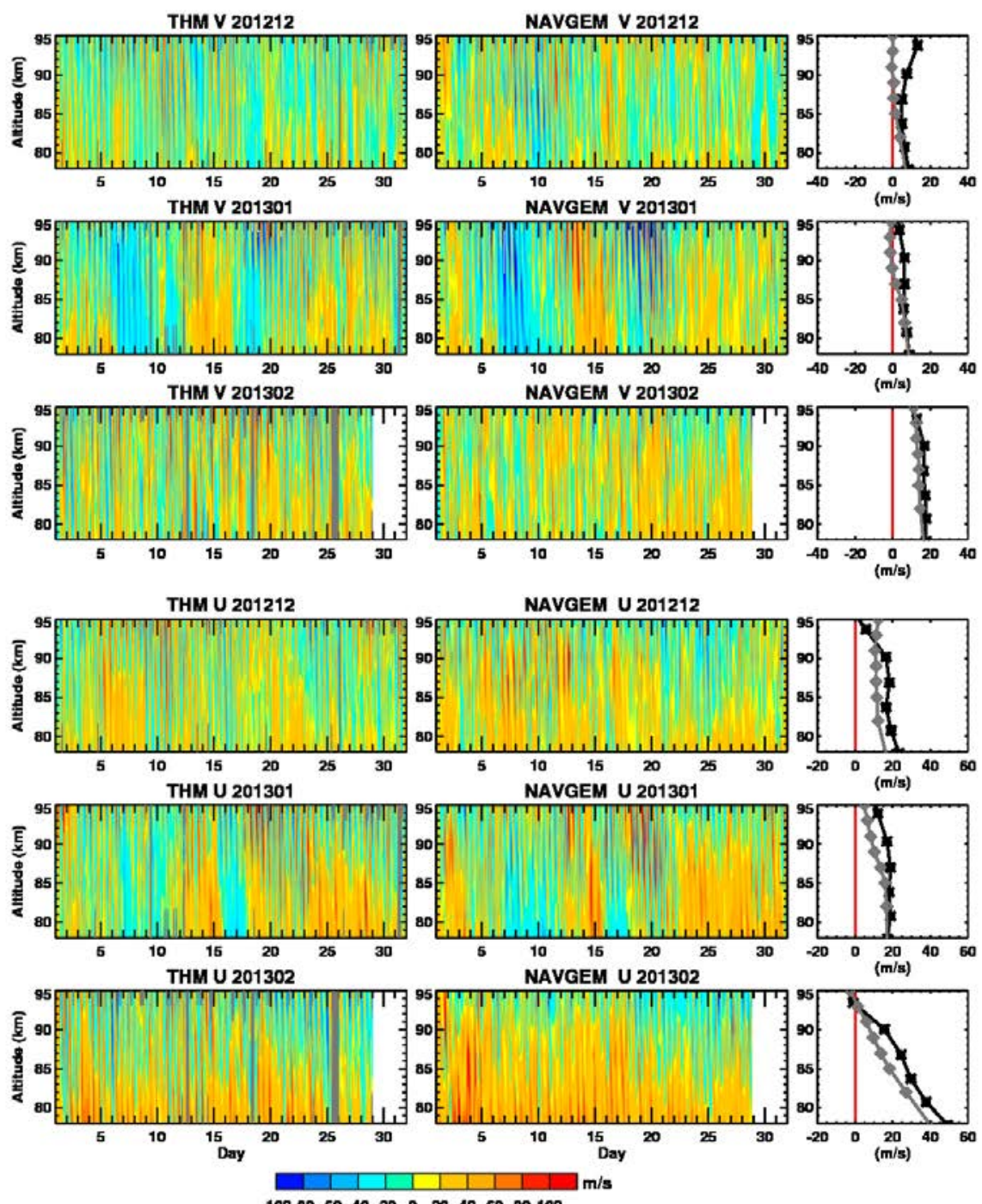

$-100-80-60-40-20 \quad 0 \quad 204060 \quad 80100$

Figure 7: Meridional and zonal winds from meteor radar observations (left column) and NAVGEM analyses (center column) at Trondheim for the 2012-2013 winter. Gray areas denote missing data. Corresponding monthly mean wind profiles (right column) from NAVGEM (black stars) and meteor radar observations (gray diamonds). 

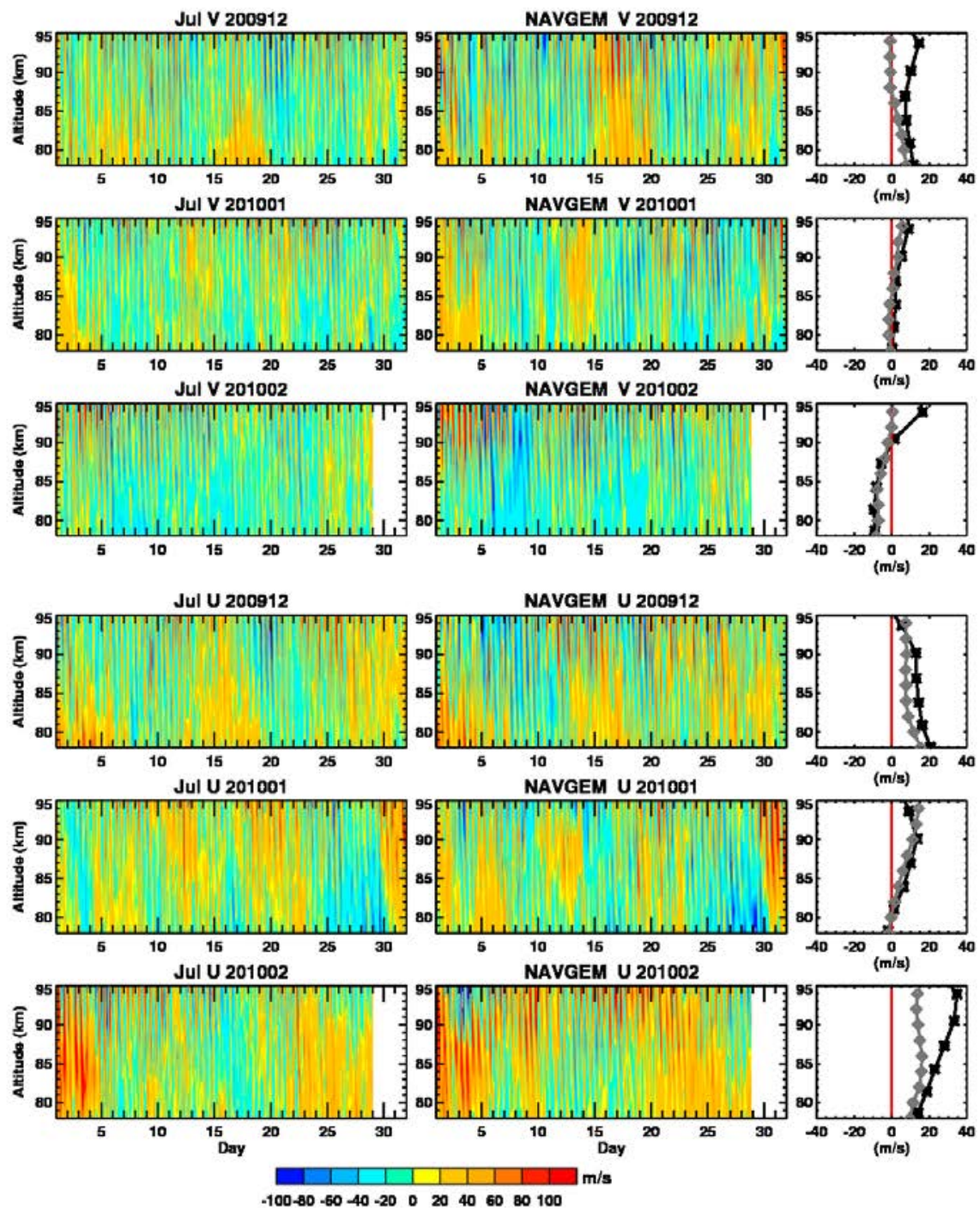

Figure 8: Meridional and zonal winds from meteor radar observations (left column) and NAVGEM analyses (center column) at Juliusruh for the 2009-2010 winter. Gray areas denote missing data. Corresponding monthly mean wind profiles (right column) from NAVGEM (black stars) and meteor radar observations (gray diamonds). 

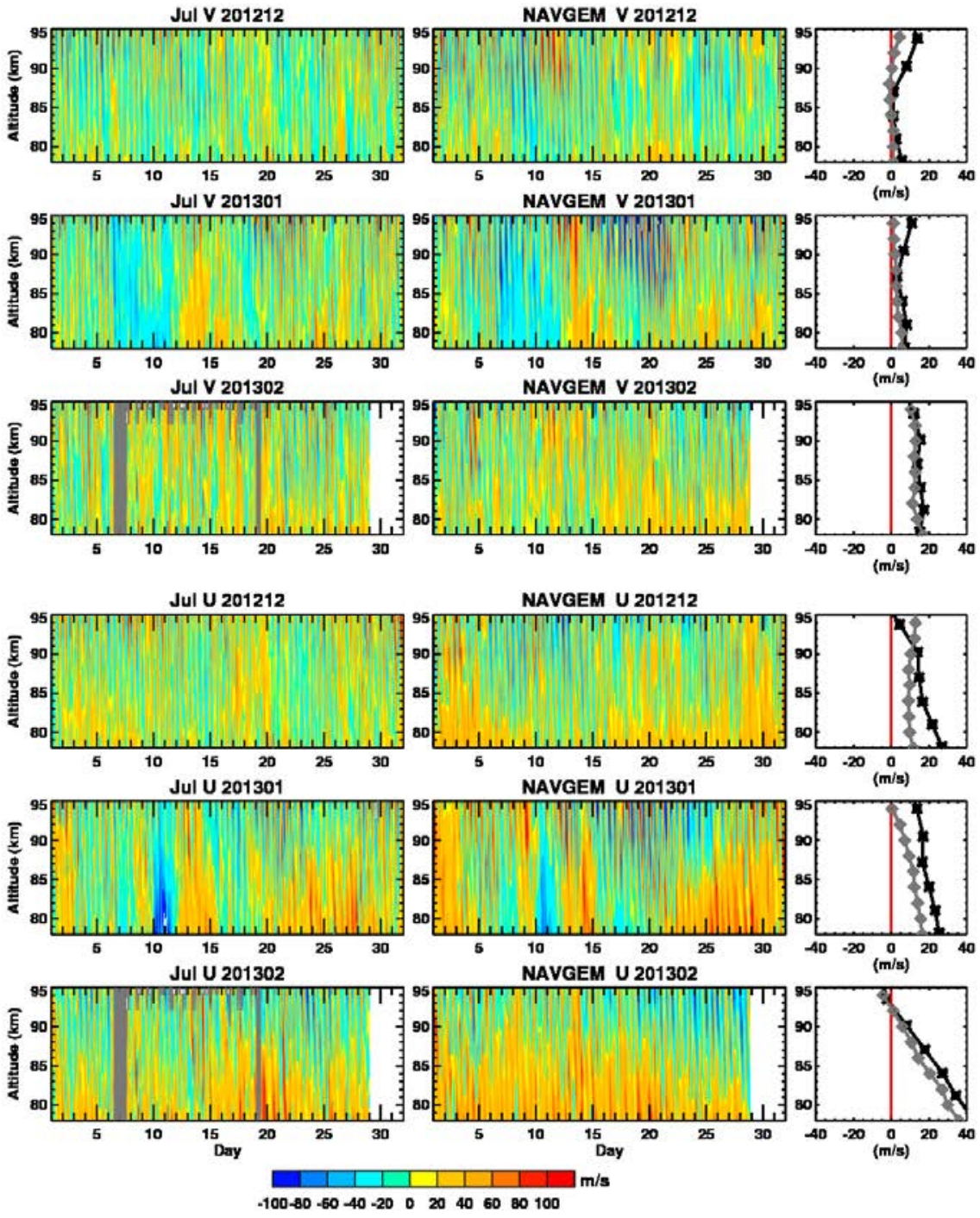

Figure 9: As in Figure 8 but for the 2012-2013 winter. 

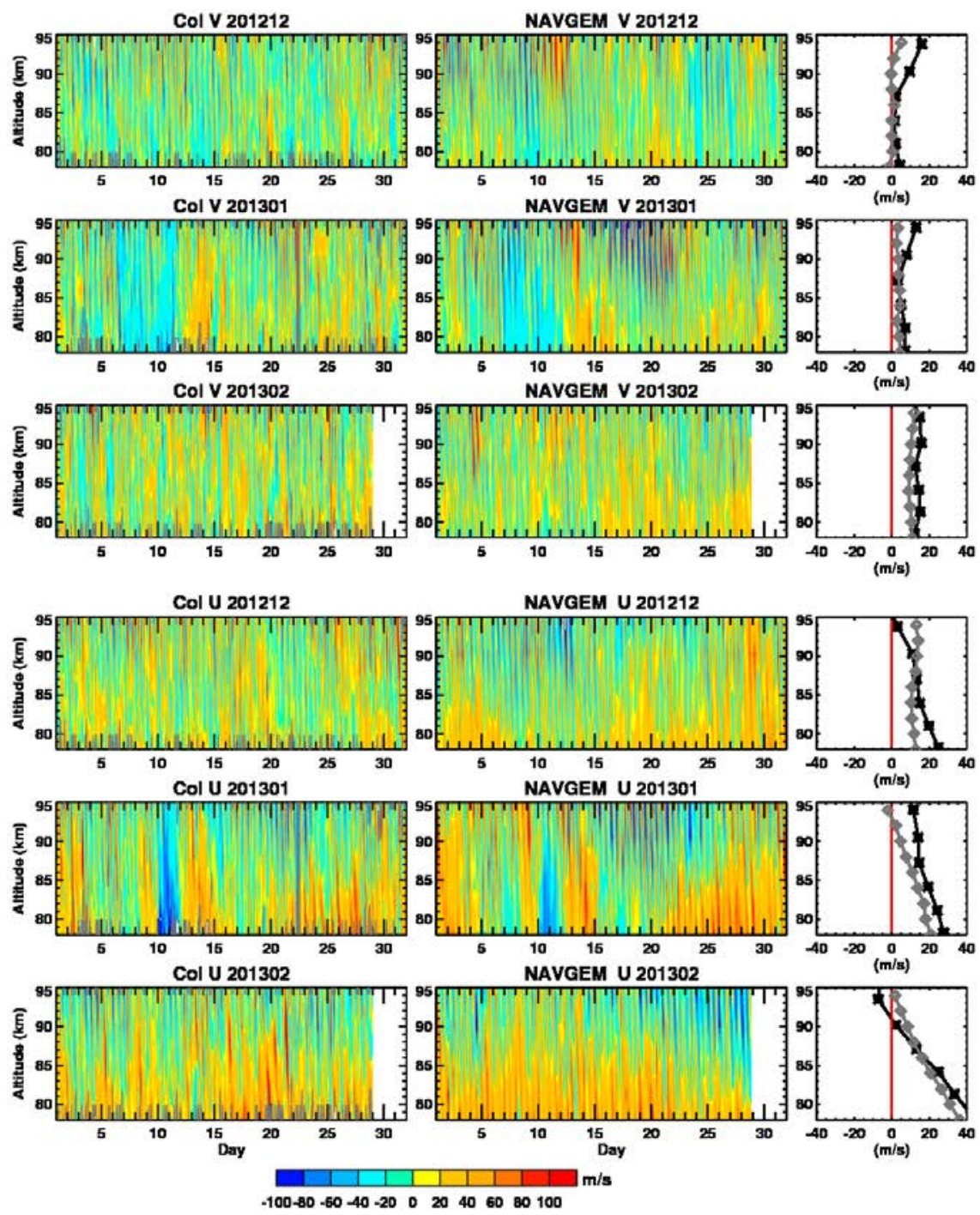

Figure 10: Meridional and zonal winds from meteor radar observations (left column) and NAVGEM analyses (center column) at Collm for the 2009-2010 winter. Gray areas denote missing data. Corresponding monthly mean wind profiles (right column) from NAVGEM (black stars) and meteor radar observations (gray diamonds). 

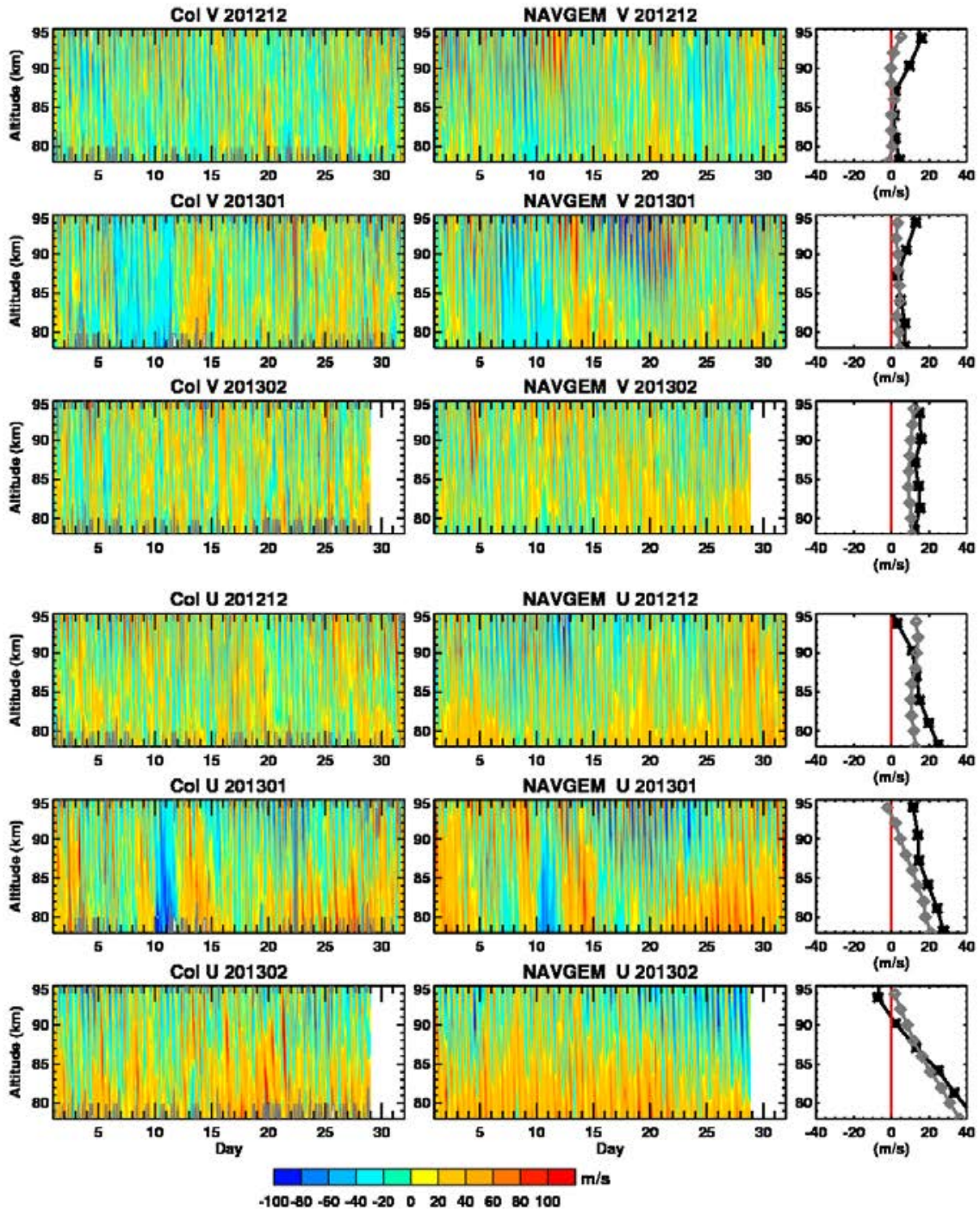

Figure 11: As in Figure 10 but for the 2012-2013 winter. 

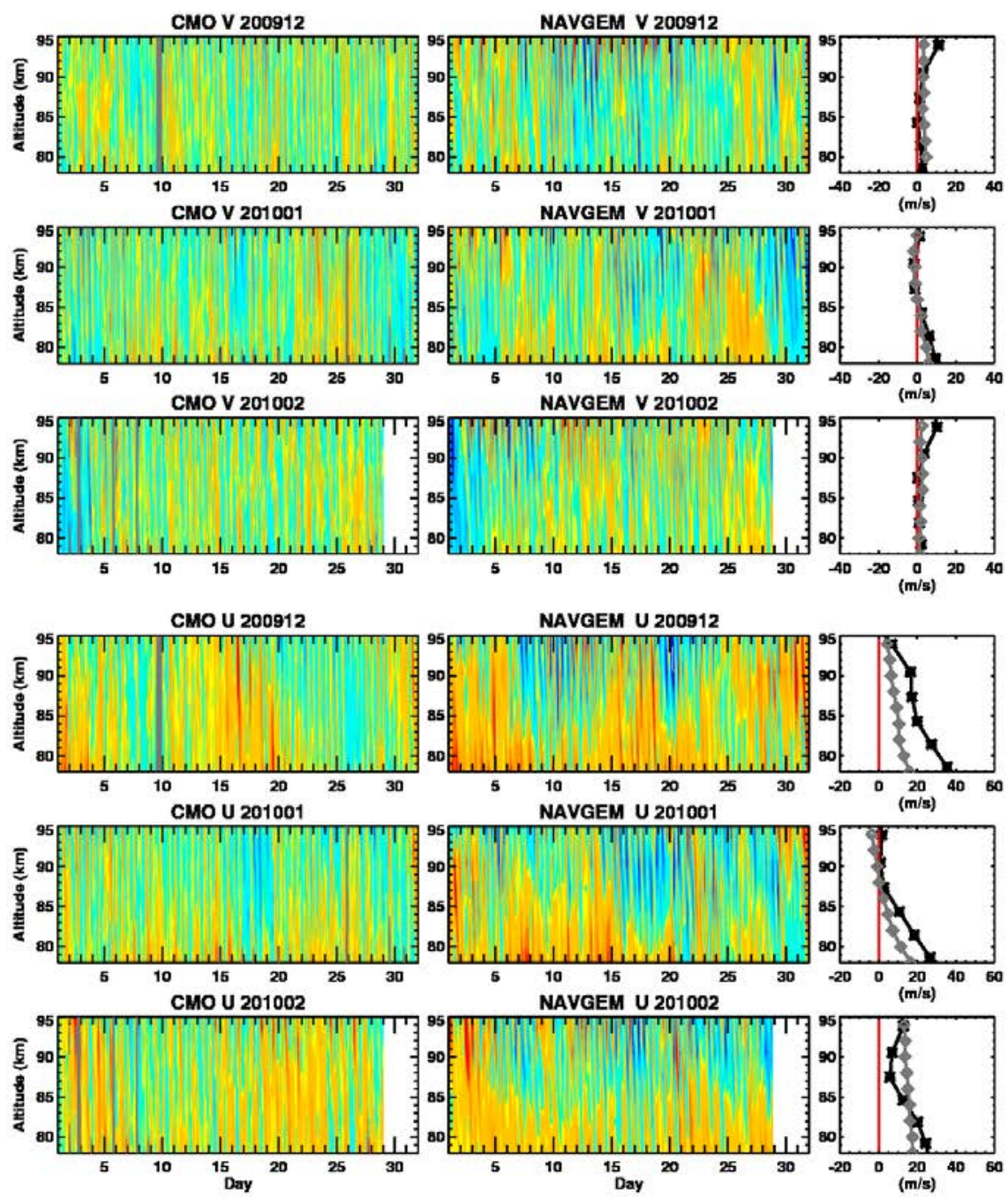

$-100-80-60-40-20 \quad 0 \quad 20 \quad 40 \quad 60 \quad 80100$

Figure 12: Meridional and zonal winds from meteor radar observations (left column) and NAVGEM analyses (center column) at the CMOR site for the 2009-2010 winter. Gray areas denote missing data. Corresponding monthly mean wind profiles (right column) from NAVGEM (black stars) and meteor radar observations (gray diamonds). 

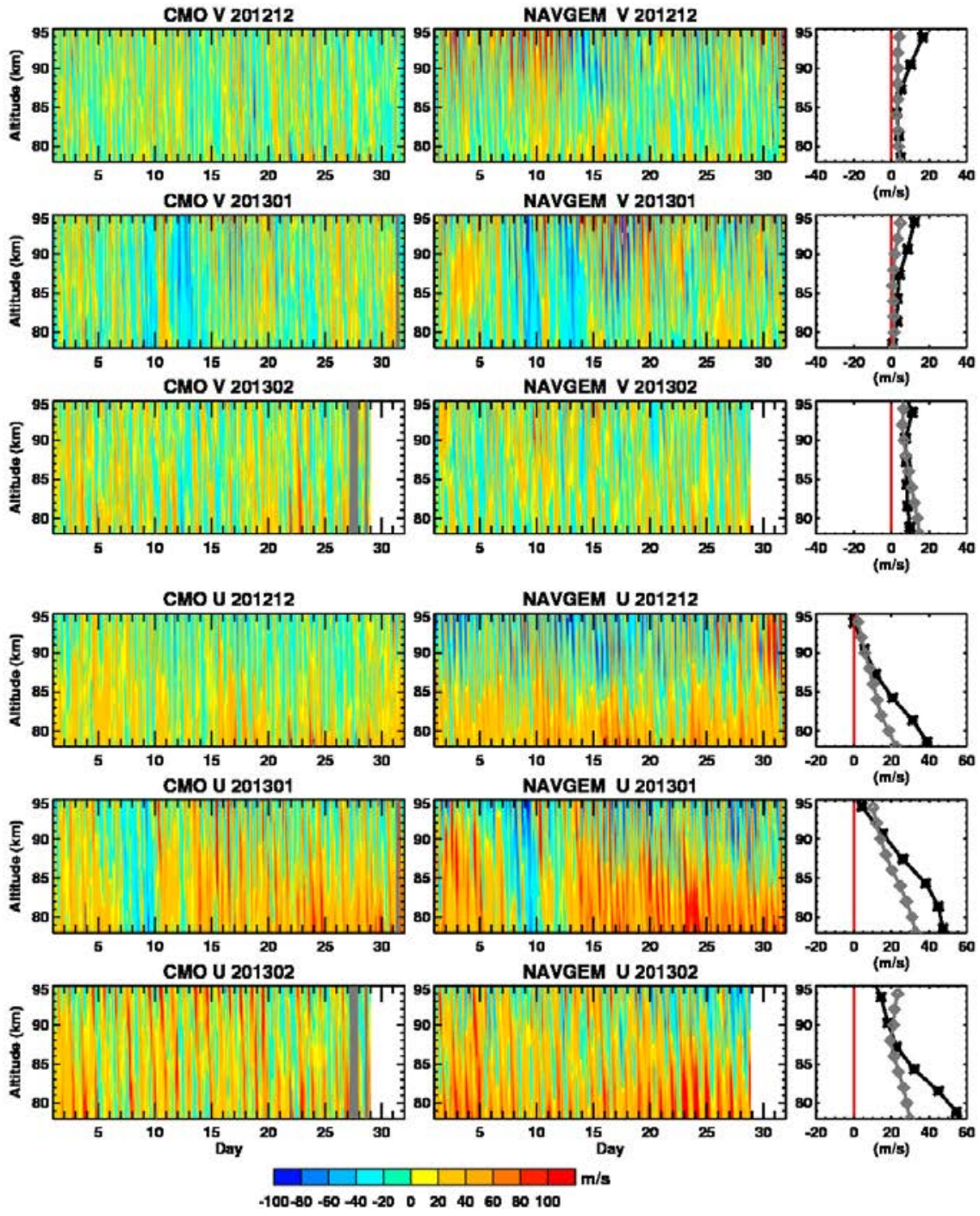

Figure 13: As in Figure 12 but for the 2012-2013 winter. 

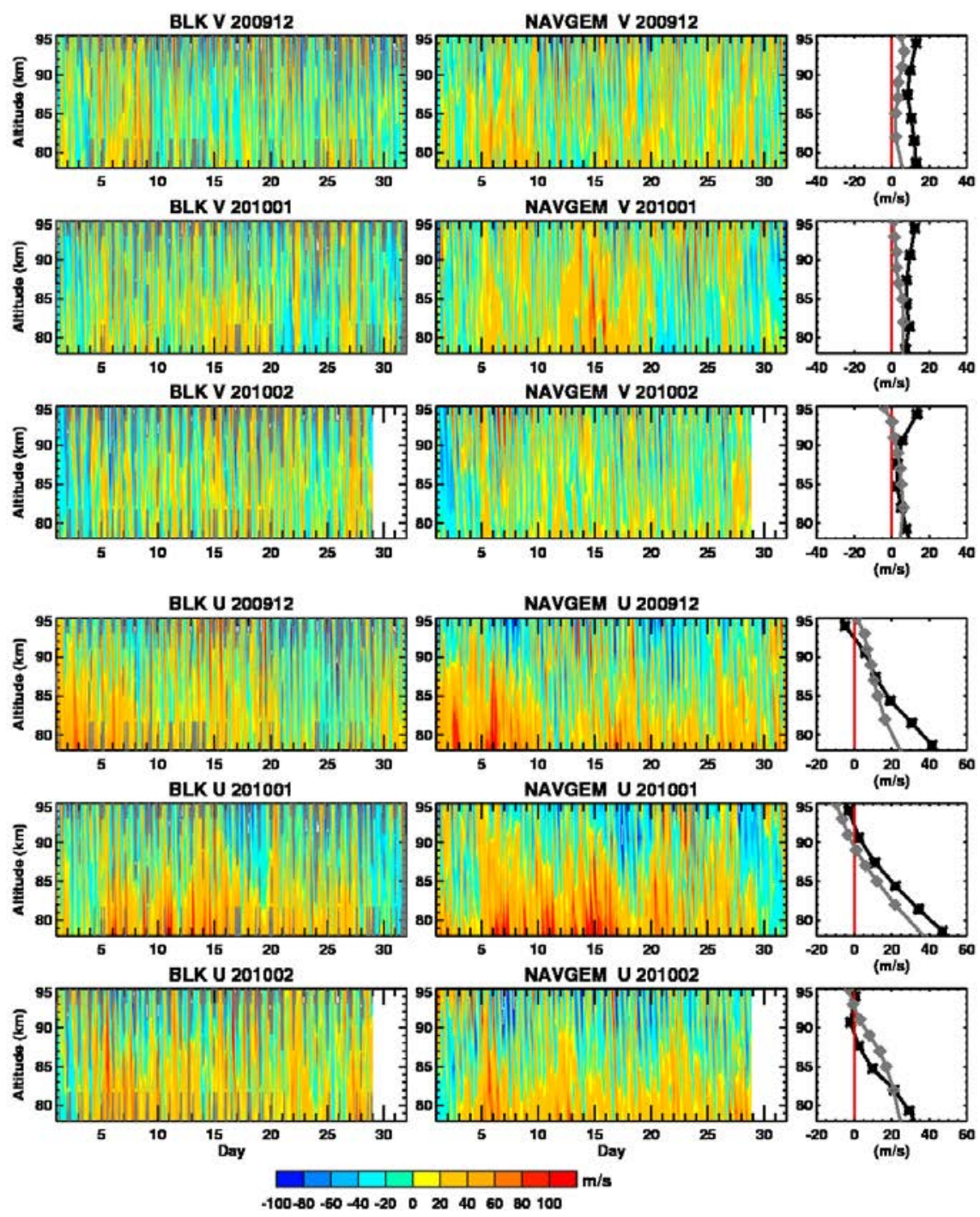

Figure 14: Meridional and zonal winds from meteor radar observations (left column) and NAVGEM analyses (center column) at Bear Lake for the 2009-2010 winter. Gray areas denote missing data. Corresponding monthly mean wind profiles (right column) from NAVGEM (black stars) and meteor radar observations (gray diamonds). 

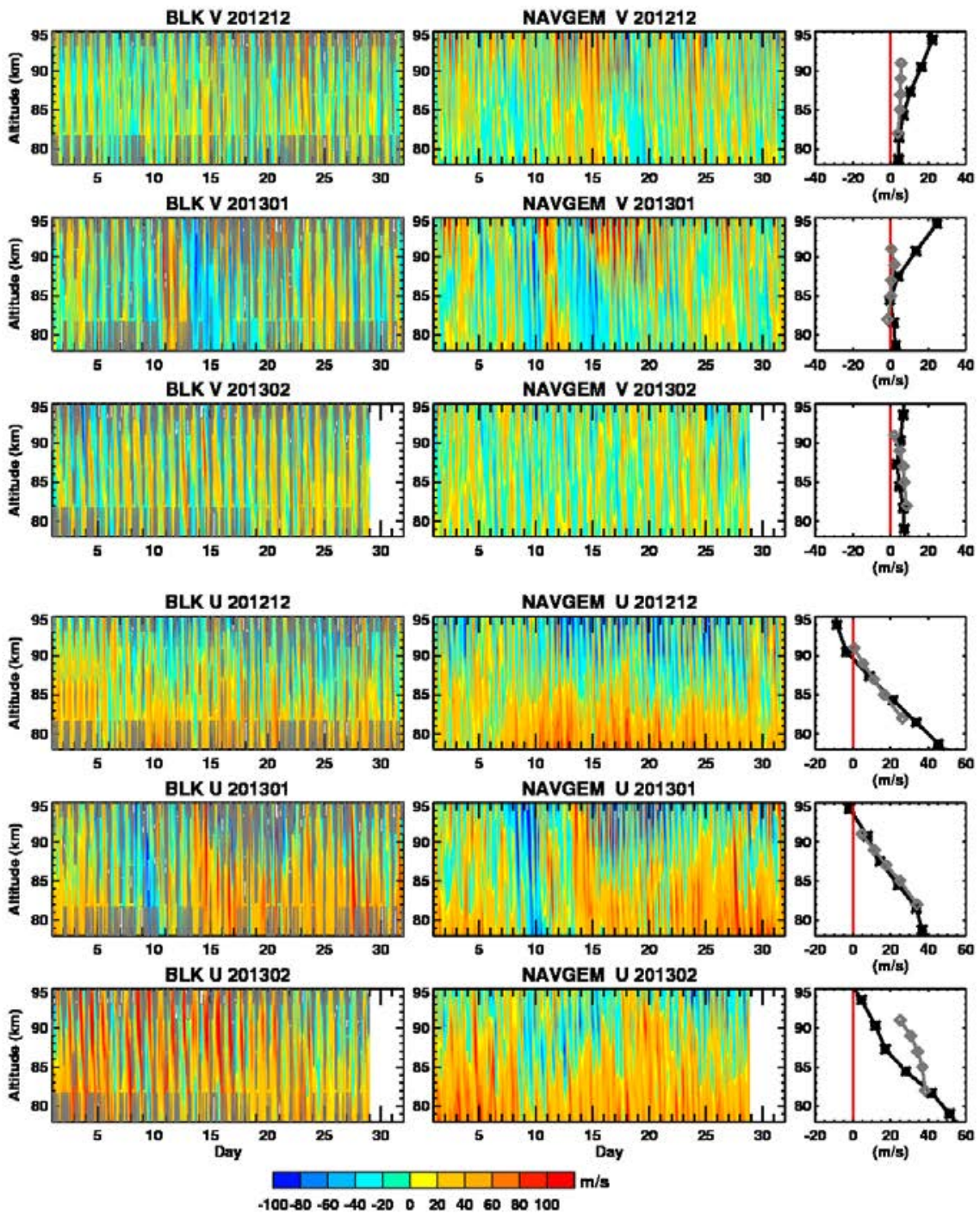

Figure 15: As in Figure 14 but for the 2012-2013 winter. 

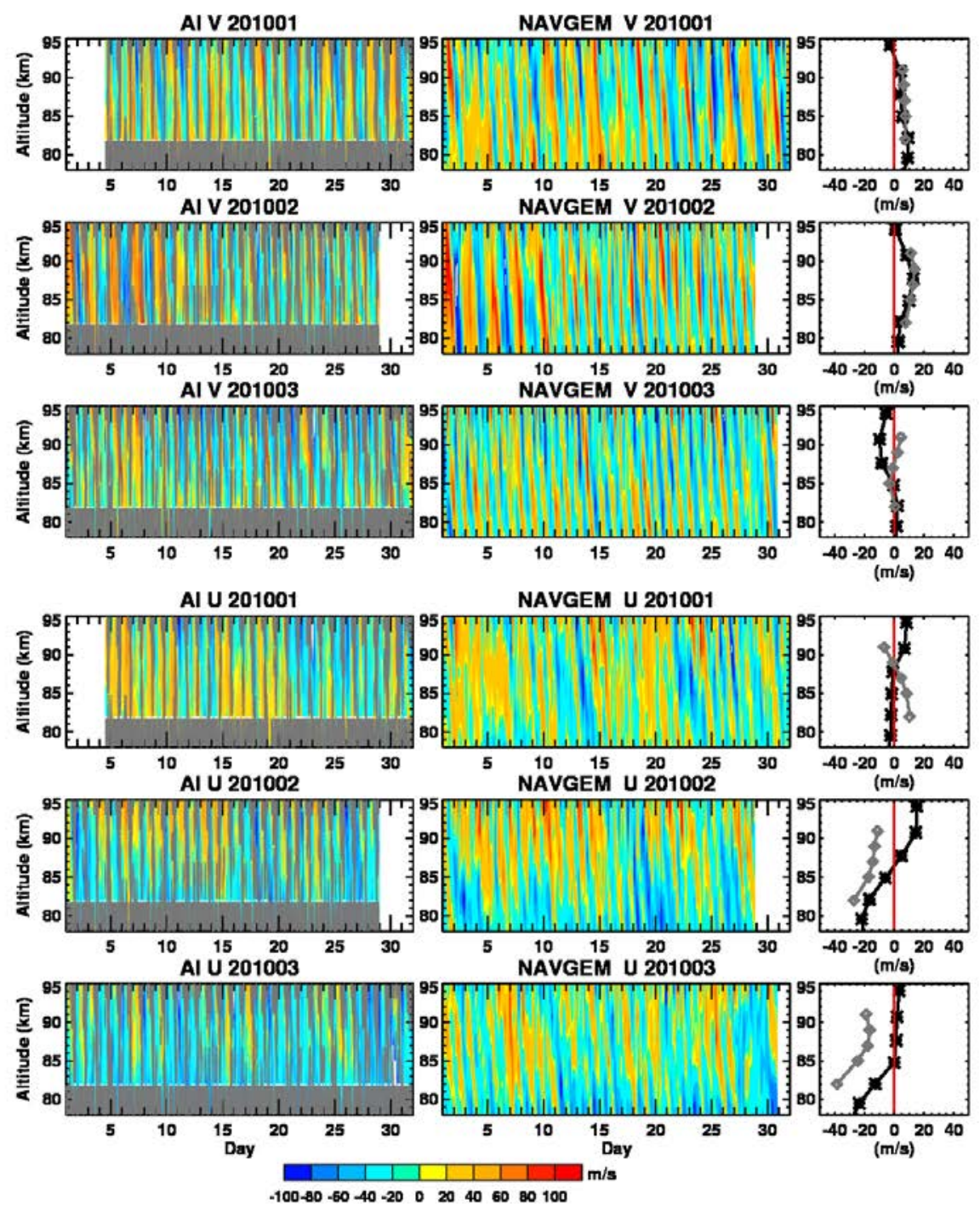

Figure 16: Meridional and zonal winds from meteor radar observations (left column) and NAVGEM analyses (center column) at Ascension Island for the period 1 Jan. - 31 Mar. 2010. Gray areas denote missing data. Corresponding monthly mean wind profiles (right column) from NAVGEM (black stars) and meteor radar observations (gray diamonds). 

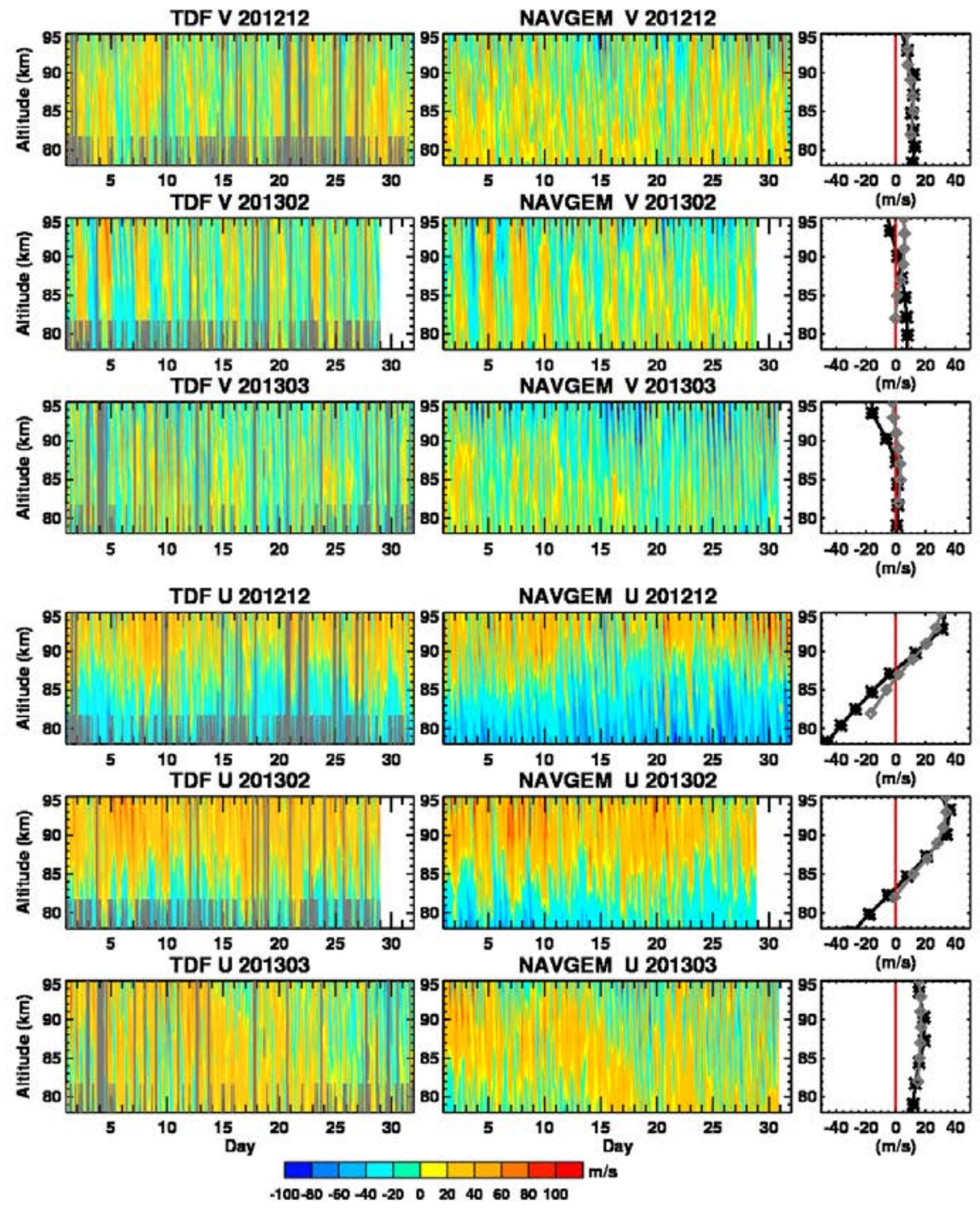

Figure 17: As in Figure 16 but for winds at Tierra del Fuego during $1-31$ Dec. 2012 and 1 Feb. - 31 Mar. 2013. 

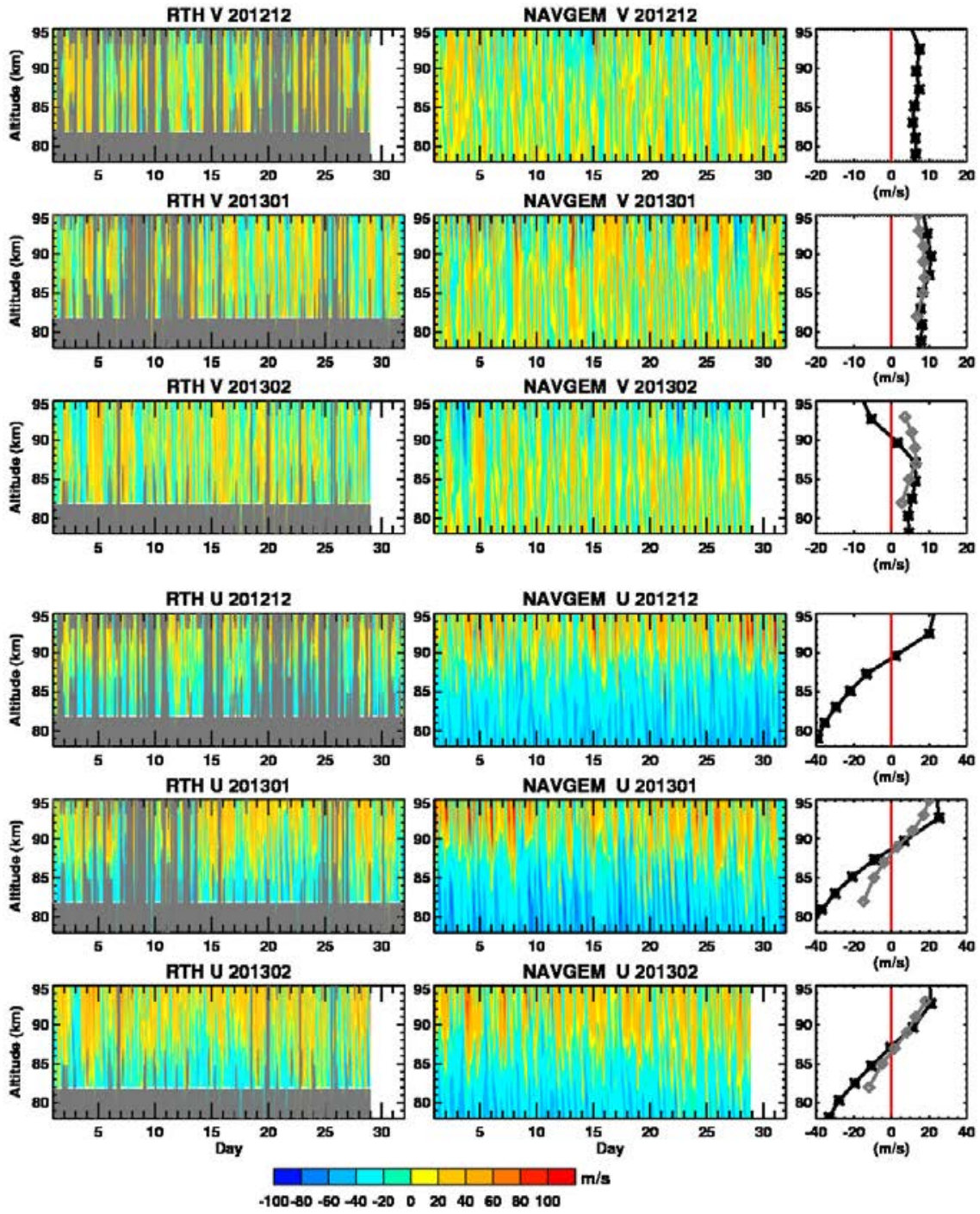

Figure 18: As in Figure 16 but for winds at Rothera from 1 Dec. 2012 - 28 Feb. 2013. 

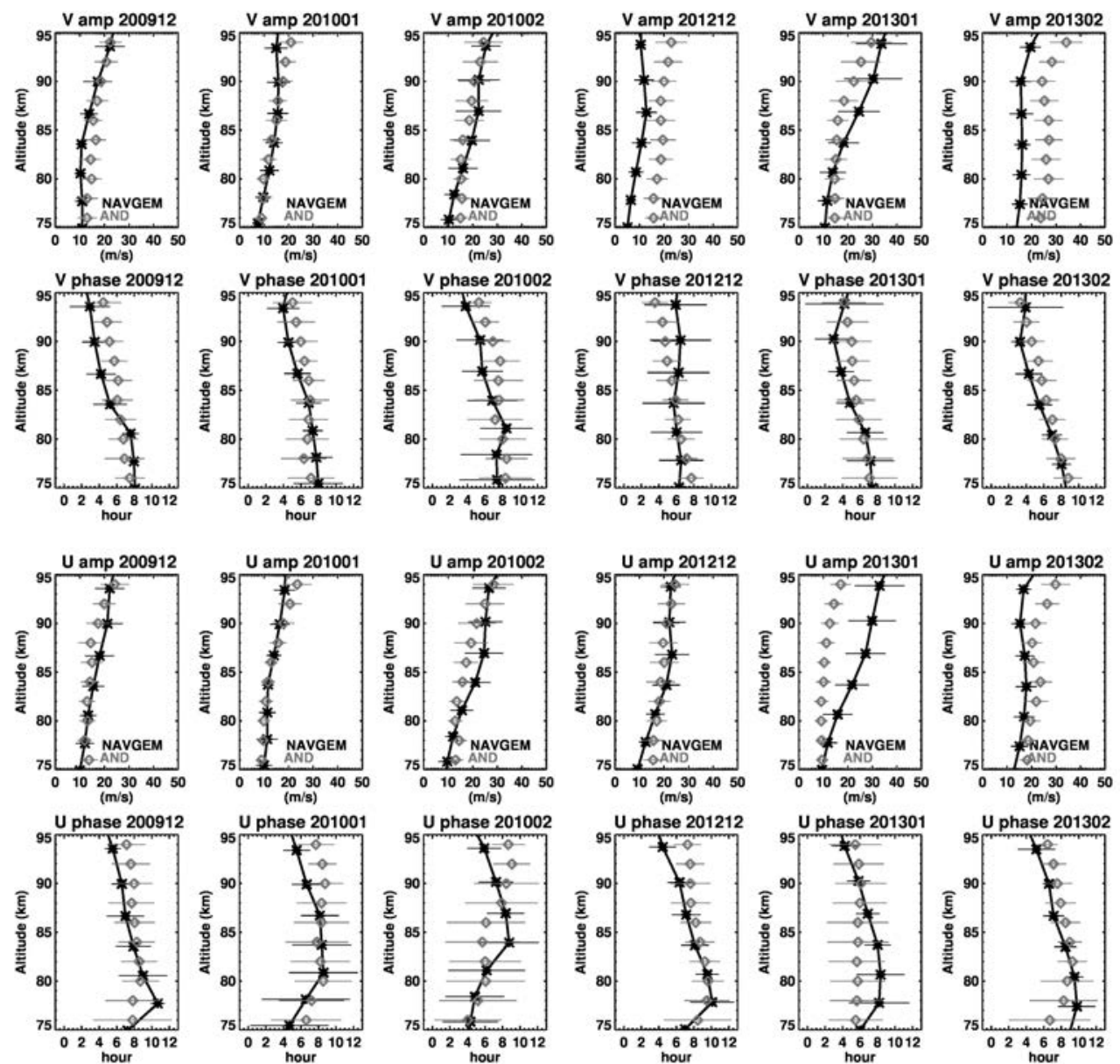

Figure 19: Time averaged vertical profiles of semi-diurnal amplitude and phase in meridional wind (top two rows) and zonal wind (bottom two rows) from NAVGEM (black stars) and meteor radar winds (gray diamonds) at Andenes over the 2009-2010 (left 3 columns) and 2012-2013 (right three columns) NH winter periods listed in Table 1. Error bars represent the standard deviation about the time mean. 

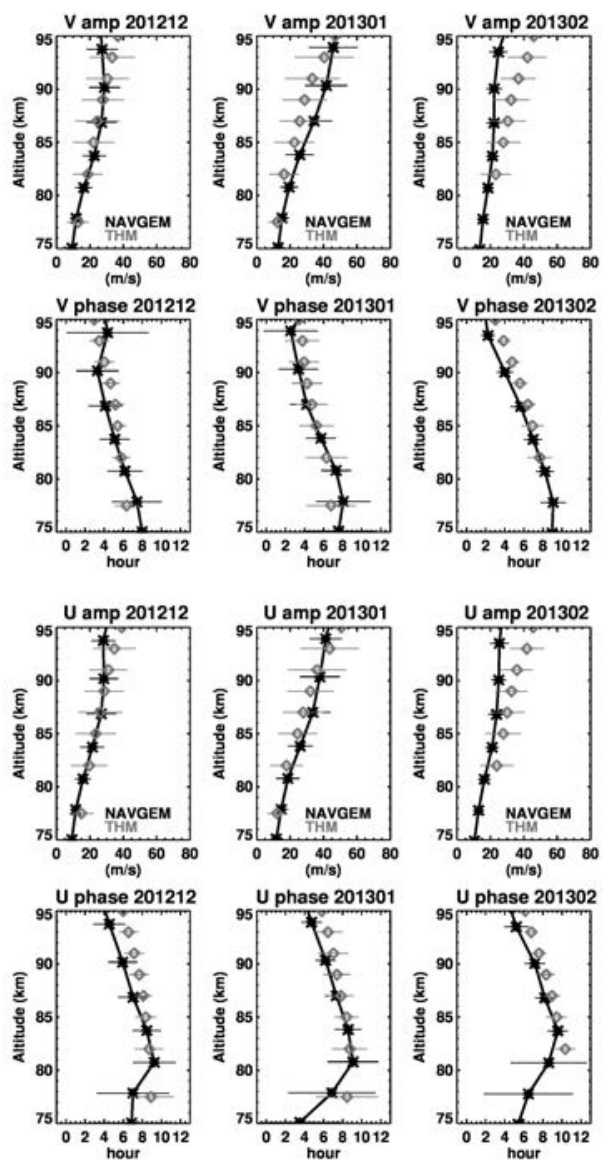

Figure 20: Time averaged vertical profiles of semi-diurnal amplitude and phase in meridional wind (top two rows) and zonal wind (bottom two rows) from NAVGEM (black stars) and meteor radar winds (gray diamonds) at Trondheim over the 2012-2013 NH winter period listed in Table 1. Error bars represent the standard deviation about the time mean. 

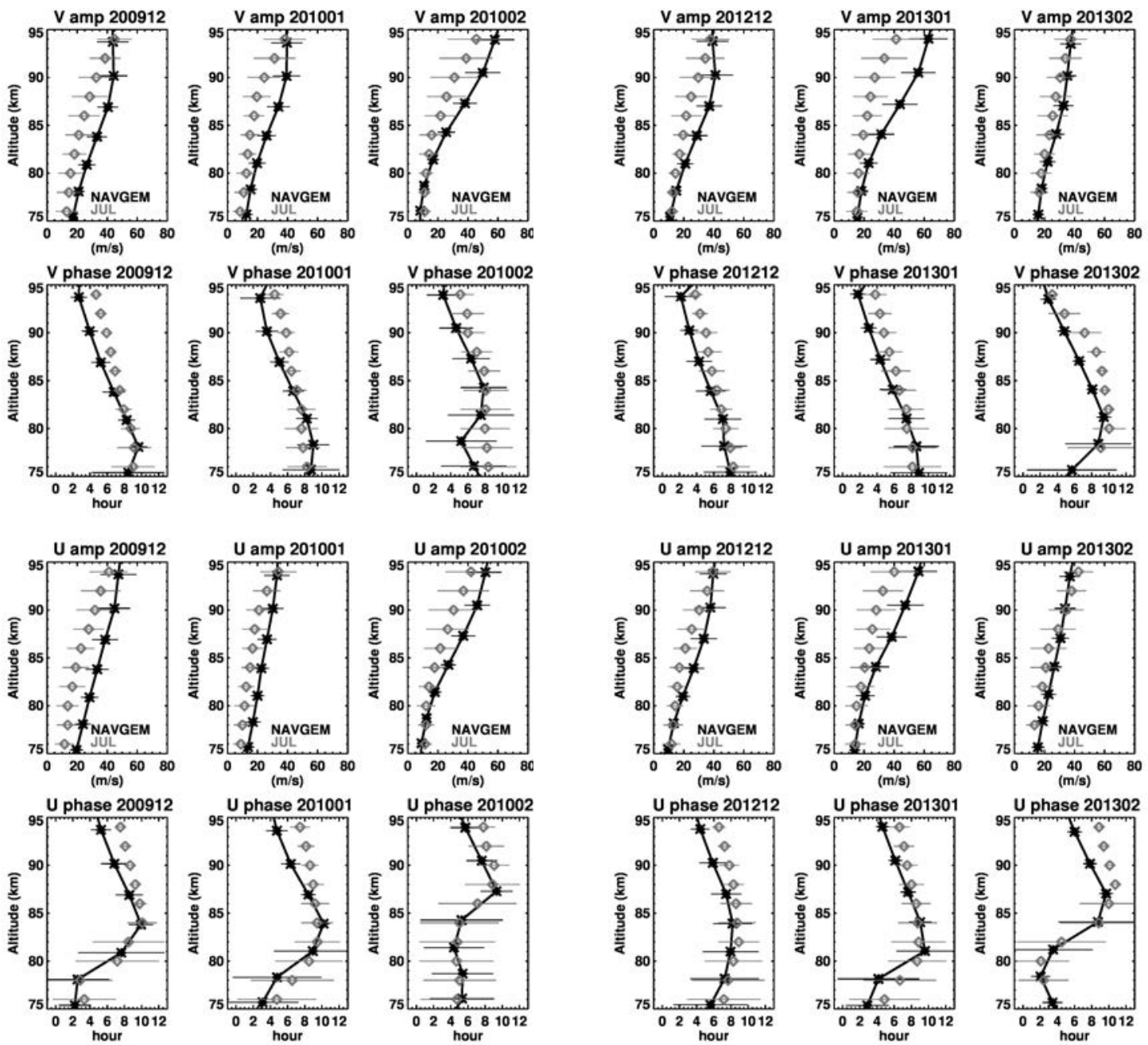

Figure 21: Time averaged vertical profiles of semi-diurnal amplitude and phase in meridional wind (top two rows) and zonal wind (bottom two rows) from NAVGEM (black stars) and meteor radar winds (gray diamonds) at Juliusruh over the 2009-2010 (left 3 columns) and 2012-2013 (right 3 columns) NH winter periods listed in Table 1. Error bars represent the standard deviation about the time mean. 

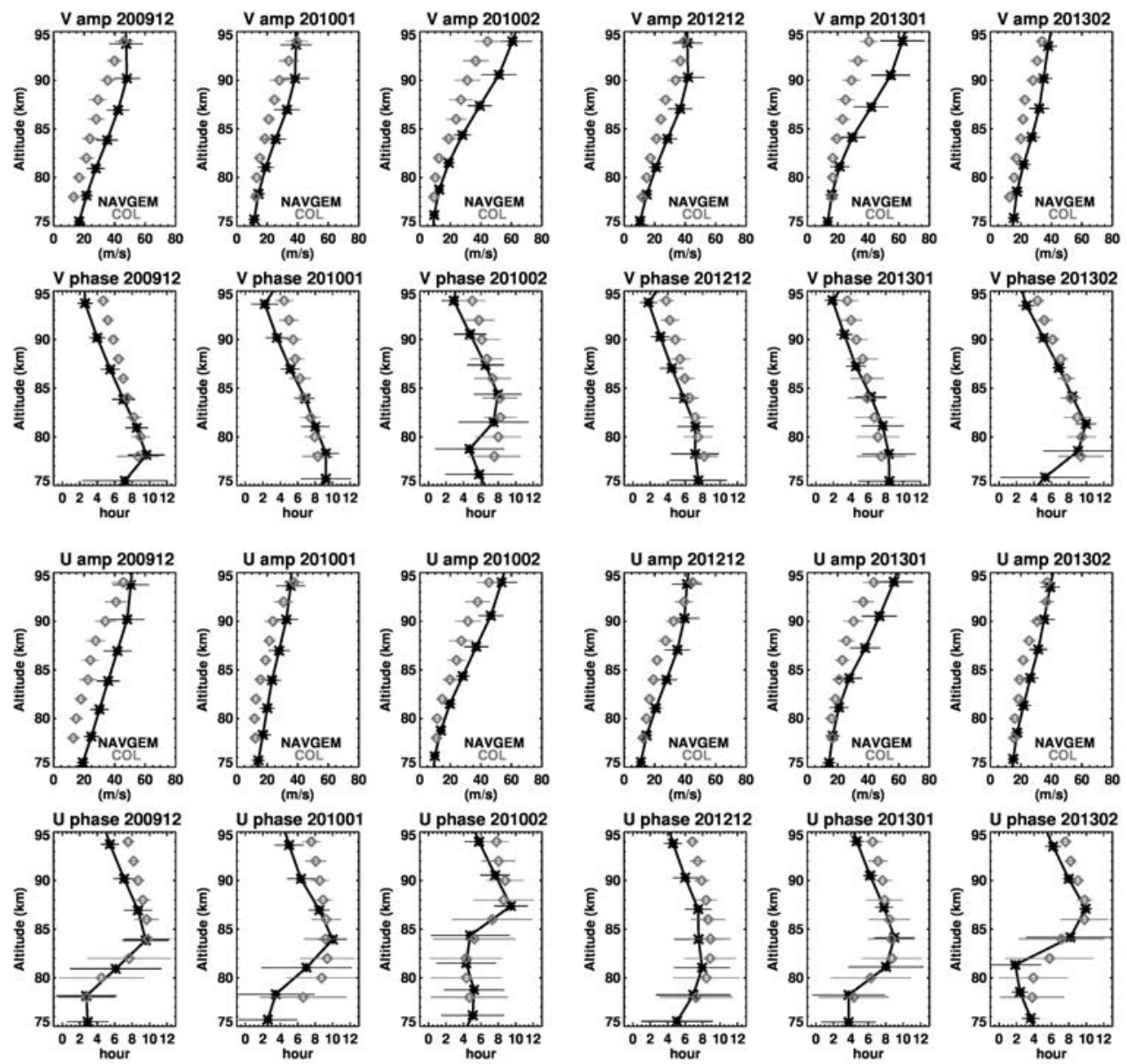

Figure 22: As in Fig. 21 but for Collm. 

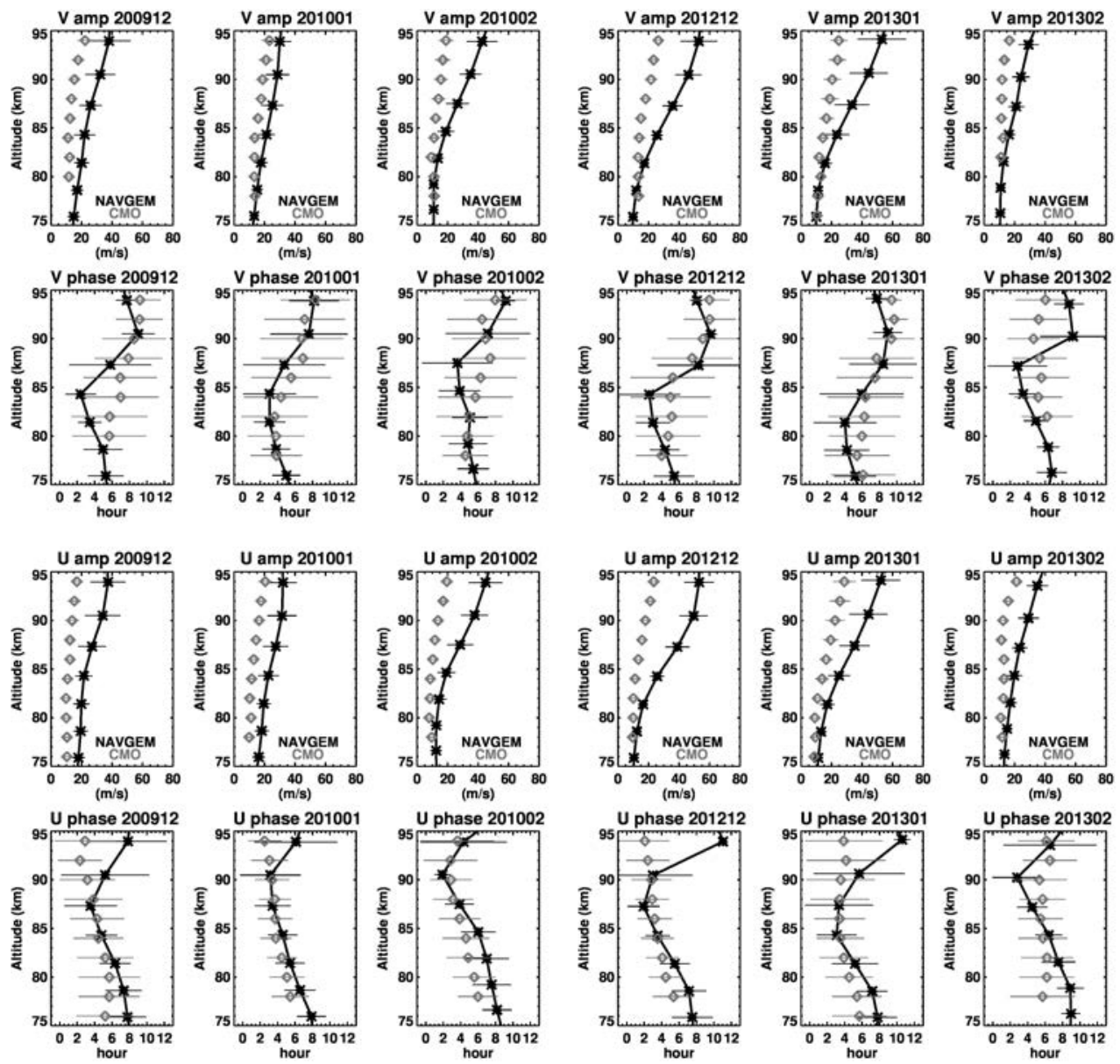

Figure 23: As in Fig. 21 but for the Canadian Meteor Orbit Radar. 

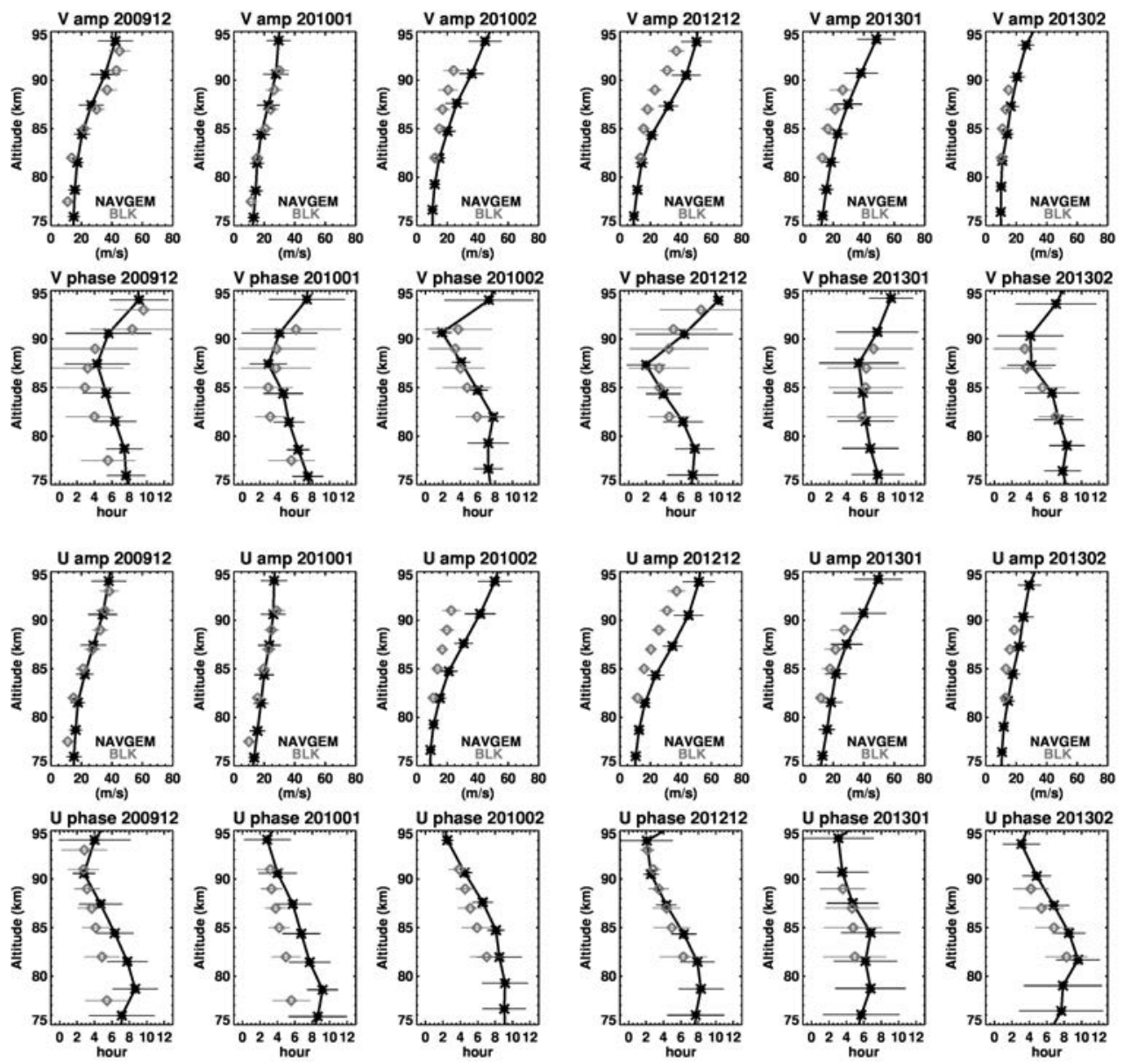

Figure 24: As in Fig. 21 but for Bear Lake. 

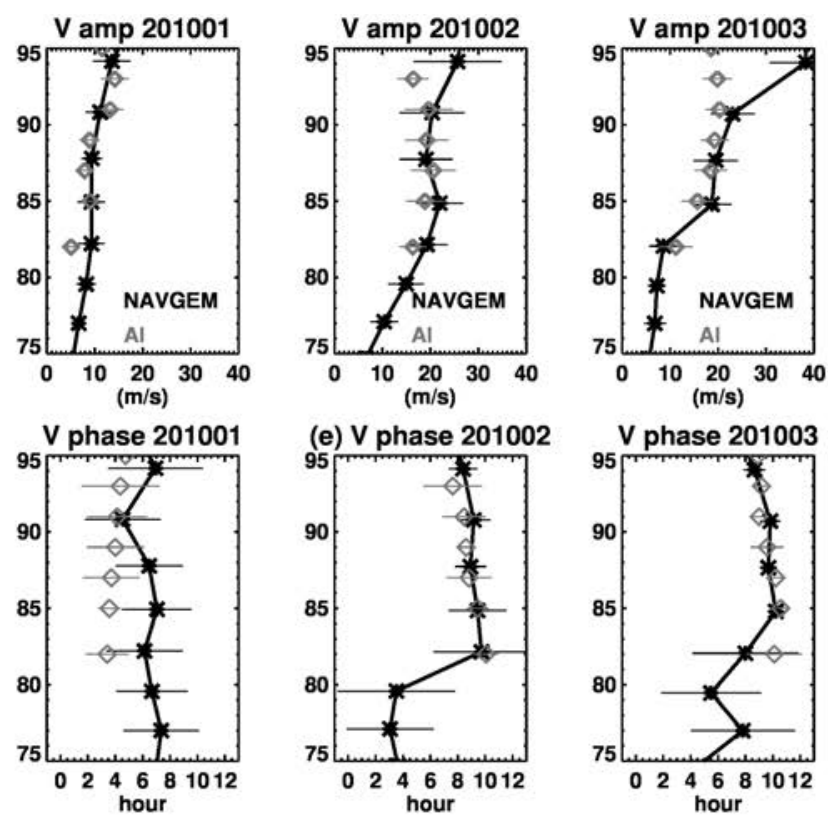

(e) V phase 201002
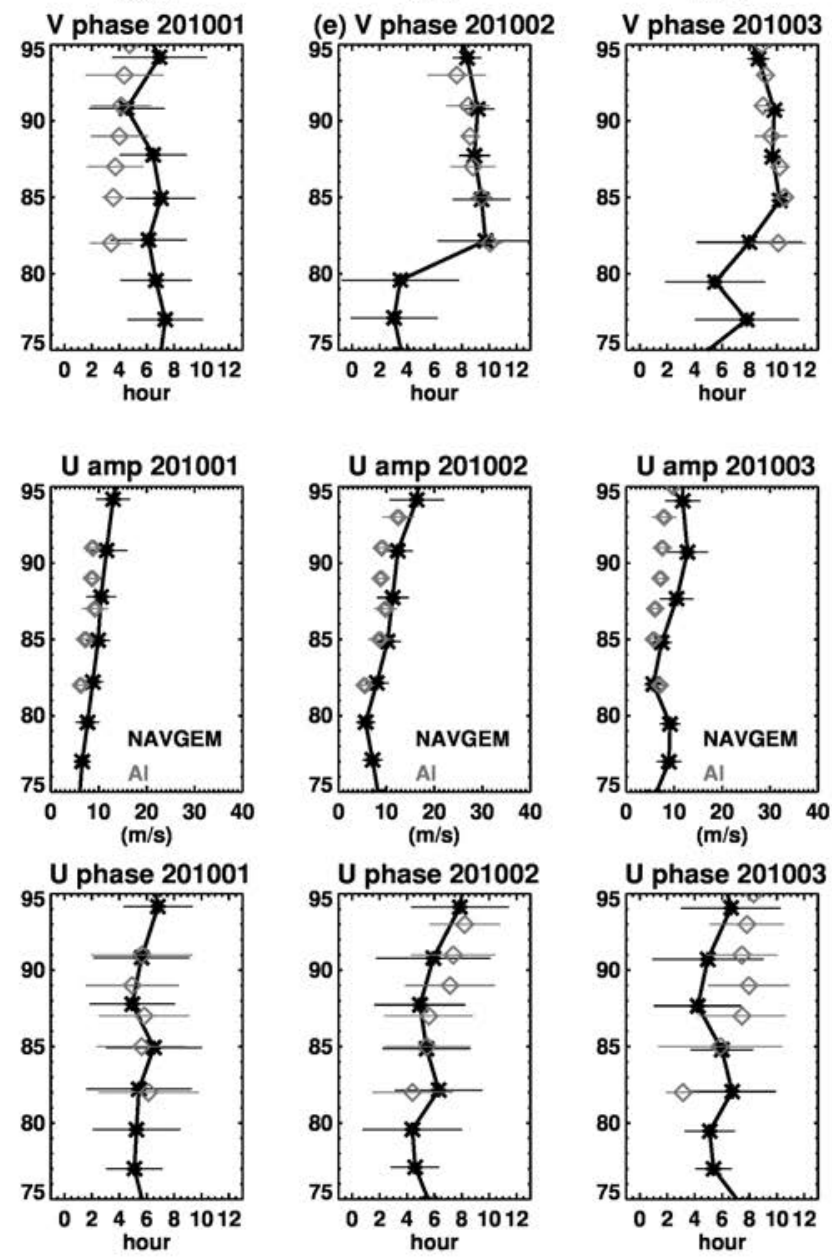

Figure 25: As in Fig. 21 but for Ascension Island for the January-March 2010 period listed in Table 1. 

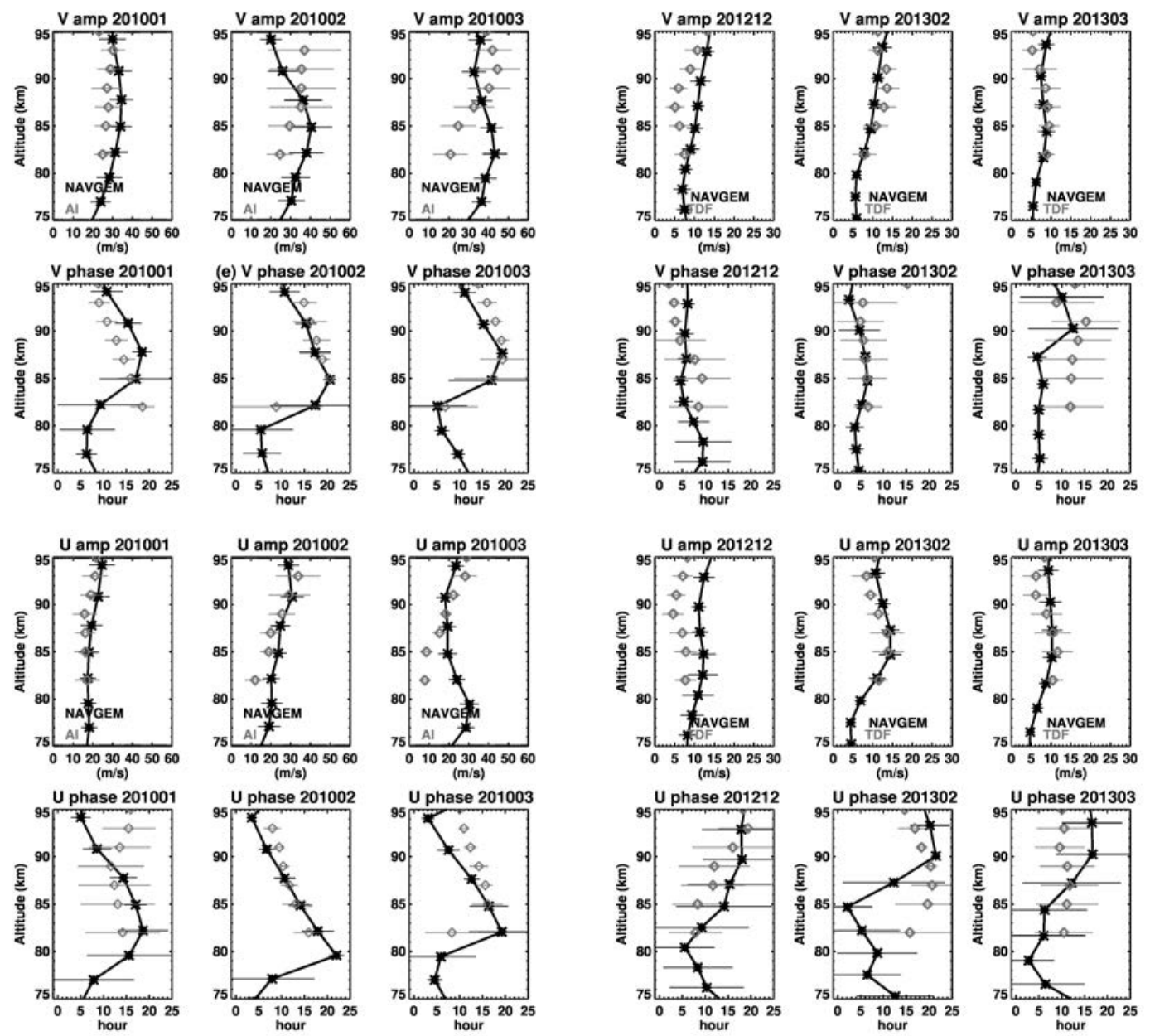

Figure 26: Time averaged vertical profiles of diurnal amplitude and phase in meridional wind (top two rows) and zonal wind (bottom two rows) from NAVGEM (black stars) and meteor radar winds (gray diamonds) at Ascension Island over the January - March 2010 period (left 3 columns) and at Tierra del Fuego (right 3 columns) for the December 2012 and February-March 2013 periods listed in Table 1. Error bars represent the standard deviation about the time mean. The horizontal axis varies from $0-60 \mathrm{~m} \mathrm{~s}^{-1}$ for the Ascension Island amplitudes, and varies from $0-30 \mathrm{~m} \mathrm{~s}^{-1}$ for the Tierra del Fuego amplitudes. 

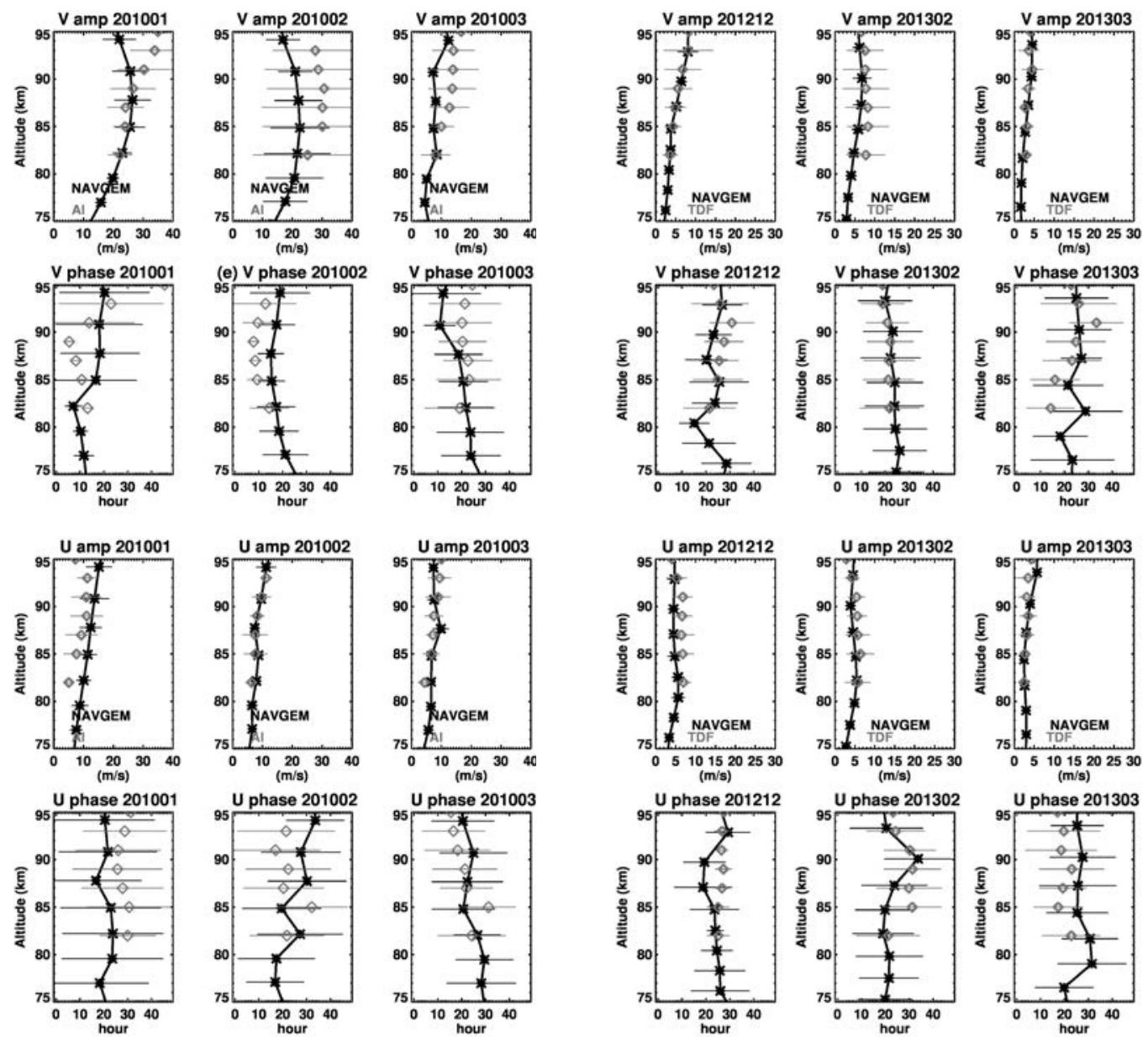

Figure 27: Time averaged vertical profiles of quasi-2 day amplitude and phase in meridional wind (top two rows) and zonal wind (bottom two rows) from NAVGEM (black stars) and meteor radar winds (gray diamonds) at Ascension Island over the January March 2010 period (left 3 columns) and at Tierra del Fuego for the December 2012 and February-March 2013 (right 3 columns) periods listed in Table 1. Error bars represent the standard deviation about the time mean. The horizontal axis varies from $0-40 \mathrm{~m} \mathrm{~s}^{-1}$ for the Ascension Island amplitudes, and varies from $0-30 \mathrm{~m} \mathrm{~s}^{-1}$ for the Tierra del Fuego amplitudes. 

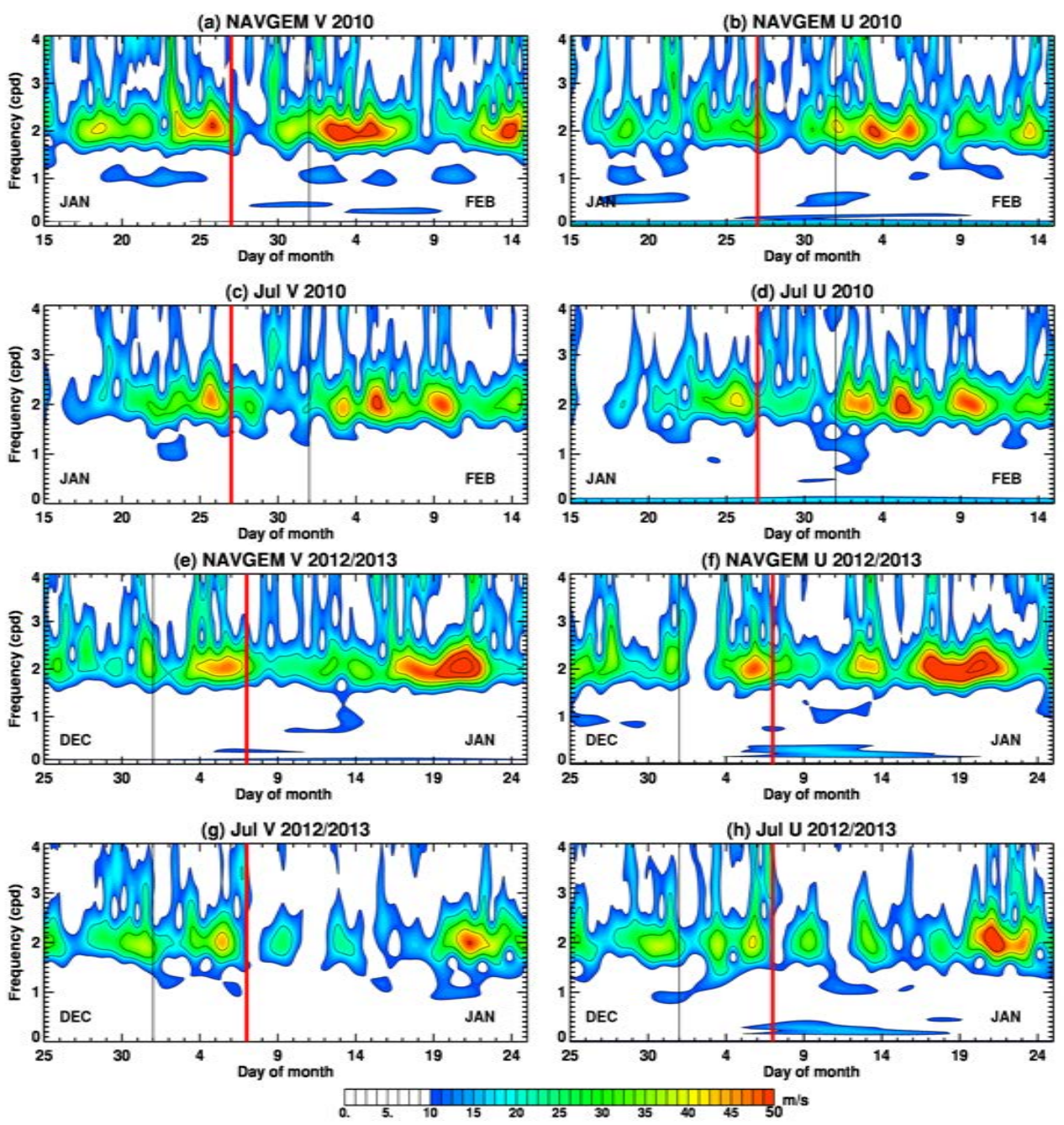

Figure 28: Time-frequency plots of meridional and zonal wind amplitudes $|S|$ at $88 \mathrm{~km}$ altitude derived from NAVGEM and radar winds for Juliusruh over the periods of 15 January - 15 February 2010 (a-d) and 25 December 2012 - 25 January 2013 (e-h). Black vertical lines denote separate months. Red vertical lines denote the onset of mesospheric easterly flow on 27 January 2010 and 7 January 2013, as indicated in Fig. 1. Contours are drawn every $10 \mathrm{~m} \mathrm{~s}^{-1}$. 

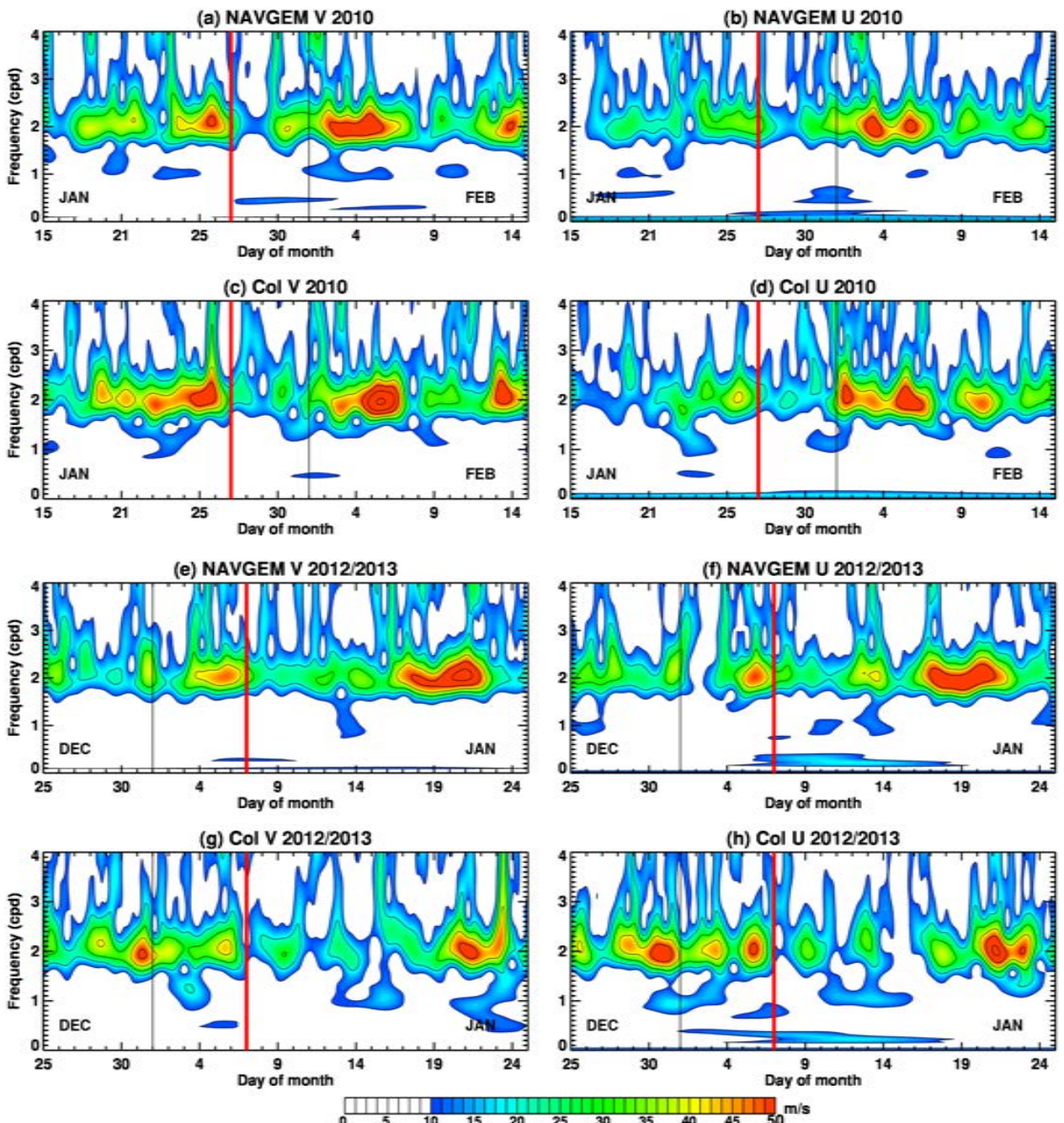

Figure 29: As in Fig. 28 but for Collm at $88 \mathrm{~km}$ altitude. 

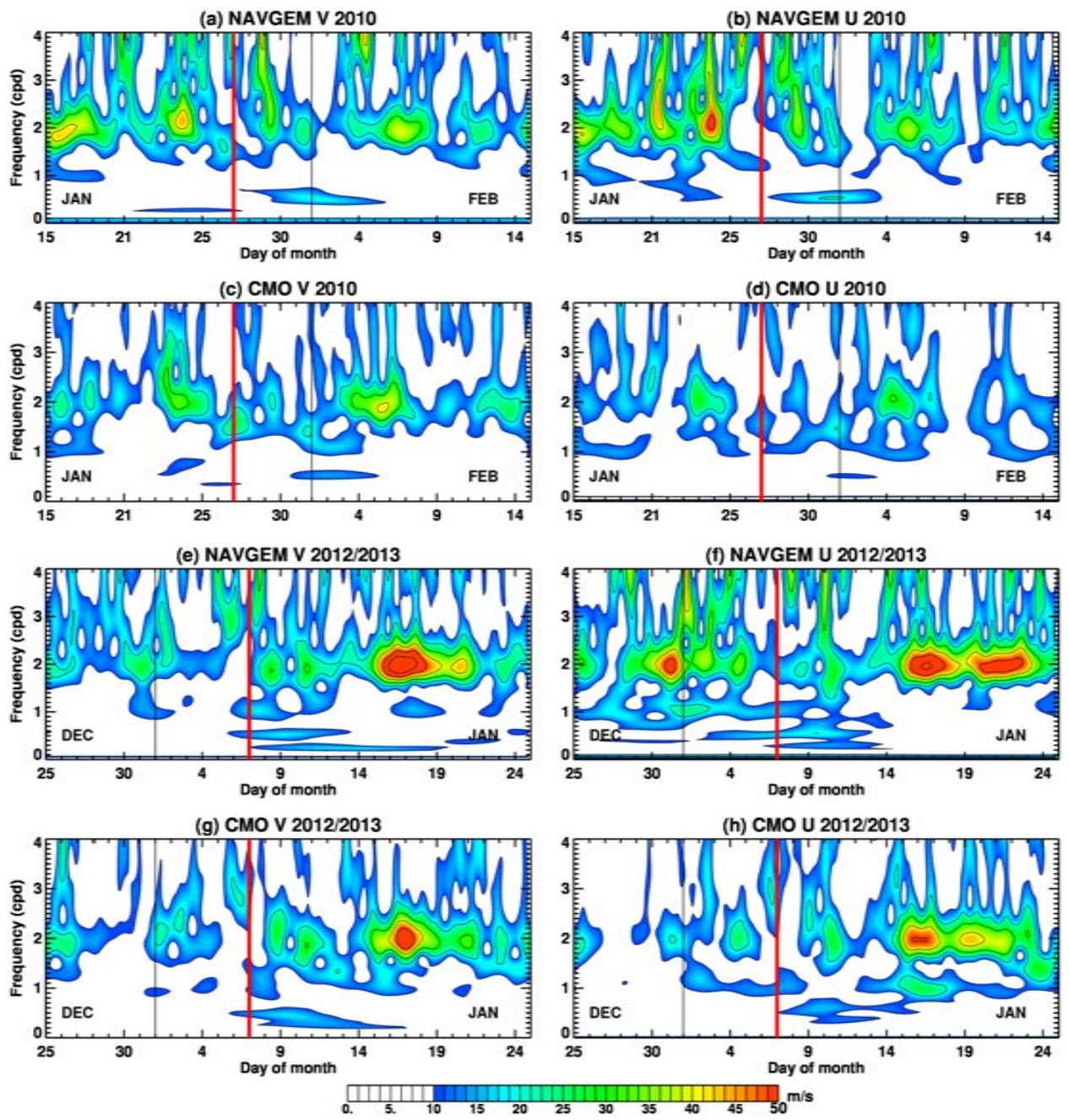

Figure 30: As in Fig. 28 but for the CMOR site at $88 \mathrm{~km}$ altitude. 

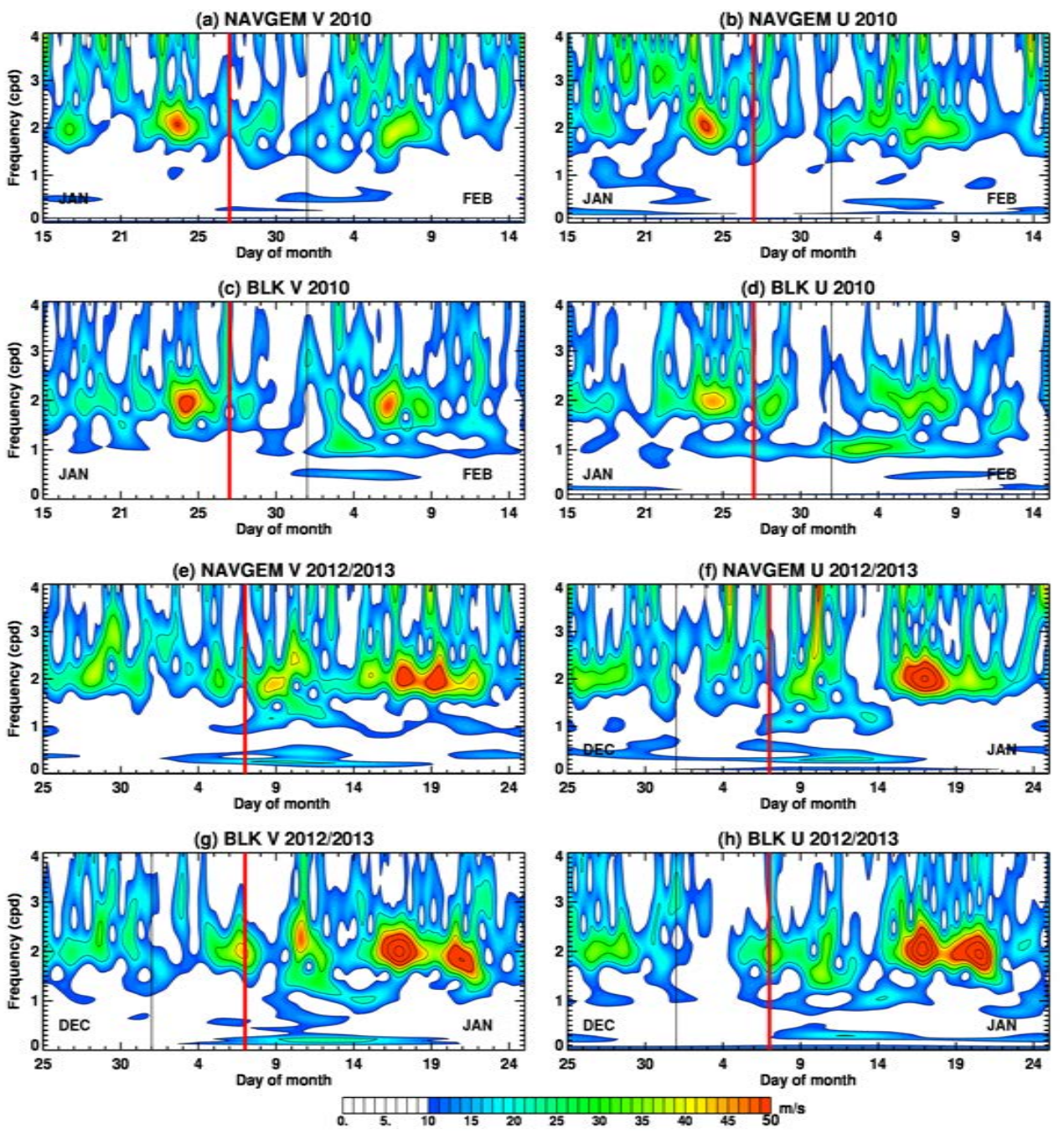

Figure 31: As in Fig. 28 but for Bear Lake at $87 \mathrm{~km}$ altitude. 

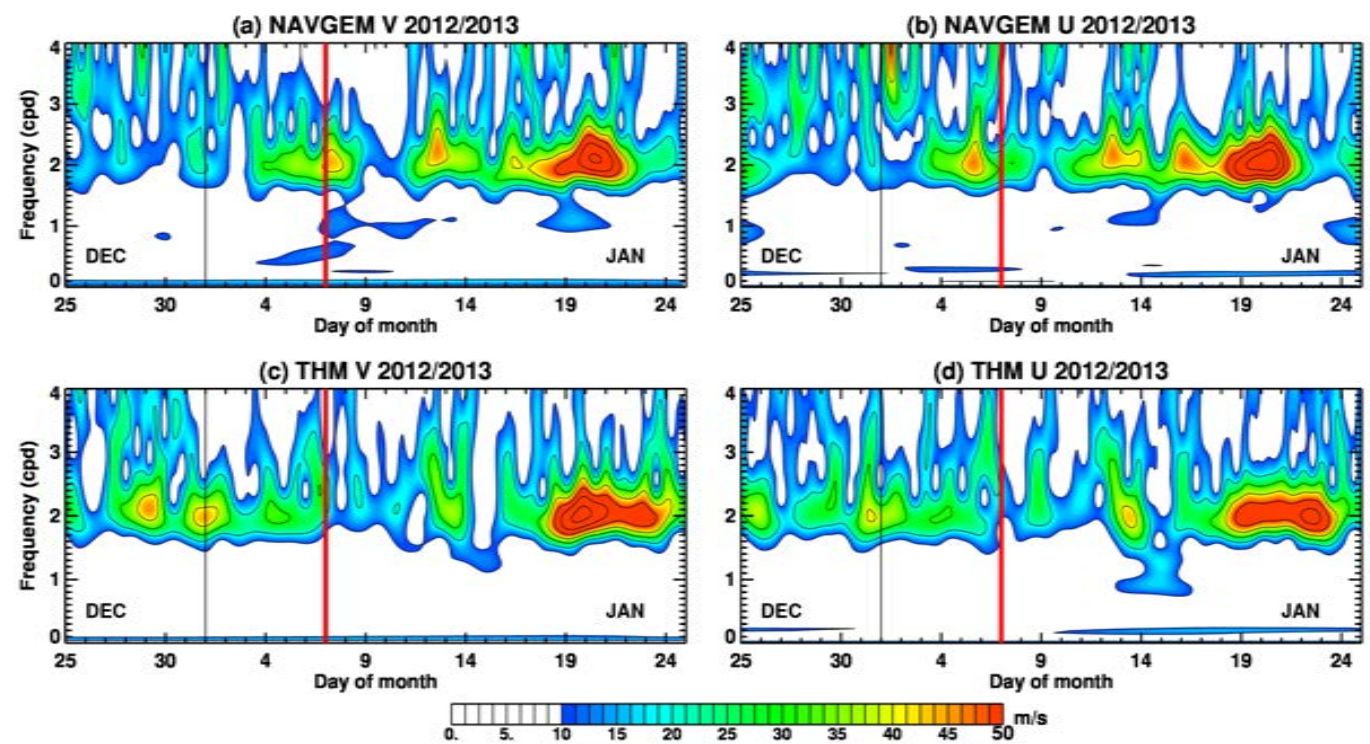

Figure 32: Time-frequency plots of meridional and zonal wind amplitudes $|S|$ derived from NAVGEM and radar winds for Trondheim at $88 \mathrm{~km}$ altitude over the period 25 December 2012 - 25 January 2013. Black vertical lines denote separate months. Red vertical lines denote the onset of mesospheric easterly flow on 7 January 2013, as indicated in Fig. 1. Contours are drawn every $10 \mathrm{~m} \mathrm{~s}^{-1}$ 

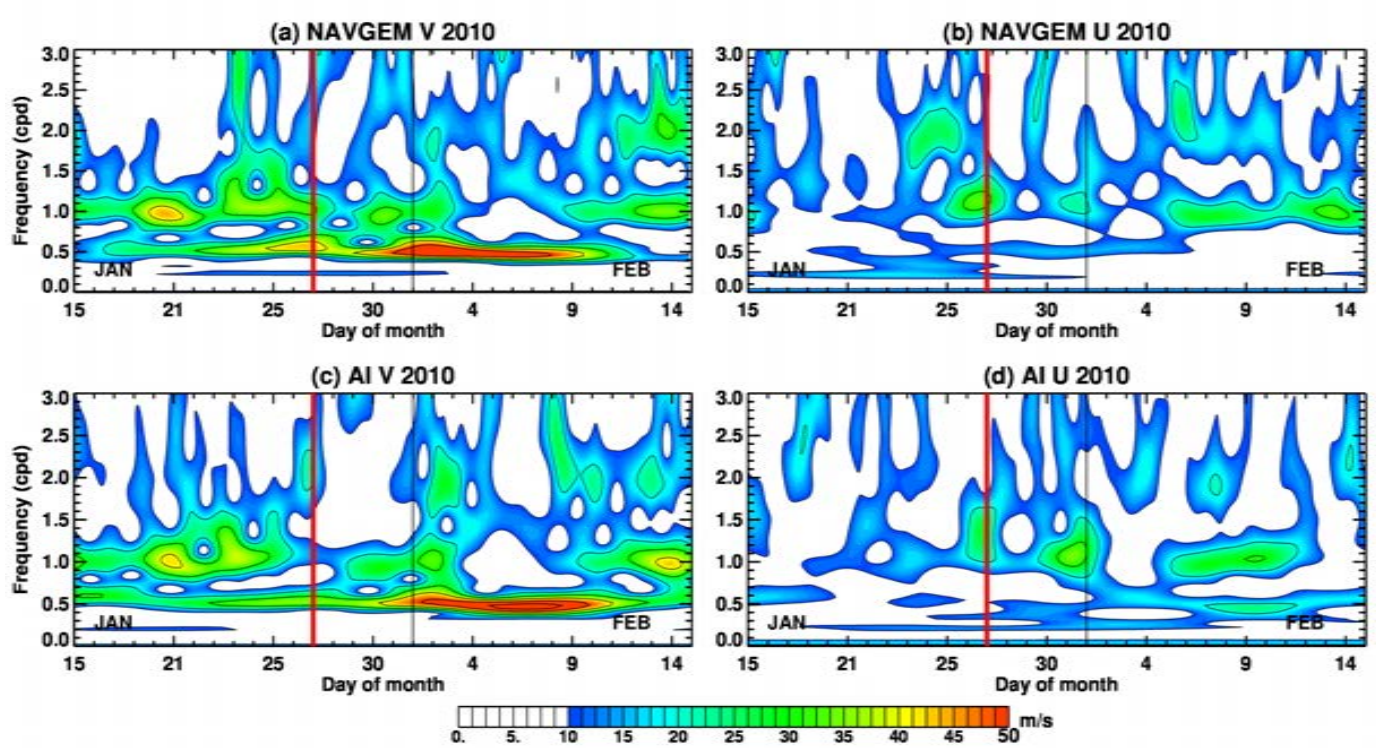

Figure 33: Time-frequency plots of meridional and zonal wind amplitudes $|S|$ derived from NAVGEM and radar winds for Ascension Island at $88 \mathrm{~km}$ altitude over the period 15 January - 15 February 2010. Black vertical lines denote separate months. Red vertical lines denote the onset of mesospheric easterly flow on 27 January 2010, as indicated in Fig. 1. Contours are drawn every $10 \mathrm{~m} \mathrm{~s}^{-1}$. 

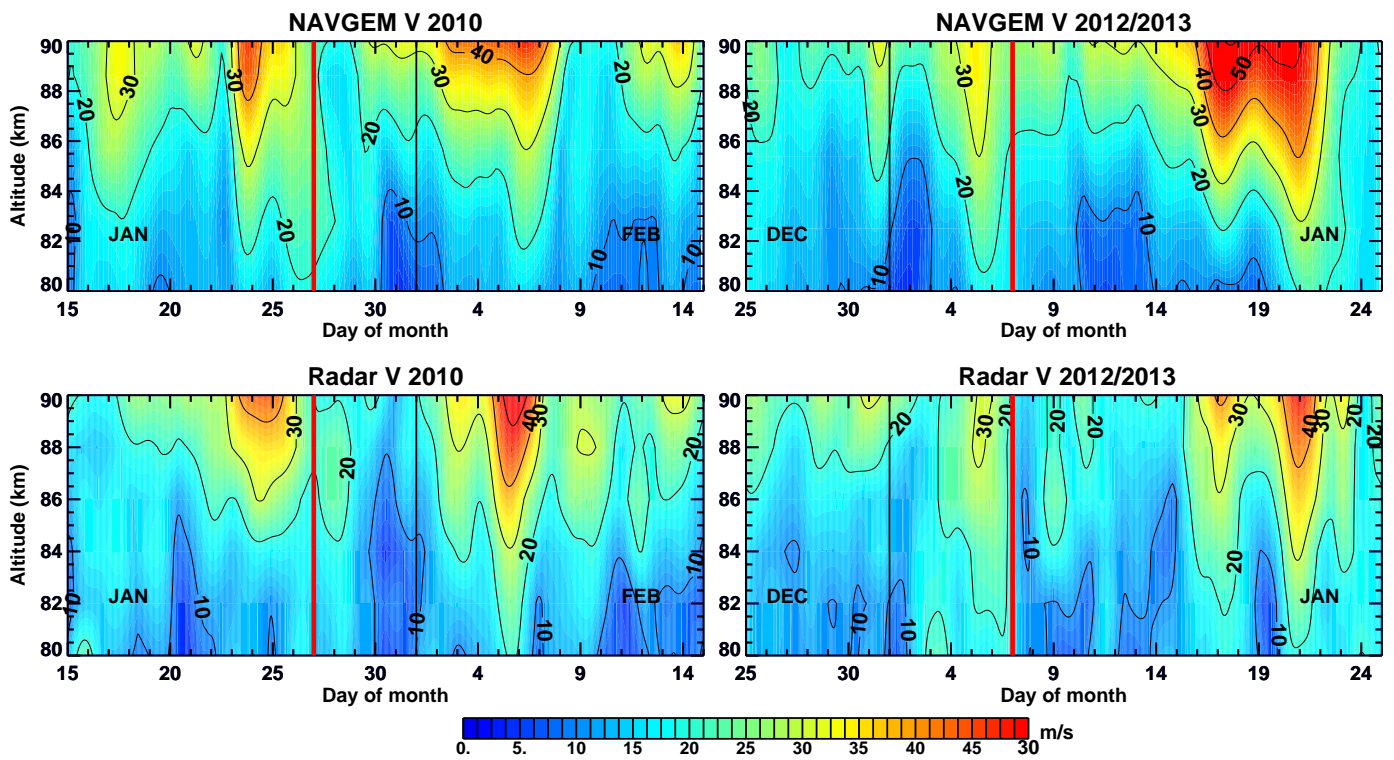

Figure 34: Altitude-time variations in semi-diurnal amplitudes from NAVGEM (top) and radar (bottom) meridional winds averaged over the locations of the Northern Hemisphere extratropical sites listed in Table 1 for the periods 15 January - 15 February 2010 (left column) and 25 December 2012 - 25 January 2013 (right column). Black vertical lines denote separate months. Red vertical lines denote the onset of mesospheric easterly flow on 27 January 2010 and 7 January 2013. Contours are drawn every $10 \mathrm{~m} \mathrm{~s}^{-1}$. 